\title{
INTEGRATING A COLLEGE TRANSITION CURRICULUM INTO SENIOR ENGLISH: INCREASING ACCESS \& PERSISTENCE
}

\author{
A dissertation submitted to the faculty of \\ San Francisco State University \\ In partial fulfillment of \\ The Requirements of \\ The Degree
}

\author{
Doctor of Education \\ In \\ Educational Leadership
}

by

Janeen Erin Malatesta

San Francisco, California

May 2020 
Copyright by

Janeen Erin Malatesta

2020 


\section{CERTIFICATION OF APPROVAL}

I certify that I have read Integrating A College Transition Curriculum Into Senior

English: Increasing Access \& Persistence by Janeen Erin Malatesta, and that in my opinion this work meets the criteria for approving a thesis submitted in partial fulfillment of the requirements for the degree: Doctorate in Education for Education Leadership at San Francisco State University.

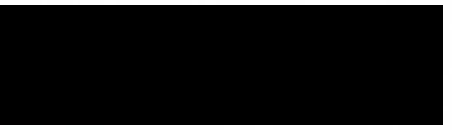

Stephanie Sisk-Hilton, Ph.D. Professor, College of Education San Francisco State University

Maika Watanabe, Ph.D.

Professor, College of Education

San Francisco State University

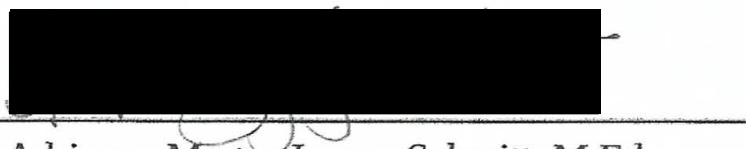

Adrienne Martee Lopez-Schmitt, M.Ed.

IB Coordinator \& Educator

Capuchino High School 


\title{
INTEGRATING A COLLEGE TRANSITION CURRICULUM INTO SENIOR ENGLISH: INCREASING ACCESS \& PERSISTENCE
}

\author{
Janeen Erin Malatesta \\ San Francisco, CA \\ 2020
}

This study was conducted to promote a better understanding of how to utilize student-centered, college-going curriculum in Senior English classes to support college access and persistence. Dozens of non-systemic programs are set up to help students transition between secondary and postsecondary institutions, and this study is set up to better understand how to support students through a compulsory twelfth-grade high school class. California's college completion rates do not proportionately reflect the demographics of the population, and this mixed-methods study endeavors to deepen an understanding of how a transition curriculum embedded into compulsory twelfth-grade English classes can work as an essential component to influence college completion. This research utilizes surveys and focus groups to garner high school and first-generation community college students' input of the degree of effectiveness and improvements needed to better the curriculum. Qualitative results revealed what components of the curriculum students felt was effective, should be deepened, and needs to be added. Quantitative results supported students' positive feedback and gave insight into areas of improvement.

Keywords: college access, college persistence, community college, first-generation college student, habits of mind, senior english, transition curriculum, twelfth-grade

I certify that the Abstract is a correct representation of the content of this dissertation.

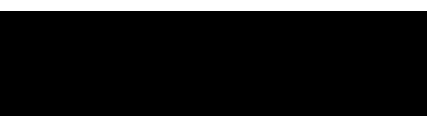

Stephanie Sisk-Hilton, Chair

Date 


\section{ACKNOWLEDGMENT}

First, I would like to express my deep thanks to the members of my dissertation committee: Dr. Stephanie Sisk-Hilton, Dr. Maika Watanabe, and Adrienne Martee Lopez-Schmitt. To my chair Dr. Stephanie Sisk-Hilton who spent countless hours patiently, enthusiastically, and thoughtfully guiding me through the process. To Dr. Maika Watanabe who kindly agreed to be on my committee when I was a fledgling doctoral student and supported my learning by asking thoughtful questions to help deepen my understanding. To Adrienne Martee Lopez-Schmitt for being an inspirational colleague and mentor for over two decades.

Second, I am also deeply grateful for my family. To my grandfather, who was there for every milestone. To my parents, Roy and Joanne, who taught me to value education and the many opportunities it brings. To Andrea, for sharing my passion for social justice and inspiring me to take opportunities when they presented themselves. To Jude, for relentlessly supporting me by completing endless amounts of chores, chauffeuring our children, and attending their many activities without me. And--of course--for your support through teaching me about statistics, coding, and analysis. To

my children, Kaetlyn and Nathan, for the innumerable times you did without so I could focus on school.

Last, I would also like to thank my students. Without you, none of this work would have been possible. 


\section{TABLE OF CONTENTS}

List of Tables.................................................

List of Appendices............................................. xii

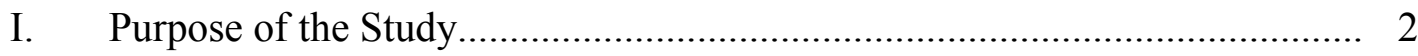

Development of the curriculum............................. 4

Problem Statement.............................................................................. 10

Levels of knowledge: college access \& persistence................. 13

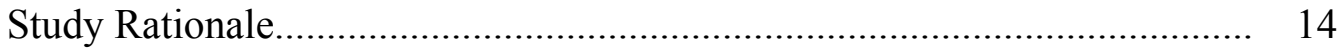

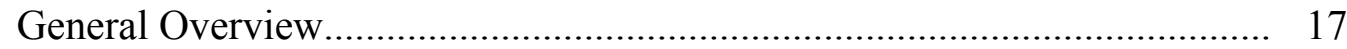

Research questions......................................... 18

Terminology.............................................. 18

Conceptual Framework.......................................... 20

Exclusion.................................................. 21

Segregation............................................... 21

Integration..................................................... 22

Inclusion ................................................... 23

Significance of Study ........................................................................ 24

II. Literature Review......................................................................... 27

College Access \& Completion.......................................... 28

Responsibilities............................................ 28 
Supporting Access \& Persistence: Strengths \& Challenges

Current approaches....................................... 29

Secondary \& postsecondary collaboration....................... 38

Disparate Levels of Support.................................... 46

Implicit bias..................................... 47

Effectively maintained inequality....................... 49

Colorblind \& powerblind neoliberalism................... 53

Conclusion........................................................... 54

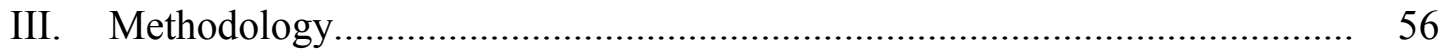

Research Questions \& Design........................................................... 56

Study Context....................................................... 57

Description Of Student-centered College-going Curriculum................... 58

Data Collection Context......................................................... 59

Role of Researcher: Positionality...................................... 60

Researcher-Participant Relationship................................................... 62

Participant Selection \& Demographics.............................................. 63

Ethics and Protection of Human Subjects........................................... 65 


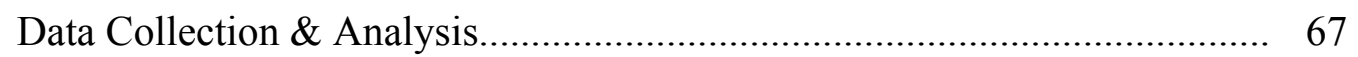

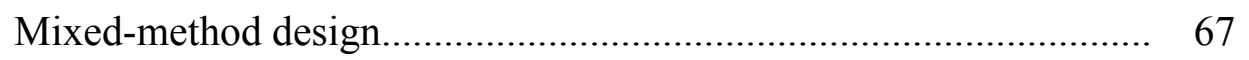

Quantitative phase: questionnaires........................................ 69

Qualitative phase: focus groups.............................................. 71

Integration of data.............................................................. 72

IV. Report of Findings.............................................................................. 74

Research questions......................................... 75

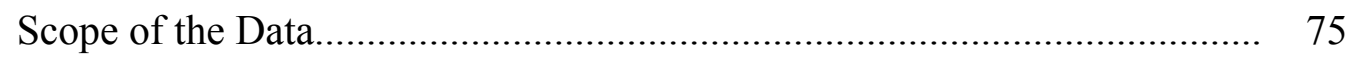

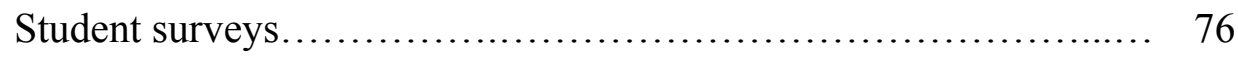

Focus-group interviews....................................... 76

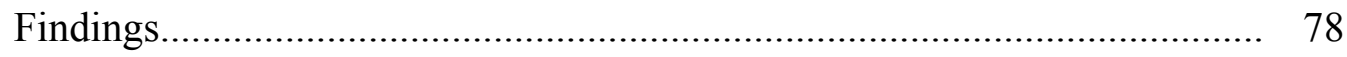

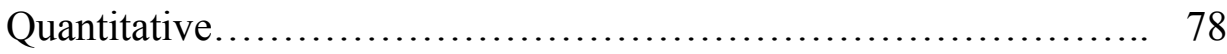

Qualitative \& quantitative...................................... 96

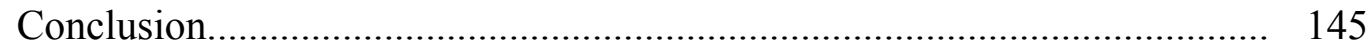

V. Discussion \& Recommendations.......................................................... 146

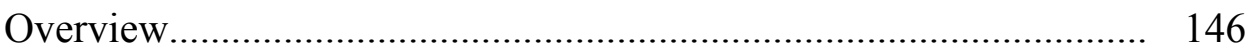

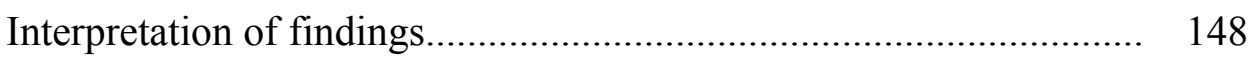

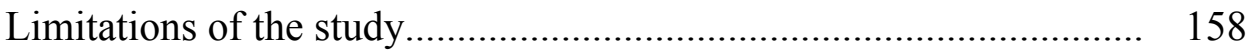

Implications \& recommendations for action.................................... 159

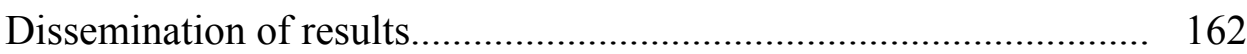

Recommendations for further study............................................... 163

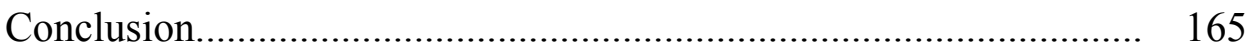

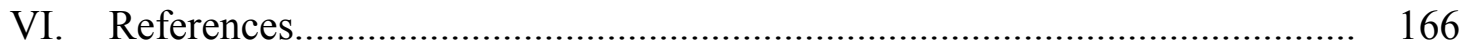




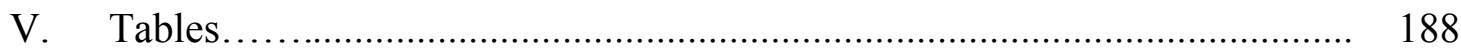

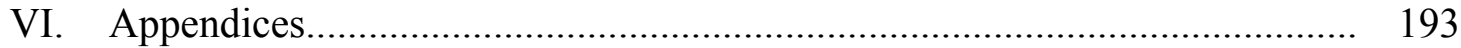




\section{LIST OF TABLES}

Table

Page

4.1 Student demographics......................................... 77

4.2 Class readings for college applications: high school survey response scores...................................................... 79

4.3 Class readings for college applications: college survey response scores..... 80

4.4 Class activities for college applications: high school survey response scores.

4.5 Class activities for college applications: college survey response scores... 82

4.6 Written assignments for college applications: high school survey response scores........................................................ 83

4.7 Written assignments for college applications: college survey response scores..........................................................

4.8 Readings for financial aid: high school survey response scores........... 85

4.9 Readings for financial aid: college survey response scores............... 85

4.10 Class activities for financial aid: high school survey response scores....... 86

4.11 Class activities for financial aid: college survey response scores.......... 87

4.12 Written assignments for financial aid: high school survey response scores $\quad 88$ 
4.13 Written assignments for financial aid: college survey response scores.......

4.14 Readings for the habits of mind: high school survey response scores...... 90

4.15 Readings for the habits of mind: college survey response scores.......... 90

4.16 Class activities for the habits of mind: high school survey response scores 92

4.17 Class activities for the habits of mind: college survey response scores...... 92

4.18 Written assignments for the habits of mind: high school survey response scores........................................................ 93

4.19 Written assignments for the habits of mind: college survey response scores........................................................

4.20 Financial aid and college persistence: college survey response scores..... 95

4.21 Problem solving and college persistence: college survey response scores... 96

5.1 Habits of mind activities: survey response scores.................... 149

5.2 Student responses: means, standard deviation and confidence intervals.... 152

6.1 High school survey \& demographic profile questionnaire........................ 188

7.1 College survey \& demographic profile questionnaire............................. 190

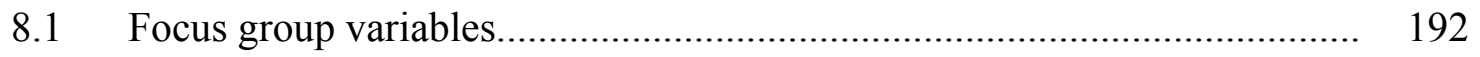




\section{LIST OF APPENDICES}

$\begin{array}{lll}\text { Appendix } & \text { Page }\end{array}$

A. SCCG Curriculum CP English Syllabus............................. 193

B. Guide for Choosing CP or AS English in BAUHSD................... 194

C. Recruitment flyer for college students............................................. 195

D. Introductory letter to participants.................................................... 196

E. Informed consent for college student participants............................... 197

F. Parental permission form for high school research participants............ 198

G. Assent form for minors: ages 18 and below........................ 199

H. College focus group script......................................................... 200

I. High school focus group script.................................................... 201

J. Focus group questions............................................................ 202

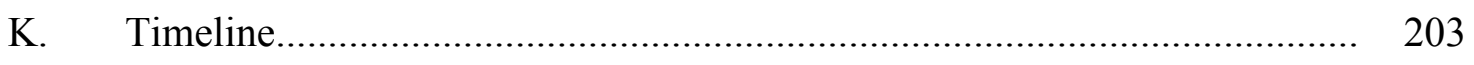




\section{Chapter One: Statement of the Problem}

Neither of my parents earned a college degree, but they successfully supported my siblings and me by turning their ideas into elbow grease and their elbow grease into lucrative businesses. My mother believed in education: she frequently took us to the library and taught me to read when I was four. There was never any doubt that my siblings and I would obtain college degrees so that our futures would be more rewarding and financially secure. This experience of having hardworking, self-sacrificing working-class parents who have high aspirations for their children is one I share with my high school and community college students. Although working-class parents who have not obtained a postsecondary education also have high educational expectations for their children (Carolan-Silva \& Reyes 2013; Pew Research Center, 2012; Pew Research Center, 2016; Wilson \& Yull, 2016; Yull, Wilson, Murray \& Parham, 2018), they are typically unable to directly provide the extracurricular opportunities and other forms of “navigational capital” (Yosso, 2005) needed to help their children access postsecondary opportunities and persist in postsecondary institutions. Contrastingly, forms of navigational capital such as extracurricular opportunities are more easily provided by more affluent American-born parents (Klugman, 2012; Klugman, 2013; Lucas, 2017). This class-based disparity in postsecondary support has resulted in a disproportional demographic representation of California's postsecondary graduates, favoring students from affluent families (Education Trust, 2019; Geiser \& Atkinson, 2010). 
In order to work towards an increased parity in postsecondary access and success, this study focuses on how postsecondary access and persistence curriculum can be incorporated into high school Senior English classes in order to help more students make the transition to and succeed at the postsecondary levels. Many students, particularly first-generation college-going students (FGCS), find the postsecondary educational system difficult to navigate and have trouble completing their academic goals because of a lack of institutional navigational capital (Silver \& Roksa, 2017, Yosso, 2005). All students could benefit from a transition curriculum implemented and thus normalized in Senior English classes since the highest national college completion rate of students who begin at a postsecondary institution is $54.8 \%$ (NSC Research Center, 2017). However, my focus is on first-generation community college-going students because although the majority of California's public school students will attend community colleges, they will be the least likely to succeed (Columbia University, 2019). Even the overall highest four-year college completion rate for the majority of California's students who begin at the community college level, $48.2 \%$ (CCC, 2018), is far from the number of graduates we will need to keep California economically strong (Bailey, Jaggars \& Jenkins, 2015).

\section{Purpose of the Study}

As aforementioned, the majority of California's college-going population is unlikely to complete college, in part because they do not have access to college-going navigational information at home (Bird, 2018; Mehta, Newbold \& O'Rourke, 2011). Prior research 
indicates that the parents of FGCS have a limited understanding of how to navigate the high school system, much less the postsecondary educational system (Kanno \& Kangas, 2014; Walker \& Pearsall, 2012). Unlike their affluent peers, FGCS do not have the ability to pay for college-going knowledge brokers (Del Valle, 2019) such as test preparation tutors, academic tutors, and college counselors. Transitional college-going curriculum (Patton, 2016; Welton \& Martinez, 2014) is also currently unavailable on a systemic basis in public schools.

In order to provide more access to systematic transition curriculum, for the past four years I have been using my own experiences as a FGCS and my twelfth-grade public school students' feedback to design and teach key curricular concepts of transitional navigational capital in Senior English class. Senior English class is an ideal place to start because it is a course in which students are already required to write intensively, think critically, and hone their skills for postsecondary endeavors. The student-centered college-going (SCCG) curriculum's overarching concepts include access knowledge, financial aid knowledge, and persistence knowledge. These components will be discussed more thoroughly below.

My goal in this research was to continue to collaborate with my students and thus iteratively design a curriculum that will support them in systemically gaining access to and persisting in postsecondary institutions. This dissertation is an important phase of this iteration because the research provides me the opportunity to follow up with my 
former students on the SCCG curriculum's effectiveness and compare this to feedback from current high school students. In short, my goal is to discover how the SCCG curriculum might have supported them during their first semester(s) of college and how the SCCG curriculum could be improved. Through this research, I will use the knowledge provided by my first-generation college-going students to support myself and other educators in understanding how to systemically SCCG curriculum into Senior English classes in a way that embeds the information and thus normalizes these supports into a course that is compulsory for every student in the nation.

\section{Development of the Curriculum}

I will use my own experiences as a mixed-race, working-class, first-generation college-going (FGCG) student to give an overview of how I understood the need for creating the SCCG curriculum. I transferred from community college and was able to earn my degree at a University of California (UC) as the result of being awarded a full scholarship; however, I found the postsecondary educational system difficult to navigate for three main reasons. The first reason I found the four-year degree-granting institutional system difficult to navigate was because I did not feel welcome. There was a socioeconomic (SES) mismatch between myself and the majority of my peers. At that time I did not realize why I felt so isolated and disconnected, but I later came to realize that I was different: the majority of students attending UCs were and continue to be from bourgeois/upper-class backgrounds (Geiser \& Atkinson, 2010). Classroom 
conversations that are full of middle-class allusions and the campus culture full of students with affluent ways of being can lead to FGCS students feeling as if they do not belong: this status as outsiders subsequently diminish academic performance (Steele, 2011). I remember experiencing subtractive schooling, as do many underserved students (Rios-Aguilar, Kiyama, Gravitt \& Moll, 2011; Valenzuela, 2010), because the curriculum was designed to meet the needs of the students from privileged backgrounds. In retrospect, it is unsurprising that I felt that I was not a legitimate member of my UC. At that time there was no systemically created community support provided for first-generation college students. A recent national study suggests that FGCS and/or students of color feel a stronger sense of belonging at community colleges than they do at four-year institutions (Gopalan \& Brady, 2019). Unfortunately, this type of isolation often pushes many first-generation students out of college (Ramsey \& Brown, 2018), isolation being one of many factors that contribute to only ten out of every hundred first-generation college-going students who began college actually completing college after six years (U.S. Department of Education, 2018). Research, conversely, correlates opportunities to connect with others from similar backgrounds with improved college persistence and completion rates (McCabe, 2016).

The second reason I found the four-year degree-granting institutional system difficult to navigate was because of my lack of institutional navigational capital (Silver \& Roksa, 2017; Yosso, 2005). I did not know how to obtain the education I desired. In 
spite of initially double majoring in Literature and Biology, I ultimately majored in the former because it was more easily navigated and I did not realize I could apply for another year of scholarships in order to finish my science degree. I thereby completed a literature major because it was easily accomplished and thus the most accessible to me. During the 1990s there were very few mentors provided to women in science (Starr, 2018), and I did not realize I could reach out to my institution by asking for a mentor to help guide my understanding. And this type of academic undermatching is a common experience for FGCS (Garriott, Flores \& Martens, 2013; Marx, Ko \& Croizet, 2019) for whom even applying and persisting in college can be an insurmountable feat, much less fully understanding how particular majors will affect their career choices and the ability to realize their full potential.

The last reason I found the four-year degree-granting institutional system difficult to navigate was that I did not understand the financial aid process. I was admitted into UC Berkeley but had no way to pay for it, and I did not realize that I could apply directly to the institution itself for one of their scholarships. Despite the fact that I had a 3.9 GPA, it never occurred to me to (learn how to) apply to Stanford University or any other private school of which I had heard because I knew that there was no way I could, as an individual, pay for a private education. As previously mentioned, I also did not understand that I could apply for additional scholarships to help me complete my science degree. All students should be thoroughly apprised of how to fund their postsecondary 
endeavors: research correlates understanding of and access to financial aid significantly improves students' college access, persistence, and completion rates (Chan \& Cochrane, 2008).

Although I used my own experiences as a foundation for determining some of what high school students needed to learn about transitioning to college, I also listened to my students' input. I felt strongly that the SCCG curriculum would be more valuable when I met the needs articulated by my students. The SCCG curriculum the students and I developed collaboratively is given a broad overview in the syllabus (see Appendix A) and can be viewed online in a digital calendar that links specific, spiraling lessons within three units . ${ }^{1}$ These three units include information to help students understand how to apply to colleges and universities as well as how to apply for financial aid. The curriculum also includes information to help students understand how to achieve a specific (potential or definitive) career goal and how to apply the needed "habits of mind" (HOM) in the postsecondary environment in order to accomplish this goal. Each unit ends with a culminating project: the completion of at least one college admissions application, at least one scholarship application, the FAFSA/CA Dream Act and/or scholarship, an individual career presentation, and a group HOM presentation, respectively.

\footnotetext{
${ }^{1}$ The SCCG curriculum is set up in a monthly format within which each day embeds links to detailed assignments. It is therefore not effective to include it in this document. For a more detailed overview of the curriculum, please email the researcher at jemalatesta@gmail.com.
} 
This collaborative effort to build the curriculum was garnered through twelfth-grade student input and subsequent teacher implementation. I initially became aware of my twelfth-grade students' needs for this curriculum through incremental steps. I first began to conscientiously integrate more SCCG curriculum into my Senior English secondary classes during 2015-2016 when I realized that the California State University (CSU) Expository Reading and Writing (ERWC) ${ }^{2}$ transition curriculum module entitled "Life After High School” was leading to more questions about postsecondary endeavors, rather than supplying sufficient answers. I developed the curriculum in partnership with my students, making changes and adjustments in response to their feedback. During the 2016-2017 school year, I integrated college access, financial aid, and career navigation curriculum along with the ERWC unit "Life After High School” because of the prior year's graduating seniors' input. The collaboration between students and the teacher took place over four years, up to its most thorough iteration during the 2018-2019 school year.

I honed the curriculum under an umbrella of three main components that have been shown to improve students' postsecondary attendance and persistence in the postsecondary system. First, students gained an understanding of how to access different types of postsecondary institutions and this focus was key to guiding my students' understanding of postsecondary opportunities. Understanding how to apply to

\footnotetext{
${ }^{2}$ Professors from California State University worked with high school English teachers to create a curriculum that would serve to teach the skills needed to prepare all high school seniors to succeed in first year postsecondary composition and content classes.
} 
postsecondary institutions in California--these being the community colleges, California State Universities, Universities of California and private institutions--is an important component to improving students' postsecondary outcomes through a raised awareness of the options (Bell, Rowan-Kenyon \& Perna, 2009; Roderick, Coca \& Nagaoka, 2011). Second, students gained an understanding of financial aid opportunities and how to access these opportunities. All of my students showed interest in learning how to fund their postsecondary endeavors, and prior research indicates increased understanding of and access to financial aid significantly improves students' college access, persistence, and completion rates (Bell et al., 2009; Chan \& Cochrane, 2008).

Last, teaching students persistence navigation to help them mitigate affective barriers such as the structural racism and classism embedded in higher education (Engberg \& Allen, 2011; Patton, 2016) by focusing on the HOM (Hazard, 2013; Karp \& Bork, 2012; O'Neill, Adler-Kassner, Fleischer \& Hall, 2012; Sullivan, 2012) is also a key component to improving students' postsecondary outcomes. Once I returned to graduate school and became aware that the persistence and completion rates were poor, particularly for first-generation college-going students (CCRC, 2019, Wilbur \& Roscigno, 2016), I began to research and thereby to integrate a component focused on college persistence during the 2017-2019 school years. Learning how to access and persist in postsecondary institutions in the twelfth-grade is particularly important for community college student success. Research suggests that while the majority of 
students who complete college attend four-year institutions are continuing-generation college students (Geiser \& Atkinson, 2010) who have access to college transition information at home, college students who are least likely to graduate are FGCS (Columbia University, 2019) who have little or no access to college transition information at home.

There are now emerging support systems for students once they enter the postsecondary systems (Bailey et al., 2015; The California State University, 2014; University of California, 2019). These opportunities to connect with others from similar backgrounds increase FGCS' success rates (McCabe, 2016). However, as I will discuss in the literature review below, none of these programs have been systematized. Thus, students who will attend community college will need to obtain an understanding of how to persist in four-year institutions before beginning postsecondary education. In order for more first-generation college-going students to obtain educational parity, secondary schools will need to systematically integrate SCCG curriculum so that every student can learn the needed HOM needed to persist during compulsory education in a compulsory class.

\section{Problem Statement}

The United States has the entire world knocking at its door to attend its postsecondary institutions: it is the number one world leader for international student representation of both undergraduate and graduate students on its campuses (Blumenstyk, 
2014). California is also enviable in its community college access: 2.1 million students attend California's 113 Community Colleges (CCC, 2016). Students in California have the opportunity to attend the community colleges without exclusive admissions processes as a result of their open-door policy, and this provides opportunities to transfer to four-year institutions or gain the needed vocational skills for a career.

One might assume that, in a country that claims to espouse equal opportunity for all, the population of students at all three institutions would match the state's demographics. When comparing high school completers in California, the demographics of potential college-students and actual college-going students do not proportionately represent the student population. While students of color comprise the majority of California's students in the graduating class of 2018 , only $57.7 \%$ attend college in comparison to $73.9 \%$ of White and Asian students (California Department of Education, 2018a). This figure also does not account for the $\sim 16.8 \%$ of students who did not complete high school (California Department of Education, 2018b). Within these groups, the financial gap between high socioeconomic and low socioeconomic students is greater today than it was two decades ago (Bailey \& Dynarski, 2011; Schneider, Hastings \& LaBriola, 2018). In light of the ever-increasing cost of college and the proportional amount of family income needed to cover this cost, this gap is unsurprising: "For families that earn $\$ 30,000$ or less, the share of total income required to cover their net price is 77 percent at four-year schools and 50 percent at two-year schools (community 
colleges) - more than double the burden placed on any other income group" (The Institute for College Access \& Success, 2017). It is an extreme economic hardship for working-class students to attend college, another reason why the FGCS students who attend college have lower rates of retention and completion (Blumenstyk, 2014).

Structural inequities are exacerbated in California's secondary institutions when no systemic support such as financial aid knowledge is provided for first-generation college-going students. While high SES students can obtain these supports outside of the public school system, for example through tutoring, paid college application help (Del Valle, 2019), and familial knowledge based on prior experience, FGCG students infrequently have the financial means to obtain the same supports (Wilbur \& Roscigno, 2016). Thus, without any systemic interventions, the gatekeeping methods that have been set up in every step of the application process often remain insurmountable (Duncheon \& Relles, 2019). In short, the more support services a student needs outside of the home, the more difficult it becomes for them to complete the application process in order to access postsecondary education (Wilbur \& Roscigno, 2016). In fact, FGCS “are 30 percent less likely to enroll in a four-year college than are their non-first generation counterparts... [and] are about 20 percent less likely to complete their bachelor's degree compared to their non-first generation peers" (Wilbur \& Roscigno, 2016, p. 5). This low college completion rate is attributed to a multitude of barriers FGCS students face. In comparison to their more affluent peers, FGCS are more likely to be dependent upon 
financial aid, to be required to work more hours, and to be under higher levels of stress (Mehta et al., 2011). FGCS correspondingly have lower grades, feel less satisfied socially and academically in the college environment, and are less likely to have the opportunity to find a sense of belonging by becoming involved on campus and interacting socially with their peers (Mehta et al., 2011).

\section{Levels of Knowledge: College Access \& Persistence}

College access and persistence depends heavily upon socioeconomics, not merit. The group of students who have the easiest route to accessing college are affluent, continuing college-going students who have access to preparation for college-entrance exams, do not need financial aid, and whose parents are college graduates of an American university (Cataldi, Bennett \& Chen, 2018). The parents of these affluent students can also pay navigational coaches to help their children apply to institutions where they are most likely to be accepted (Del Valle, 2019). They also have a family member at their disposal who can either directly answer or find the answers to the questions that arise in the application process.

The group of students with an easier route to accessing college are the (upper) middle-class college-going students who might need financial aid but whose parents are usually college graduates (Cataldi et al., 2018). These (continuing) college-going students will need to navigate the standardized testing process and the financial aid process, but generally have a family member at their disposal who either understands the 
college system or who knows how to seek out the answers to any questions that arise in the process (McCabe \& Jackson, 2016).

The six-year college completion rate at a public institution for affluent continuing-generation students, (upper) middle-class (continuing) college-going students, and first-generation college-going students is $55.3 \%, 54.8 \%$, and $38.6 \%$, respectively (DeAngelo, Franke, Hurtado, Pryor \& Tran, 2011). The majority of California's college-going students now belong to the last group (Education Trust--West, 2017) and therefore have the most challenging route to college access and persistence. These students and their families do not usually have first hand knowledge of the college going process or funds for outside supports and thus may not receive support regarding college access and navigational advice (Mehta et al., 2011). Although they are quickly becoming the majority in California (Education Trust--West, 2017), the literature review below shows they are underserved through erratic access to transition knowledge. Despite these changing demographics, there have been no systemic coursework interventions set in place in a manner in which each and every one of California's public secondary students will be provided access and persistence curriculum.

\section{Study Rationale}

Currently, high schools' student-centered college-going access and persistence curriculum takes an unsystematic approach, and the amount of navigational skills students obtain therefore completely depends upon the socioeconomic status of the 
students. It is well known that schools are not funded equally due to disparities in school funding based on locally assessed taxes in wealthier school districts attended by high SES students (Darling-Hammond, 2015). Without a systemic approach integrating SCCG curriculum into Senior English classes, I believe that California's students will continue to be given a piecemeal approach for postsecondary access and persistence, thus leading to the same dismal results in which the majority of college graduates will be made up of those with the most privileged backgrounds (Bowles \& Gintis, 2011).

The literature indicates that current intervention curriculum such as the federally funded TRIO programs, Middle Colleges, dual enrollment, Early Assessment and default curricula have the potential to improve the completion percentages for every student (Venezia \& Jaeger, 2013). However, current approaches provide inconsistent access through the requirements that students opt-in and/or are recommended by teachers to be a part of these special programs. I am thereby arguing that the SCCG curriculum becomes the centerpiece of Senior English class because it is an opportune moment: during each students' last year of compulsory education, they can be supported in their transition to postsecondary education. The transition between compulsory and postsecondary education is when students are the most vulnerable. The college attrition rate is the highest for first-year college students: "Of all students who started college in fall 2015, 73.4 percent persisted at any U.S. institution in fall 2016, while 61.1 percent were retained at their starting institution. The persistence rate is the percentage of students who 
return to college at any institution for their second year, while the retention rate is the percentage of students who return to the same institution" (NCS Research Center, 2018). Providing college access and persistence curriculum to every student during this critical transitional period is an accessible and comprehensive way in which to help decrease the college attrition rate which is highest during students' first year of college.

The current approach to providing college access and persistence knowledge to high school students is to haphazardly provide the information and is thus not designed in a way to ensure equitable access. I propose a system-wide approach, embedded in an existing, required class, that addresses the key aspects of navigational capital needed to gain full access to California's college system. Integrating this SCCG curriculum into compulsory English classes at the high school level would make college access and persistence curriculum systemic in order to support the improvement of college access and completion in a state that has a plethora of postsecondary opportunities. It would enable high school educators to support all of California's students in postsecondary endeavors rather than to support only those of California's students who have more financial means or to support only a very limited number of California's FGCS students who were handpicked for small, albeit supportive, programs as will be discussed in the literature review below.

This study used a teacher research design to examine the impacts of an SCCG curriculum on high school graduates who were enrolled in my Senior English class. The 
purpose of the study was to identify the impacts of a SCCG curriculum that integrates, into high school Senior English classes, the development of knowledge and skills necessary for enrollment and persistence in college. My students went on to attend every type of postsecondary institution California has to offer. From those surveyed, 30 students planned to attend community college, 12 students planned to attend a CSU, 7 students planned to attend a UC, and the remainder planned to attend either a private or out-of state postsecondary institution. However, because of the importance of community college as a pathway to four-year degrees for the majority of California's low-income and/or FGCS for financial success (Columbia University, 2019)--students who now make up the majority of our state's population but are the least likely to graduate (Cataldi et al., 2018)--my study will specifically investigate how my FGCS' exposure to the SCCG curriculum has affected their transition to community college.

\section{General Overview}

This study is based on documenting the experiences of students using their own words and modes of expression. Listening to student voices as a way to help solve educational problems such as access to, retention in, and completion of rigorous coursework have been underexplored (Kallick \& Zmuda, 2017). This study focuses on listening to students' experiences in order to improve the SCCG curriculum. Students will have the space to validate and utilize their "funds of knowledge" (Esteban-Guitart \& Moll, 2014) to become change-making agents of social justice and equity (Cammarota \& 
Romero, 2011) in their community. I believe that recommendations originating from our own students are critical to improving access and persistence in higher education because through their first hand feedback we will have the opportunity to better meet their needs.

\section{Research Questions}

The study is guided by the following research questions:

For students who participated in the SCCG access and persistence curriculum in Senior English and continued their education at community college:

1. What do students perceive is needed for college success?

2. What course structures and practices used in SCCG curriculum do current and former students report being supportive of college success?

3. What additional or different supports do students recommend adding to the SCCG curriculum to better support college success?

In answering these three questions, the traits students feel are effective contributions to a successful high school to postsecondary community college transition can be discerned and contribute to the literature. This knowledge enables practitioners to identify and implement key characteristics of SCCG access and persistence curriculum that are associated with an effective transition between high school and community college.

\section{Terminology}


For the purpose of this study, there are several operational definitions key to its design, as follows:

1. Access is defined as completing the steps needed to be accepted into a postsecondary institution and obtain federal, state, and privately funded (scholarships) financial aid.

2. Aspirational capital is defined as "the ability to hold onto hope in the face of structured inequality and often without the means to make such dreams a reality" (Yosso, 2005, p. 77).

3. Effectively maintained inequality (EMI) is defined as the manner in which socioeconomically powerful parents will obtain advantages for their children whenever possible in order to maintain their privileged status while simultaneously making it impossible for FGCS to achieve educational parity.

4. First-generation college-going/college students (FGCS) are defined as students whose parents have not earned a bachelor's degree in the United States and thus need direct, explicit support in order to acquire the navigational help needed to access and persist in postsecondary education.

5. Habits of mind (HOM) are defined as a rough guideline of the identifiable, teachable skills that assist with persistence and success in postsecondary educational settings (Hazard, 2013). They are broken down into discrete components, as follows: Curiosity, Openness, Engagement, Creativity, 
Persistence, Responsibility, Flexibility \& Metacognition (Hazard, 2013; Karp \& Bork, 2012; O’Neill et al., 2012; Sullivan, 2012).

6. Navigational capital is defined as students' skills and abilities to navigate "social institutions," such as educational spaces in which they use this capital to “maneuver within unsupportive or hostile environments" (Yosso, 2005, p. 80).

7. Persistence is defined as a student's ability to successfully utilize navigational capital in order to persevere in working toward achieving their educational goals.

8. Transition curriculum/programs is defined as curriculum/programs that are designed to support students successfully advance from the secondary to the postsecondary educational institution.

\section{Conceptual Framework}

I have adapted my conceptual framework from Hehir, Grindal, Freeman, Lamoreau, Borquaye \& Burke (2016), who have broken down the levels of inclusion for Special Education students based upon the provided services and subsequent participation in educational institutions. The four stages of integration are defined as Exclusion, Segregation, Integration, and Inclusion with Inclusion being the only effective component of the framework. There is evidence of exclusion, segregation, and integration in current policies for (not) supporting high school students' ability to navigate postsecondary education. The SCCG curriculum being evaluated in this study aims to move toward an inclusive approach. 


\section{Exclusion}

Currently, I believe that FGCS are not persisting in their postsecondary endeavours because they are being excluded through the high school's piecemeal approach for college access and persistence. Low socioeconomic status schools do not provide access persistence strategies needed to succeed. Even if two children start out with similar I.Q. scores, the real determinant of postsecondary academic success is whether or not the child comes from a racial group holding a position of power (Bowles \& Gintis, 2011) because socioeconomically advantaged students have access to the opportunities, such as the rigorous coursework that will help them access higher education (Klugman, 2013; Lucas, 2017) and private college counselors who will help them navigate the college process (Del Valle, 2019). FGCS do not have access to the same level of support these opportunities provide for their more affluent counterparts.

\section{Segregation}

Another reason FGCS students in California are not being prepared to obtain postsecondary degrees is that they are not always seen as college-going material. Our FGCS students are infrequently enrolled in rigorous high school classes (Theokas \& Saaris, 2013) in which instruction is given on college access (Kanno \& Kangas, 2014). In spite of the fact that FGCS students have been identified nationwide as eligible for advanced classes, over half a million of our low socioeconomic status students are not

enrolled in high track courses (Theokas \& Saaris, 2013). Inequitable high school district 
placement practices have tracked these students into the least rigorous classes for decades, and these low-level classes do not prepare students for college either academically (Darling-Hammond, 2015; Kelly \& Price, 2011; Oakes, 2008) or navigationally. Another reason these ability sorting practices have long been normalized is because of prejudicial counselor consulting and teacher recommendations. As a result of teacher bias (Carman, 2011; Flores \& Gomez, 2011; Hatt, 2012) and counselor bias (Vela, Zamarripa, Balkin, Johnson, \& Smith, 2013) low SES students are often excluded from the college preparation process.

\section{Integration}

When the students are placed in college-level courses even during high school, studies have revealed that their socioemotional well-being is affected negatively because of the separation from their support systems while in higher track courses. Teachers are not prepared to actively integrate their first generation college-going students into these courses (Chambers, Huggins, Locke \& Fowler, 2014). The result is a weakening of their community connectedness as well as their sense of identity (Chambers et al., 2014; Chambers \& Tabron, 2013; Walker \& Pearsall, 2012). The students experience negativity no matter what track is taken: they either feel less academically capable as a result of being excluded, forced to give up preparation for postsecondary access by opting out or forced to lose close ties with their peers and community by opting in. In short, studies show that students feel the same sense of disconnection and need to pay an 
“opportunity cost” (Venzant Chambers, Locke \& Tagarao, 2015) in both secondary and postsecondary institutions (Chambers \& Huggins, 2014).

\section{Inclusion}

As mentioned above, because of implicit bias, the majority of California's students who are enrolled in Senior English instead of an advanced English course will likely have been excluded from, segregated in, and poorly integrated into the courses where college access curriculum is most prevalent. Conversely, teachers who make room for the proposed intervention of including SCCG access and persistence curriculum move away from exclusion, segregation, and integration and toward inclusion. Students will be exposed to the key elements of college access and persistence. In short, said interventions can potentially shift the educational structure away from gatekeeping and toward one of inclusivity in which the majority of high school seniors can obtain systemic college-going knowledge. All seniors will thereby be exposed to the navigational capital they need to access and persist in postsecondary education. 


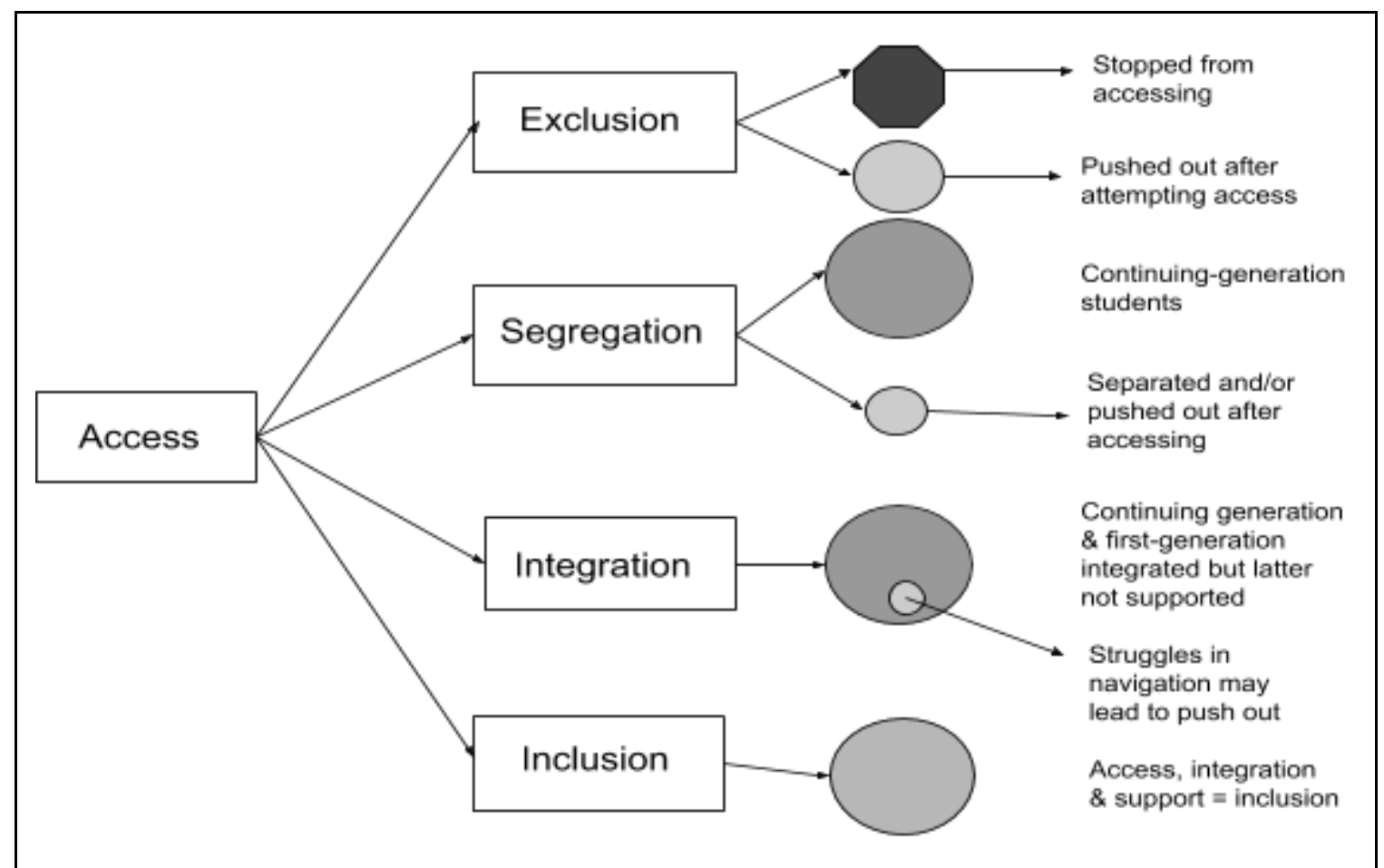

Figure 1.1. Conceptual framework.

\section{Significance of Study}

This study's goal was for me to determine, as the teacher-researcher, how to systematically implement impactful, college-going units in Senior English classes through a phenomenological research design (Seidman, 1998). In short, I utilized the suggestions offered by the students to help provide information on how to improve the college-going units and to thus provide more comprehensive postsecondary navigational capital to other Bay Area High School (BAHS) seniors. The anticipated significance of this research to the field is to understand how to increase BAHS students' navigational 
capital and thereby improve the students' access and also the HOM needed for college enrollment and success, respectively.

I have also been asked by the Deputy Superintendent of Human Resources to present the findings and recommendations of the study to the Bay Area Union High School District's (BAUHSD's) School Board. The board can subsequently consider whether or not these college-going units should be implemented district-wide. The head of the English Curriculum Council (ECC) is also interested in these results, and the ECC could utilize the BAUHSD's School Board's agreed-upon recommendations for future SCCG instruction and curriculum. The research thereby has the potential to inform not only the researcher's classroom practice but also district policy and programs in order to improve BAUHSD students' postsecondary outcomes. In short, the study has the potential to provide over two thousand seniors, during each school year, the needed navigational capital to access postsecondary education and also the HOM needed for college persistence. An ERWC teacher-trainer from the BAUHSD is also interested in creating an ERWC unit from the results, and once published through the ERWC the ERWC Senior English teachers throughout California could choose to teach the SCCG curriculum unit. During the summer of 2019, I also provided a component of the curriculum to a non-profit organization that supports FGCS. The provided curriculum is currently being used by this organization. Finally, if the SCCG curriculum itself shows a correlation to supporting students' college completion rates in multiple schools, my goal 
is to approach a lawmaker to consider putting forth a bill that will require that SCCG curriculum be a required component of Senior English classes, just as AB2015 has required that both documented and undocumented students complete their federal aid application as part of the curriculum before they reach twelfth grade.

\footnotetext{
${ }^{3}$ Please see https://leginfo.legislature.ca.gov/faces/billNavClient.xhtml?bill_id=201720180AB2015 for an
} overview of the bill 


\section{Chapter Two: Literature Review}

This chapter reviews the literature regarding the need to provide navigational support to first-generation college-going students (FGCS) during Senior English classes in order to support them in successfully transitioning from high school to postsecondary institutions as well as persisting in the latter. It is critical to understand the college access and persistence needs of FGCS because although they make up a third of the college population, they are the least likely to earn a college degree (Cataldi et al., 2018). FGCS currently have the least amount of success accessing and persisting in higher education (PNPI, 2019). After six years of college attendance, 64\% of the nation's continuing-generation students graduate with four-year degrees, while only $50 \%$ of the nation's FGCS graduate with four-year degrees (DeAngelo et al., 2011).

This chapter discusses current research on the importance of college access and completion, the problems with the most common type of in-school FGCS support at the secondary level, the current state of postsecondary and secondary collaboration in the college access transition, disparate levels of support provided in the college transition to students from differing socioeconomic groups, the contribution of colorblind neoliberalism to the disparate levels of support, and the potential to reduce this disparity for and by Senior English students who were exposed to and co-created the student-centered college-going (SCCG) curriculum. This study examines the perceptions of college students who were exposed to the SCCG: what they perceive is needed for 
college success, what course structures and practices included in the SCCG curriculum were supportive of college success, and what additional or different supports students recommend adding to the SCCG curriculum to better support college success.

\section{College Access \& Completion}

It is a pressing issue that FGCS are becoming the majority of students to be eligible to pursue college degrees but are the least likely to complete those degrees (Bird, 2018). It is both an ethical and an economically good-sense (Apple, 1979) decision to implement systemic solutions that will enable more of our majority population, first-generation college-going students, to access and persist in obtaining a postsecondary education.

\section{Responsibilities}

Historically, (higher) education has always separated those in power from those who are disempowered (Freire, Ramos \& Macedo 2000), but in a truly democratic society, educational access has the potential to lay the foundation for social equality. Yet, as aforementioned, the college completion rate in the USA is far from ideal (Tate, 2017). These poor college completion rates results in the ability to obtain economic and community prosperity on both personal and societal levels (Auguste, Hancock \& Laboissiere, 2009; Orfield, Marin \& Horn, 2005). Conversely, helping all students acquire a postsecondary degree through appropriate preparation is beneficial both for 
individuals and for society as a whole (Bailey \& Dynarski, 2011; Blumenstyk, 2014; Kirsch, Braun, Yamamoto \& Sum, 2007).

It is also in the best interest of Californians' economic future to support our FGCS in obtaining postsecondary degrees because of the training it provides for employment. A lack of postsecondary completion will become a significant problem because, by the year $2020,65 \%$ of the nation's jobs will require postsecondary education (Carnevale, Smith \& Strohl, 2013). Therefore, in order to promote economic health for both the individual and the state, it is imperative to develop and implement an effective, systemic method of supporting FGCS in accessing and persisting in postsecondary schooling.

\section{Supporting Access \& Persistence: Strengths \& Challenges of Existing Programs}

\section{Current Approaches Of The High School To College Transition}

There have been a number of effective, non-systematized interventions offered to high school students. Both secondary level internal programs, as well as community and non-profit external organizations, have been designed to help support high school students through programs to improve postsecondary access and persistence. In a general overview of the literature, Contreras (2011) provides an extensive list of over forty of these institutionally-based and externally-based programs. She specifically discusses AVID as a school intervention, Math Engineering Science Achievement (MESA) and Puente as statewide interventions, The Posse Foundation as a private non-profit intervention, Meyerhoff Scholars Program (MSP) as a school-university partnership 
intervention, Communities in Schools (CIS) as a community organization intervention, and Dual Enrollment as a programmatic intervention. The author makes recommendations on how to improve interventions, but neither specifies how these recommendations were determined nor gives specific steps for how these recommendations would be implemented. In a forty-nine study metaanalysis of credit-based transition programs, Bailey \& Karp (2003) give an overview of the effectiveness of secondary students' access to postsecondary credit-earning options in relationship to persistence. The analyzed programs consist of dual enrollment, Tech Prep, Advanced Placement (AP), International Baccalaureate (IB), and Early College High Schools (ECHS). They found that the majority of these studies were qualitative and thus did not provide the needed quantitative program evaluations to ensure stronger correlations to improved outcomes. However, according to their metaanalysis all of the listed programs are well-utilized today, and we can turn to other researchers who have conducted studies on these programs for more information on their effectiveness.

I have selected the high school studies below based upon their frequent implementation as used in the Bay Area Union High School District (BAUHSD). A very common in-school national intervention to support FGCS' access to postsecondary education is the Advancement Via Individual Determination (AVID) program. AVID was established in 1980 and serves students who begin the program as an elective class in middle school, based on teacher recommendation as promising FGCS, and students are 
offered this elective throughout high school (AVID, n.d.). The curriculum developed for the AVID Secondary level includes eight domains within the Grade 12 AVID Elective Standards, one of which focuses on preparing for college. ${ }^{4}$ Within the college preparation domain, students learn more about college through guest speakers, field trips, college admissions, financial aid, and selecting a college major. Because there are seven other domains, the college preparation domain of the curriculum has breadth, not depth. Through the seven other domains, students are asked to modify their ways of learning and being by practicing specific academic skills and changing their own behaviors. How underserved students can succeed despite structural inequities of postsecondary institutions are not directly addressed or taught. Students are expected to change and postsecondary institutions are therefore implicitly framed as unbiased, as neutral. The AVID program employs both internal and external researchers to evaluate the AVID program; these program-funded studies laud the program's success through (AVID, 2019). At this time, a scientific, comprehensive metaanalysis research study has not been conducted and the existing data can therefore not correlate the program's impact on AVID students' postsecondary success as would a more objective, peer-reviewed examination of the program.

\footnotetext{
${ }^{4}$ The information provided here is derived from material downloaded from the AVID website that I had access to as an AVID teacher. The information can also be downloaded through different organizations via search engines.
} 
However, more objective individual researchers not affiliated with AVID have conducted studies on the program. As I will delineate below, these studies have both confirmed and refuted a positive correlation between the AVID program and the outcomes of students; external researchers have given accolades, identified areas of concerns, and suggested changes for the program's shortcomings. In one mixed-methods study of 161 high school students, Llamas, López, \& Quirk (2014) found that enrollment in AVID resulted in benefits for students, particularly with regards to a greater degree of engagement with school and resilience. In a quantitative study of 527 high school participants, Pugh \& Tschannen-Moran (2016) also found that students' self-efficacy improved when enrolled in AVID. When researchers Huerta \& Watt (2015) studied 329 college students using quantitative methods, they found that students who had been enrolled in AVID were more likely to persist and thus begin the second year of college. They also found that the four-year college attendees used AVID-learned social skills while the community college students used AVID-learned academic strategies.

Conversely, AVID has been found to exclude male students and promote bias towards students of color. In Watt, Butcher \& Ramirez' (2013) quantitative study at a Hispanic-serving postsecondary institution, the researchers did not find that using AVID strategies during college improved the participants' academic outcomes more than that of their control group. Watt, Huerta \& Martinez (2017) used mixed-methods to study over 200 schools and determined that although boys are now falling behind in postsecondary 
completion, there is an extreme gender imbalance in that very few males were recruited into and/or supported in persisting in the AVID program during the last two years of high school. Brooks (2018) utilized two case studies to highlight the ways in which the AVID curriculum and its delivery by teachers are structurally racist, colorblind, and powerblind because the teachers promote assimilation skills through the myth of meritocracy.

Instead of perceiving AVID students' differences as strengths students should draw upon, teachers viewed AVID students as deficient. In short, students were viewed through a deficit-based lens and thereby expected to change to conform to White ways of being. Teachers saw themselves as saviors and were thus unaware of the need to teach students how to navigate the inequities in postsecondary institutions. Although this is a small study, it lends itself to further inquiry since those outside of the AVID community rarely have access to the program evaluation of the curriculum in either content or delivery. Unpacking the name itself, Advancement Via Individual Determination highlights how the program lauds a colorblind, powerblind individual determination philosophy rather than an approach that would help students develop the habits of mind needed in a system set up to push out working-class students and/or students of color (byrd, 2019; Harper, 2012). What is also notable is that none of the researchers who conducted non-AVID funded studies set up their study to follow AVID students into postsecondary schools to determine if and how AVID may or may not have had an impact on students' 
postsecondary success. The long-term effects of AVID's transition curriculum have not been evaluated through a program review conducted by more objective sources.

Even assuming the impact that the AVID program has upon students is to improve their postsecondary success, it is important to consider the number of students who are able to access the program. Although AVID researchers conclude that $42 \%$ of AVID students complete college as compared to $11 \%$ of their peers (AVID, n.d.), the percentage of students per school who have access to the program during their senior year is unclear. For example, I was one of the two Senior AVID teachers for the Class of 2019 at Bay Area High School, and of the graduating class only 25 of $\sim 450$ students, or $5.5 \%$ of the Senior class, completed the program. Conversely, if an effective SSCG curriculum had been implemented in every Senior English class, $100 \%$ of the senior class (regardless of gender) would have had the opportunity to learn more about how to access and persist in college. As a former AVID teacher trained in the program's most recent 2017-2019 curriculum, I designed the SSCG curriculum in a manner that was developed much differently from the AVID Senior curriculum. Although I had multiple students who were in both my AVID and Senior English classes, the curriculum never overlapped. The AVID curriculum focuses more on traditional academic and test-taking skills when applying to four-year colleges. The SSCG curriculum focuses on understanding the differences between educational systems, applying to each type of postsecondary institution based on student interest (AVID excludes community college knowledge), 
obtaining financial aid for each system, selecting a purpose for attending, researching that purpose for attending, and obtaining college persistence knowledge for postsecondary institutions that were founded on systems of gatekeeping (Kirst \& Venezia, 2017). AVID appears to me to focus primarily on the "how" of college and supports a small percentage of the FGCS population. Conversely, the SCCG curriculum that I propose implementing more broadly focuses on both the "why" and the "how" of college and exposes every high school student to a college-going curriculum.

Advanced Placement (AP), International Baccalaureate (IB), the California State University Expository Reading \& Writing (ERWC) are also programs utilized in the BAUHSD in which the college-going curriculum is directly embedded into the high school classes. The curricula in these programs neither reach students equitably nor systematically. Suneal Kolluri's (2018) extensive program review metaanalysis of the AP program revealed the program's continued disproportionate representation of students and difficulty preparing students for postsecondary academics. In a similar study of the International Baccalaureate Diploma (IBD) program (Perna et al., 2015), researchers conducted a review through national statistics and surveys to 76 IBD program coordinators, the majority of whom were Floridians. Similar to the AP program, researchers found that although the IBD program is growing the proportional representation of enrolled students of color is not. 
The ERWC curriculum, developed together by California's State University and California's English and Math high school educators, is made available for every student in California when teachers are trained to teach it. The Early Assessment Program (EAP) is taken as part of the California Assessments of Performance and Progress (CAASPP) to determine and inform students whether or not they need to take the ERWC course to avoid college remedial classes through preparation in high school. However, each district differs in the curriculum's formal adoption and methods of implementation. The BAUHSD allows each school to determine whether or not they will incorporate the ERWC curriculum systemically or through a piecemeal approach. For example, Bay Area High School (BAHS) allows senior teachers to choose whether or not they will use all or part of the ERWC curriculum although students who take the ERWC course can bypass costly remedial coursework at the postsecondary level. The EAP has been found to be an effective intervention for improving students' college readiness as per a quantitative study of $\sim 1.5$ million of Californian students' EAP tests (Howell, Kurlaender \& Grodsky, 2010). Almeida's (2016) more focused qualitative study of 24 low-income Latinx high school seniors reviewed the students' perceptions of the EAP program and found that students and their families were largely unaware of the purpose and benefits of the EAP and therefore did not necessarily take advantage of the program. The potential benefits of taking the ERWC course as determined by the EAP results are not uniformly 
provided. The ERWC is also not systemically taught within districts or even individual schools.

Accessing college curriculum by earning college credits in high school through dual enrollment and at Early College High Schools (ECHS) are also commonly implemented interventions used in an attempt to increase college access and persistence. Dual-enrollment programs bring college professors to teach college-level courses on the high school campus while ECHS programs bring the high school students to the college campus. Early College High Schools are designed differently from traditional high schools because students take all of their classes on the community college site and simultaneously take courses with high school teachers and college courses with college professors. Yet neither of these programs reach students equitably or systematically, and the effects of dual enrollment programs on student positive outcomes are mixed. In a state-wide, comprehensive quantitative study of the effects of dual-credit enrollment, the program in which high school students can earn college credits and only second to Advanced Placement in students' college-earning opportunities, Cowan \& Goldhaber (2015) found that it had little impact on Washington's students' college persistence and completion. Phelps \& Chan (2016) conducted a quantitative study of 2,300 students from 20 Midwest in which the outcomes of the dual-enrollment programs were compared to the technical classes in which college-level technical preparation classes were offered to high school students. Similar to the Cowan \& Goldhaber (2015) study, the researchers 
found that dual-credit enrollment programs taught by college professors did not affect college completion and career success. However, they did find that college-level technical preparation classes taught by high school teachers improved the students' completion rates and career success. ECHS programs in which both high school and college educators support students' learning have also been found to improve secondary and postsecondary success. In a retrospective, quantitative, randomized trial of $10 \mathrm{ECHS}$ programs (Haxton et al., 2016), the programs were found to positively affect college enrollment, college completion of two-year degrees, and the high school experience. In a mixed-methods study, Edmunds et. al (2017) also found positive correlations for students enrolled in ECHS programs. When compared to the 1,211 student control group, the 1,647 student treatment group suggested that underrepresented college-going students enrolled in the ECHSs were more likely to complete the courses needed for college entrance and also graduate from high school. College professors also perceived these students as being college-ready. Both studies attribute these positive outcomes to ECHS' ongoing navigational support of their students.

\section{Secondary \& Postsecondary Collaboration}

Nationwide, high school and postsecondary institutions have had difficulty working together to systematically provide access and transitional supports students need to succeed in postsecondary education. Multiple researchers give a detailed historical overview of the multifaceted reasons why educational institutions in the United States 
were set up and continue to be siloed (Kirst \& Venezia, 2004; Mitchell, Shipps \& Crowson, 2017). These reasons include politics and the absence of clearly delineated follow-up processes. Governing boards are siloed politically by institutional levels and lack a financial incentive to collaborate across institutional types. When governing boards do work together they frequently focus on small student population groups and lack clarity in follow-up protocol. Instead of a focused collaborative effort to transition between educational levels, what has emerged is a variety of ineffective and/or unsystematic interventions. Through a mixed-methods metaanalysis, Perna \& Armijo (2014) examine why each of the seven P-20 partnerships in different states continue to have difficulty aligning their educational systems despite these partnerships. Politics and bureaucracy also appeared to be the key components preventing a streamlined and effective collaborative process.

However, comprehensive research has been conducted to help make recommendations that can help secondary and postsecondary institutions work together, and it has been found that such collaboration improves student outcomes. Effectively communicating with students and their families as well as using research-based methods to determine how to improve programs were found to be central components of effective collaborative efforts. Researchers at the University of California, Santa Cruz (Moran, Cooper, López \& Goza, 2009) utilized three studies from their P-20 partnership to garner the feedback of close to 700 student and parent participants in order to make 
recommendations for future work and other partnerships that support Latinx students' science aspirations. They recommended that governance structures set goals and include all stakeholders in reaching those goals, and that research-based designs and cyclical data be used to determine the most effective program components that will serve to facilitate improvements. Although this study is limited to one particular demographic area, researchers from Columbia's Teachers College, Barnett, Bucceri, Hindo, \& Kim (2013), also published a report to recommend that decisions made be based on data collected from each Early College school site and from prior studies to determine what would be most effective for student success. In an even more expansive six-year study conducted through Stanford University’s Bridge Project, Venezia, Kirst \& Antonio’s (2003) policy report gives research-based, ${ }^{5}$ multi-state overview of the information students need for a successful transition. They emphasize the need for all stakeholders at all levels to become informed and to collaborate with and for the students.

Yet within secondary schools, the implementation of inconsistent transitional support and an absence of direct collaboration with postsecondary institutions is the norm. Barnett, Fay, Bork \& Weiss (2013) utilized mixed-methods to more broadly illustrate the existence of transition curricula between high school and postsecondary institutions state by state. They wished to determine if the curricula was implemented

\footnotetext{
${ }^{5}$ The research methods are not delineated or made available online. Author Andrea Venezia was contacted for further information and explained that the authors conducted focus groups with students, interviews with counselors and teachers, and gave surveys to parents and students.
} 
through local or state initiatives for informational purposes and future study of how to utilize transition curricula to better prepare and set up students for postsecondary success. Although their study did not take into account the curriculas effectiveness, they found that the development of the curricula was not always developed collaboratively between secondary and postsecondary state agencies. They also found that state agencies from secondary institutions were more likely to take the initiative to create and implement the curricula. Bell, Rowan-Kenyon \& Perna (2009) conducted individual and focus group interviews with 596 high school students in five states at fifteen high schools. They determined that there was no consistent method for students to learn more about accessing educational opportunities, types of financial aid, and applications for financial aid. Fitzpatrick (2019) highlights this inconsistency on a larger scale, within counseling, through his quantitative study of over 23,000 students nationwide in which he describes access to college-going knowledge as "Darwinian." Similarly, a report from researchers Venezia \& Jaeger's (2013) gives an overview of the most comprehensive literature available for eight common college readiness interventions: TRIO (Upward Bound, Talent Search, GEAR UP), Early/Early College High School, Dual Enrollment, Early Assessment Program, and Default Curriculum (college preparation course-taking sequences). They found positive outcomes for these programs to be either small or mixed. They recommend that educators be provided more professional development to 
help students develop not only academic skills but also the habits of mind (HOM) that will prepare them to succeed in college.

Postsecondary institutions also attempt to bridge the transition between the high school and college experience, albeit disconnected from direct collaboration with secondary institutions, by implementing transitional support the summer before students begin college. These summer programs provide early transitional support for those who are identified as needing said support. Yet the varied recruitment of participants as well as content of these summer programs makes it difficult to determine effectiveness. Sablan (2014) analyzed the literature from the past thirty years to evaluate the effectiveness of summer bridge programs. She discovered that the summer programs varied widely in implementation and that most utilized surveys to review the program. The absence of consistency and lack of qualitative methods--including the criteria for the recruitment of students--therefore made the programs difficult to compare and would have benefited from more follow-up, respectively. To better determine more generally, through qualitative methods, what helped students persist, succeed, and thus complete college, Arana, Castañeda-Sound, Blanchard \& Aguilar (2011) interviewed 33 students from a postsecondary Hispanic Serving Institution. The 16 current students were interviewed in a focus group, the 11 students who did not persist were interviewed via telephone, and the 6 graduated professionals were interviewed in-person. The researchers discovered that the students who persisted and completed college did so 
because of familial, faculty, and staff support. On-site validating cultural experiences also supported students in persisting. It is notable that the support each individual student received from the institution differed. Although this study is one small window into understanding what helps students succeed in college, it contrasts how qualitative methods can help garner insights from the very students who are affected by (a lack of) programs and services.

Additionally, there have also been a number of commonly used transition interventions that begin when students attend college: undergraduate mentorship, supplemental instruction, and first-year experience (FYE) programs. These programs have also been difficult to assess. Through metaanalysis, Gershenfeld (2014) reviewed 40 (in)effective undergraduate mentoring programs and, similar to the metaanalysis of Summer Bridge programs, concluded that their effectiveness were hard to determine due to the lack of uniformity in both the programs themselves and the methods of program review. In a quantitative study of 284 first-year college seminars, researchers Permzadian \& Credé (2016) discussed how the seminars correlated with an improvement in students' first-year GPAs $(\mathrm{N}=52,406)$ and persistence rates $(\mathrm{N}=169,666)$. Researchers Dawson, van der Meer, Skalicky \& Cowley (2014) conducted a 29-study analysis of the benefits of Supplemental Instruction (SI) through college peer learning and reiterated that although SI appears to be effective, the studies lack uniformity of review. More comprehensively, all three of California's institutions of higher education, 
community colleges (Bers \& Younger, 2014), state universities (Kitchen, 2020), and the University of California have also implemented FYE programs. These programs include first-year seminars, learning communities, orientations, early alert systems, and academic advising, all implemented in order to improve college persistence. Bers and Younger (2014) give an overview of the FYE community college programs and make recommendations for community college stakeholders to work together to collaborate and also collect data to determine their effectiveness. Kitchen (2020) also reviewed the literature of FYE programs and recommended that the programs become more comprehensive and integrated with their approaches by providing academic, social, and personalized student service support in order to help retain more first-year college students.

Many of these studies are limited because they are nongeneralizable due to their focus on one particular state, due to their small sample size and/or due to their lack of uniformity in implementation and research methods to determine program effectiveness. Yet there is a notable repeated theme: although there are many interventions offered, many of these programs are established as the result of an unquestioned assumption that they are beneficial for students. Consequently, they are infrequently reviewed for their effectiveness and inclusiveness. This institutional normalization leads to an acceptance of established practices that lack research-based methods to determine effectiveness, and thus, lack accountability. Although these types of transition interventions can be helpful, 
they are problematic because they help some students but not all, thus decreasing the urgency to find systemic solutions that help all students, not some.

Yet the knowledge gleaned through the multifaceted implementation of these transition curricula can work to serve all students. Through a review of their effectiveness, they can serve as the foundations upon which we can build a systemic transitional curriculum into comprehensive programs that serve all students. In order to better help all students succeed at the postsecondary level, it would be highly advantageous for research-based, effective access and persistence navigational knowledge to be interwoven systematically with content knowledge. Although content knowledge and cognitive strategies as the indicator of college-readiness has typically been lauded as the key component for student success (Conley \& French, 2014), Conley (2014) has been a leader in delineating a more complex understanding of the skills needed for students to be college-ready. When defining and grouping the college readiness knowledge that students need to be successful in their postsecondary endeavors, Conley (2014) also recommends that key learning skills and techniques and transition knowledge be included in addition to content knowledge and cognitive strategies.

Through the SCCG curriculum, transitional curriculum developed by both teacher and students is integrated into Senior English high school classes. The SCCG information students need to support their success after high school has the potential to be made available to every student through a compulsory content class. The curriculum 
includes access navigation (Bell et al., 2009; Conley, 2014; Roderick et al., 2011) to help students apply to the CCC-CSU-UC and California's private school systems, financial aid guidance (Bell et. al, 2009; Conley, 2014), the HOM (Conley, 2014; Hazard, 2013; Karp \& Bork, 2012; O’Neill et al., 2012; Sullivan, 2012), and the persistence strategies (Conley, 2014) needed to mitigate the structural barriers embedded in higher education (Engberg \& Allen, 2011; Patton, 2016). As reviewed by Lombardi, Seburn \& Conley's (2011) consecutive quantitative exploratory and confirmatory study, the researchers found that the HOM could be measured and suggest that the use of these tools have the potential to modify programs of study, organizational structure, and culture in high schools to improve college-readiness. However, these non-academic college knowledge factors are not yet systematically included in the high school's college-going interventions (Venezia \& Jaeger, 2013). The SCCG curriculum, therefore, includes curriculum on academic preparation, and also focuses on the non-academic factors that promote college persistence because of the postsecondary institutional habitus (Bourdieu, 1974; byrd, 2019) that reproduces "the sources of messages, assumptions, norms, and expectations that lead to 'structurally preferential treatment' typically by race, gender, and/or social class, which influence student outcomes" (byrd, 2019, p. 181).

\section{Disparate Levels Of Support}

Why has comprehensive college-going support not already been embedded in the curriculum through policy? Perna, Klein \& McLendon (2014) comprehensively review 
the literature on educational policy and college readiness and direct their recommendations for improving college completion to state policy leaders. The Common Core Standards, as per the Common Core Standards Initiative (2019) were theoretically written to help support students gain needed skills in College \& Career. ${ }^{6}$ Nonetheless, policy recommendations and national standards have not provided students with a systemic curriculum that intertwines the College \& Career Standards with the practical key college-readiness knowledge. Current curriculum does not include the implementation of mandated learning skills and techniques combined with transition knowledge and skills. As aforementioned, this knowledge includes the transition knowledge and skills of applying to college, applying for financial aid, as well as the learning skills and techniques--the HOM--needed to persist in postsecondary institutions. Below is an overview of how implicit bias, disparate resources, and colorblind-powerblind neoliberalism affect the ways in which adult stakeholders of secondary institutions fail to support FGCS' access and persistence through the absence of providing opportunities to obtain college-readiness knowledge.

\section{Implicit Bias}

Research on implicit bias in education indicates that administrators' and teachers' affinity for those similar to their own backgrounds impacts student experience (Staats,

\footnotetext{
${ }^{6}$ For a comprehensive understanding of the nepotism and neoliberal policies involved in the creation of these standards, as well as little involvement on the part of teachers and child development experts, see Schneider, M. K. (2015). Common Core Dilemma Who Owns Our Schools?. Teachers College Press.
} 
2016). Administrators who, like teachers, do not reflect the diversity of their students (U.S. Department of Education, 2016), often do not provide students full access to educational opportunities as a result of policies and practices that privilege the norms of high socioeconomic (SES) students (Holme, Diem \& Welton, 2014). Students of color are disproportionately FGCS due to the persistence of economic, social, and educational systems that have historically (and continue to) limit access to higher education for these groups (Wilbur \& Roscigno, 2016). Although public high school teachers (Pinchak, 2018) and counselors (Poynton \& Lapan, 2017) can make a significant difference in a student's college transition, many research studies have shown that teachers and counselors have higher college-going aspirations for high SES students than for potential FGCS students (Patton, 2016; Welton \& Martinez, 2014).

Implicit bias frequently impacts high school students' educational opportunities. After discussing diversity with site administrators and teachers in nineteen high schools across the nation, Tyler's (2016) study indicated that both administrators and teachers felt diverse students, who are frequently FGCS (Atherton, 2014), were culturally and linguistically deficient. Researchers have found that school leaders are not providing professional development (Turner, 2015; Tyler, 2016; Welton et al., 2015) to address the biased, normalized, deficit (Gorski, 2008) viewpoints of less affluent students' intellectual capabilities and cultures. The teachers in Tyler's (2016) study also revealed that they felt unprepared to teach students unlike themselves, but that they would 
appreciate having the opportunity to learn how to more effectively teach their diverse student population. Providing these opportunities would help reframe their viewpoints, i.e. help administrators and teachers understand that students who come from backgrounds different from their own are also academically capable and exhibit college-going potential (Hammond, 2014).

\section{Effectively Maintained Inequality}

The majority of our first-generation college-going high school students will need systemic access and persistence curriculum to support their transition from high school to postsecondary institutions because it is information that will not be readily available at home. The parents of FGCS will neither have had the experience in accessing a college education themselves nor will they have had the experience of persisting when making this transition to college (Crosnoe \& Mueller, 2014). Caretakers of FGCS will therefore not be able to pass on their own navigational capital (Yosso, 2005) to specifically navigate postsecondary spaces. Although our students come with a vast amount of social capital (Yosso, 2005) through the strength of their supportive families (Hamilton 2016; Wilkins 2014), navigating the university space is one with which their family members are unable to directly help them (Wilbur \& Roscigno, 2016).

As highlighted by the 2019 college "scandal" (Litow, 2019), most affluent parents will utilize every resource possible to enable their children to access and persist in postsecondary education which has resulted in affluent students being much more 
successful in obtaining postsecondary degrees (US Department of Housing and Development, 2018). Lucas' (2017) theory of effectively maintained inequality (EMI) highlights that socioeconomically powerful parents will obtain advantages for their children whenever possible. In this manner, the parents maintain their privileged status while simultaneously making it impossible for FGCS students to achieve educational parity.

EMI has contributed to high SES students being better prepared academically and also needing to spend less time in college because they are much more likely to gain access to college-going curriculum offered in AP classes than their first-generation college-going peers (Theokas \& Saaris, 2013). AP course offerings in California, courses that prepare students for college, have been particularly scarce or absent in schools educating potential FGCS students until the late 1990s. During the late 1990s, two different lawsuits were brought against the state of California for a lack of equitable access to AP classes (Koch, et al., 2012). Consequently, the federal government provided millions of dollars to increase AP classes (Koch, et al., 2012). Klugman's (2013) mixed-methods research study showed that in California affluent parents were able to offset the government funding that provided California's FGCS students more access to AP courses from 2000-2002 by, likewise, increasing the number of AP courses at socioeconomically advantaged schools by placing pressure on district officials. 
EMI has also contributed to an inability for FGCS to compete for spots on college campuses. In a recent quantitative study, researchers (Wolniak, Wells, Engberg \& Manly, 2016) utilized two national datasets to determine that socioeconomically advantaged parents" use of "enhancement strategies" was the highest predictor of college enrollment. High SES parents' enhancement strategies consist of ensuring that their child has the academic opportunities--including expensive college test preparation--and extracurricular activities admission offices use to determine whether or not the student has shown college-level promise (Klugman, 2013). Klugman (2012) utilized a quantitative study to determine if said strategies improve college admission to elite colleges. He found that AP enrollment, enhancement strategies, and a lack of FGCS status all increased the likelihood of students to enroll in a selective college. Even if FGCS students were able to pursue rigorous coursework and extracurricular activities at the same rate as high SES students, these studies suggest that it would still be impossible for them to compete with families whose economic resources far outstrip those from less economically privileged backgrounds.

One reason course sorting practices have long been normalized in many of California's suburban school districts' assessment policies is because socioeconomically advantaged parents wish to continue to segregate their own children within schools in order to maintain a position of privilege (Bonilla-Silva, 2015), despite extensive research demonstrating mixed level classes are beneficial to all students (Watanabe 2012). 
Socioeconomically advantaged parents' use of enhancement strategies for extracurricular opportunities and access to private college counselors is the highest predictor of college enrollment (Wolniak, Wells, Engberg \& Manly, 2016). Lucas' (2017) theory of effectively maintained inequality (EMI) highlights that socioeconomically powerful parents will obtain advantages for their children whenever possible. In this manner, the parents maintain their privileged status while simultaneously making it impossible for first-generation college-going students to achieve educational parity.

Schools need to debunk themselves of the American myth of meritocracy: not everyone has access to the same educational opportunities because of the pervasive discrimination embedded in school policies and procedures. Since implicit bias norms the idea that high SES students are the most worthy candidates for postsecondary opportunities, the implementation of college-going curriculum for low SES students is therefore piecemeal, at best (Bell et al., 2009; Engberg \& Allen, 2011; Roderick et al., 2011). High SES students also have parents who attended college and will thereby be able to provide more of the navigational access students need to access and persist in postsecondary education. High SES students are more likely to have the support of curriculum, teachers, counselors, and parents when pursuing college degrees.

First-generation college-going students have great potential, but their potential can only be accessed if school communities committed to working together against "color-blind 
racism" (Bonilla-Silva 2006) and power-blind practices by acknowledging and finding solutions for these inequities in college access and persistence.

\section{Colorblind \& Powerblind Neoliberalism}

On a larger scale, this lack of a direct avenue to college access and persistence strategies could be considered a part of what the Italian political leader Antonio Gramsci described as part of "the web of institutions in civil society [that] creates a culture that upholds capitalist domination"--the hegemony (Goldberg, 2016, p. 10). At one time in our history, Americans advocated for programs and policies that were "state-centered, generally democratizing legacies of the New Deal, World War II, and the Great Society" until the political and economic power hegemony was threatened through the success of 1960s social activists (Omi \& Winant, 2015, p. 213). However, along with many other social programs (Omi \& Winant, 2015) our college access and persistence navigation has been privatized for the profits of neoliberal businesses at a level only the highest bidder can afford. In addition to donating money to universities in the hopes that their child will more likely be accepted, affluent parents spend $\$ 2$ billion annually on private educational consultants (Del Valle, 2019). This is in addition to said parents employing private academic tutors, financial aid consultants, college trip facilitators to determine fit, and college admission test coaches (Del Valle, 2019). College access is a lucrative enterprise and outsourcing college access and persistence strategies can be sold to those who can afford it: the most affluent parents of college-going students. 
In stark contrast to this plethora of resources up for sale, FGCS' navigational guidance is limited to their high school counselors. And although counselors are also able to make a significant impact on college access (Poynton \& Lapan, 2017), even with the implementation of training needed to remedy implicit bias, it is difficult for students to access counseling help because California has the highest counselor-teacher ratio in the nation (National Association for College Admission Counseling, 2014). It is little wonder that FGCS have trouble competing with their affluent counterparts on college admission tests (Astin 2016) and drop out because of financial concerns (Mehta et al., 2011) or poor college fit (Wilbur \& Roscigno, 2016). Moreover, neoliberal for-profit universities prey on FGCS because these students have the least amount of college financial aid knowledge (Lynch, Engle \& Cruz, 2010).

\section{Conclusion}

Bonilla-Silva (2006) discusses the "American mythology" of how those in power believe equity will arise through democratic procedures, rather than through governmental mandates. He highlights that if those in power are treated as equally as those who are disenfranchised, parity will never be achieved because those in power are already ahead (Bonilla-Silva, 2006). The author also notes that racism is normalized through "social processes" such as education, so very normalized that those in power do not question their own discriminatory policies, and this normalization results in the lack of strategic implementation to combat racism in the educational system (Bonilla-Silva, 
2015). In this case, the discriminatory policy is to provide college access and persistence strategies to the most elite, to those who can afford to purchase them, while conversely ignoring the disparate levels of support for FGCS. Essentially, these frames allow for the continuing-generation college graduates who make up the majority of administrators, counselors, and teachers in public education to believe that no interventions need to be made in order to obtain parity (Bonilla-Silva, 2006). School officials are adopting a harmful colorblind and classblind approaches by not addressing racial bias and economic privilege by developing and implementing comprehensive policies and procedures to better support FGCS' access to and persistence in postsecondary education. 


\section{Chapter Three: Methodology}

This study explored the ways in which first-generation college students, after their senior year of high school and first year of college, made use of a student-centered college-going curriculum (SCCG) intended to support access and persistence. The study was aimed at better understanding the emerging needs first-generation college students (FGCS) have when accessing and persisting in postsecondary schooling due to the relative absence of available systemic navigational capital within educational institutions, in the community, and at home. This study examined students' perceptions of the effectiveness of the SCCG curriculum integrated into their Senior English class during the first few years of their college experience.

\section{Research Questions \& Design}

The study was guided by the following research questions for students who participated in the SCCG curriculum in Senior English and continued their education at community college:

1. What do students perceive is needed for college success?

2. What course structures and practices used in SCCG curriculum do current and former students report being supportive of college success?

3. What additional or different supports do students recommend adding to the SCCG curriculum to better support college success? 
These questions were explored with recent graduates immediately following their Senior English experience as well as with former students who had completed 1-5 semesters of community college.

\section{Study Context}

The study took place in the context of the year-long Senior English class that I taught at Bay Area High School (BAHS). BAHS is a comprehensive high school, part of the Bay Area Union High School District (BAUHSD) and is located in California's San Francisco Bay Area. When compared to California's public schools as a whole, the Education Data Partnership (EdData) website indicates that BAHS' rates of Free and Reduced lunch are quite below the state's (36.5\% compared to $60.1 \%)$ but also above the general rates for the county $(36.5 \%$ compared to $34.3 \%)$. The state's metric used to measure the diversity of a student population (in which the highest index for a real Californian school is 76/100 (see this link for an explanation of the EdData algorithm) rates both the BAUHSD and BAHS at a 60 . This score has been at a nearly constant 60 for the past few years (2014 to 2018).

BAHS is the largest and most socioeconomically diverse school in the district, and houses a student body of approximately 1,700 students. Currently, approximately $9 \%$ of the students enrolled in Honors/Advanced Placement (AP) classes at BAHS are African-American or Latinx-American whereas $45.5 \%$ of the school population is African-American or Latinx-American (BAHS School Profile, 2017-2018). Conversely, 
91\% of students enrolled in AP classes are European-American and Asian-American although they account for $46 \%$ of the student body. This racial segregation based on academic track is not, however, fully represented in non-AP Senior English classes (see Appendix B for how BAUHSD tracks English levels). CP Senior English classes more proportionately reflect the demographics of BAHS because many high SES students have opted out of AP English and into other AP courses of higher interest. (This disinterest in twelfth grade AP English was reflected by only one 35-seat Senior AP Literature class being offered at BAHS despite a population of approximately 400 seniors during the 2018-2019 school year.) Thus, my Senior English classes have proportionally represented the school's demographics as compared to the lack of proportional representation of students of color in Senior AP English.

\section{Description of Student-Centered College-Going Curriculum}

A large portion of the Senior English class consisted of providing students the support to iteratively improve their writing skills so that by the time they graduated they were more prepared to delve into college writing. Additionally, the Senior English SCCG was also integrated into the writing process and said curriculum was developed through my seniors' suggestions over the 2015-2019 school years. The time frame and content of the SCCG curriculum for the 2018-2019 school year can be delineated in three distinct phases. During the first six weeks of the semester, the seniors wrote a personal statement and created a resume that served as a foundation for applying to scholarships, 
another required assignment. They also applied to four-year universities and for the available Equal Opportunity Programs (EOP) available at UCs and CSUs during this time frame. During the first six weeks of the second semester, students focused on applying for federal financial aid and for community college, including support services. Beginning in the middle of the second semester, students focused on creating career presentations and writing a corresponding essay in which they included the habits of mind (HOM) they need to succeed in college. Students also worked in subject-focused panels or in jigsaw groups to present the HOM needed for college success.

\section{Data Collection Context}

Because this study is an investigation into the impact of SCCG, I collected data from students at two different stages of the college-going pathway. Phase one elicited the perspectives of all of my 2018-2019 seniors prior to graduation. High school students who participated in Senior English gave feedback via surveys and focus group discussions on what they perceived was needed for college access and success during their last week of Senior English. Participants in the quantitative portion of this study included the 22 high school students who submitted their consent forms. Because the qualitative data were conducted through focus group discussions, the study included direct quotes from the same 22 students as well as contextual discussion information to highlight and determine themes, respectively. Next, phase two documented the perspectives of former SCCG participants who matriculated at the community college 
located closest to their former high school after one to five semesters of college. Participants in this segment of the study included 14 community college students who participated in the SCCG curriculum in their senior year of high school during 2016-2017, 2017-2018, or 2018-2019 school years. The second phase of this study focused on community college students because these students need the most institutional college-going support: FGCS have the lowest completion rate of students pursuing postsecondary degrees (Wilbur \& Roscigno, 2016). Additionally, the second phase of the study focused more precisely on postsecondary students attending the same community college to control for administrative systems. By only looking at community college students the study was able to control for confounding environmental variables.

\section{Role of Researcher: Positionality}

My own interest in college access and persistence arose from my own experience as a working class, mixed race, first-generation college graduate and my experience as a secondary and postsecondary educator. At the time the high school set of data of the study was collected, I was teaching at BAHS as well as currently employed as a professor in the Bay Area Community College District (BACCD, a pseudonym). I am qualified to conduct this specific research project because I taught high school for twenty years: 9th-12th grade English Language Development (ELD), 11th-12th grade Advancement Via Individual Determination (AVID), and 9th-12th grade English, among other courses. I have also taught Academic Reading, English as a Second Language (ESL), and 
college-level English at the community college level intermittently over a twelve-year period. Students in my college-level English classes include regularly enrolled and Early College (dually enrolled, on-campus program) high-school students. Most recently, I was trained for and taught the California State University (CSU) transition curriculum to Early Start students during the summer of 2019 and First-Year Composition during the fall of 2019. Both courses were developed using San Francisco State University's first-year-experience (FYE) transition curriculum.

In addition, this is a self-study of an intervention that I designed and implemented as part of the Senior English curriculum, and my stance as an "insider"/practitionerresearcher gives me a perspective that cannot be replicated by traditional research design (Groundwater-Smith \& Mockler, 2011). My perspective as a local also cannot be easily replicated because of the common experiences I share with my students: I am a FGCS who grew up in a nearby suburb located fifteen minutes away from BAHS. The two suburbs have similar demographics. I also attended and graduated from a public school in the BAUHSD and attended Bay Area Community College (BACC), the community college where phase two of this research took place. At the time the community college data were collected, I taught ESL at my local adult school and English at the university where I was a doctoral student.

In short, my background is similar to that of my students because I am a FGCS who transferred from the BACCD to the University of California (UC). My ability to 
transfer was based on being awarded a full scholarship for academic performance, financial need, and my status as a FGCS. In short, I have been and continue to be part of this community because I was raised in the community, was a student in the community, achieved my postsecondary degree through this community, and taught at both the secondary and postsecondary levels in the community.

\section{Researcher-Participant Relationship}

I was the developer and teacher of the SCCG curriculum and therefore clearly an advocate for the said curriculum to be incorporated in Senior English classes. My role as a research-practitioner resulted in my direct interest in both the SCCG curriculum and the postsecondary outcomes of the students. Consequently, there was a potential reporting bias on both the part of the researcher and the students. There was a real risk of over-emphasizing the positive aspects of a program I care deeply about and of students altering what they said to maintain positive relations. By participating in the focus groups, students may have felt obligated to only give positive feedback. To mitigate these issues, I emphasized to my students the importance of articulating their own opinions so that I could understand their true beliefs in order to improve the SCCG curriculum for future students. I also designed the focus group and survey questions as both open-ended and non-leading. The qualitative narratives and quantitative survey results also served to decrease potential bias through triangulation, i.e. by helping to affirm or dispel the findings. These are unarguably necessary and important safeguards. 
The research community also acknowledges that researcher-practitioners who study their own communities have the potential to contribute to their own society, to create an avenue for further aesthetic discussion, to be reflexively self-aware, to be impacted on a personal level, and to articulate an authentic reality (Richardson, 2000). There are therefore many benefits for practitioners to conduct research because of the potential to obtain insightful data as the result of an inside perspective. For example, my existing, positive relationships with students may have elicited more complete and accurate responses; participants may have felt more inclined to fully engage in the focus group process and provide details that would have been omitted if the researcher had been unknown to them (Cochran-Smith \& Lytle, 1993). I also deeply understood the intended goals and actual implementation of the curriculum which may have led to a more nuanced understanding of how it could be improved to better serve the needs of students (Cochran-Smith \& Lytle, 1993).

\section{Participant Selection \& Demographics}

All participants were already known to me as my former students. There were thirty-six participants in the research. Twenty-two participants were high school students who took the survey and participated in the focus groups on the last day of our English class during their senior year. Fourteen participants were community college students who are high school graduates and my former students. Fourteen of the college students completed the survey and eight of these fourteen were interviewed in focus groups 
through a recorded conference call. The community college participants had completed one to five semesters at BACC. The high school participants were seventeen years of age or older and, due to their status as minors, are considered to be a vulnerable population. Granted all of the participants are fluent English speakers, some of the students' parents communicate primarily in Spanish. Written information for minors was thereby provided in both English and Spanish.

The high school students were recruited through a brief speech and a "consent to participate in research" letter. This letter was passed out, signed by the participant and, if the participant was under eighteen, an additional letter was signed by a parent or guardian. The "consent to participate in research" letter was also mailed. The college students were recruited through mailed recruitment flyers and social media. The college students were provided a "consent to participate" research letter that was signed before submitting the survey.

This project was completely voluntary, and current students in the researcher's class were informed that the choice to participate or not participate had no impact on their grade or status in the class. I also gained access to the high school participants by being granted official permission in an email from the Deputy Superintendent of Human Resources in the BAUHSD and a verbal agreement from the principal of BAHS. Appropriate consent forms and protocol procedures were followed. I gained access to the 
BACC students by obtaining verbal permission from the BACCD Vice President of Human Resources.

\section{Ethics and Protection of Human Subjects}

Guided by the SFSU Office for the Protection of Human and Animal Subjects, this section discusses the measures taken to protect participants' rights in both phases of the study. The prime risk for participants may have been experiencing uncomfortable emotions (anger, fear, sadness, discomfort). Authentically listening to the participant and giving supportive feedback minimized this risk.

Furthermore, because the focus groups included discussion of personal opinions, extra measures were taken to protect each participant's privacy. I began each focus group by asking the participants to agree to the importance of keeping the information discussed in the focus group confidential. I then asked each participant to verbally agree to keep everything discussed in the focus group confidential and reminded them at the end of the research period not to discuss the material outside. There was a risk of loss of privacy due to recording the focus group interviews. Only the researcher had access to the raw data collected. Once transcribed, all names were changed to pseudonyms. All identifiable data will be destroyed five years after the conclusion of the study.

Students and parents of the high school students were informed that participation was completely voluntary and that the students' grades would not be affected whether or not they participated. There were no direct benefits or costs to high school participants. 
All high school students participated in the surveys because it was part of a curricular unit that was taught as part of the regular class; however, the researcher only used data only from those students who agreed and had permission to participate. The alternative for the high school focus groups and the college students was to choose not to participate in the research. Although there was no payment for high school participants, the college participants were provided a $\$ 25$ gift card both at the end of the survey and the end of the discussion as an acknowledgment of the time they voluntarily devoted to the study. The process took place at BAHS for the high school students and through an online form and a recorded phone conversation for the college students. The researcher answered the participant's questions, obtained signatures, and kept the informed consent documents in the office of the dissertation chair.

All research data were stored on the researcher's password-protected encrypted box server. Only the researcher and her faculty advisor have access to the data. All identifying information was removed and pseudonyms for participants and their schools are provided. Last, data will only be presented to the administration and board members in the aggregate, i.e. as a finished report with all identifying information removed. Five years after the conclusion of the study, data, audio recordings and notes will be destroyed.

The informed consent process was as follows. The students were given the letter describing the study, read aloud by the researcher, that informed them of the procedures and purpose of the study. The students were given the opportunity to ask questions and 
have them answered by the researcher. The students were given the consent form, read aloud by the teacher, that informed them of the voluntary nature and confidentiality process of the study. The students were given the opportunity to ask questions and have them answered by the researcher. The participants and parents/guardians, if the participant was under 18 , received a signed copy of the consent/assent form. They also received the results of the study, if requested on the consent form. All students turned in a signed, informed consent and/or assent document form before participating in the study. The high school students had until the end of May to make a decision whether or not to participate in the study. The students who were attending community college had until the day of the focus group meeting to make a decision whether or not to participate in the study.

\section{Data Collection \& Analysis}

\section{Mixed-method Design}

The study used a convergent, parallel mixed-methods design; the qualitative and quantitative data were collected in two phases: the survey was given, and the participants subsequently discussed their answers to the focus group questions with one another. To address the research questions, this study used survey responses and 2-4 participant focus groups to give a holistic understanding of the students' understanding of the skills needed for college access and retention strategies. High school surveys and focus groups were conducted in person, at the site of the institution. College surveys and focus groups were 
conducted digitally, through an online form and recorded phone conversations, respectively. Demographic information and GPA were collected at the end of the survey.

Data were collected by administering a survey to high school and college students (see Tables 1-2, respectively). Students later discussed their answers in focus groups.

Students participating in the study:

- reviewed the goals and purposes of the study with the researcher

- took the survey:

- high school students took the survey as part of their regular classwork, and

○ community college students took the survey prior to the focus group conversation (see Table 7).

- met with the researcher in focus groups of 2-4 participants

- read the questions and jotted down ideas as so desired before the beginning of the focus group session

- discussed the focus group questions for approximately 60-70 min.

The high school student phase of the research took place during class at the high school in the regular classroom. The community college research took place in the morning at an agreed-upon time and day that was most appropriate for the students' schedules. The total time commitment was no more than 80 minutes: 5-10 minutes for the survey, and 60-70 minutes for the focus group discussion. There were no high school non-participants since this was a part of a regular curricular unit, although only those 
students who were granted parental consent have neither quantitative data nor direct quotations used in the study. There were no college non-participants since it was a volunteer group.

\section{Quantitative Phase: Questionnaires}

To prepare for the data analysis using the software $\mathrm{R}$, the quantitative data collected in the survey were cleaned in several ways. First, a copy was made of the raw data and all personal identification information was removed from the copied version. Second, the column titles of original data were shortened for ease of analysis and columns containing non-essential data were removed. Third, GPA in the original data set was given as a range and the midpoint of the range was utilized in the analysis. Next, dummy variables were used for ethnic background, ranging from 1-7, and gender, ranging from 0-2. Last, the data were downloaded as a CSV and then uploaded into R. The cleaning process was performed identically for both the high school and college participants.

Each category was analyzed independently and then compared via a correlation matrix with the focus group data. The purpose of this comparison was to determine, by category, how each numeric response correlated to each other. The values were utilized to identify the strength of the correlation. The convergent design helped to inform the researcher of the participants' perceptions of the skills needed for postsecondary access and success. 
Survey responses were analyzed individually and in the aggregate to identify relative areas of strengths and weaknesses in the current curriculum. The data were presented in relative frequency tables and bar graphs. This data indicated any relationships between college access and preparedness curriculum embedded in the Senior English course. Correlation between survey question responses and GPA were also calculated. Additionally, correlation was measured on survey responses and GPA based on demographic factors. Responses with high positive or high negative correlations were used in a regression model with GPA as the response variable. Demographic factor variables were included in the regression model. The regression model was examined for key explanatory variables to determine if the survey question foci had a significant influence on GPA.

Confidence intervals for each mean survey response were constructed and compared. The confidence intervals served to show the mean response plus/minus margin of error. They indicated which responses had more consistent responses (smaller margin of error) versus responses with a lot of variation (large margin of error) in order to better understand the consistency in the responses. When there was a sufficient sample size in different demographic groups the survey question responses were analyzed by demographic variables using conditional bar graphs, i.e. bar graphs that disaggregate data by specific variables. For example, a bar graph comparing the results between male responses as contrasted with female responses. Last, before the quantitative data were 
finalized I discussed them with my chair and also reviewed them with a statistician in order to check for accuracy.

\section{Qualitative Phase: Focus Groups}

In order to illustrate what students felt was needed for college success, if/how the SCCG curriculum was supportive of college success, and what additional/different supports students recommended adding to the SCCG curriculum to better support college success, I facilitated recorded focus groups with my former Senior English high school students who had completed at least one semester of community college. The approach to inquiry is the use of phenomenology in focus groups, in which the participants describe their lived experiences (Hancock, Amankwaa, Revell \& Mueller, 2016). I am particularly interested in the lived experiences of FGCS at the community college level and better understanding the "common features of lived experiences" (Hancock et al., 2016, p. 1375) in order to gain insight into the essential elements that work to support and/or needs to improve the SCCG curriculum in order to better serve students.

This study took measures to address reliability through its use of clear protocols, specific questions, and focus groups. The initial list of questions was created by aligning questions with three categories: college application process, financial aid process, and HOM needed for college persistence and success, i.e. the affective domain. All focus groups were facilitated using a semi-structured format, using sets of questions focused on navigational skills (see Appendix J). Not all questions were answered as thoroughly by 
all participants, but the questions were asked across participants as appropriate to identify where agreement exists, diverged and/or was expanded.

All focus groups were recorded, transcribed verbatim, and then reviewed and refined for accuracy. The transcripts were coded holistically for themes by hand using an emergent coding scheme (Charmaz, 2014). Themes in the qualitative evidence were explored through multiple coding cycles using a grounded theory methodology and through data memos (Charmaz, 2014) using Google Docs. My first cycle of the process consisted of my high school focus group data. Second, I analyzed my college focus group data. After reviewing the themes, each line of the transcript was recorded in Google Sheets and coded by both topic and theme. I then looked for the themes that showed themselves to be the most relevant for a better understanding of what would support students' access and persist in higher education. Additionally, before the data were finalized I discussed them with my chair and also reviewed them with a colleague in order to check for accuracy.

\section{Integration Of Data}

Survey responses, both qualitative and quantitative, were used to measure attitudes toward the ability to access and/or succeed in postsecondary education. Comparisons of qualitative data and quantitative data indicated a level of consensus on factors such as the effectiveness of SCCG curriculum and/or needed college navigational skills. The reflections about students' experiences with access to postsecondary education 
combined with any correlation between survey questions responses and GPA showed relationships in the effectiveness of the SCCG curriculum to support college persistence. Additionally, comparisons between survey question responses and demographic variables provided relationships in the effectiveness of the SCCG curriculum to support college persistence. The results of the qualitative and quantitative data provided a richer understanding of emerging themes through the use of parallel comparisons. 


\section{Chapter Four: Report of Findings}

This mixed-methods study was guided by the need to better understand how college-going students transitioning to two and four-year institutions can be supported in college access and persistence through their student-centered college-going (SCCG) class curriculum. This study utilized focus groups and surveys to understand how to design and refine a curriculum that will support college-going students in systemically accessing and persisting in postsecondary institutions. Data were collected by administering a survey to high school students (see Table 6) and to college students (see Table 7). Students participating in the study first took the survey. Students later discussed their answers and made additional suggestions in focus groups (see Appendix J). High school students took the survey as part of their regular classwork, and community college students took the survey prior to the focus group conversation (see Table 7). Students then discussed the research questions in focus groups of 2-4 participants for approximately 60-70 $\mathrm{min}$.

The focus group transcripts were coded holistically for themes by hand using an emergent coding scheme (Charmaz, 2014). Themes in the qualitative evidence were explored through multiple coding cycles using a grounded theory methodology and through data memos (Charmaz, 2014) using Google Docs. My first cycle of the process first consisted of analyzing my high school focus group data for themes and writing data memos. I repeated this process to analyze my college focus group data. After reviewing 
the uncovered themes in the data memos, each line of the transcript was recorded in Google Sheets and matched to the themes. I then looked for the themes that showed themselves to be the most relevant for answering the research questions. I also looked for areas of overlap and areas of distinction between the two groups to better understand how they might inform each other. This chapter explicates the scope of the data from each group and the mixed-methods findings.

\section{Research Questions}

The study is guided by the following research questions. For students who participated in the SCCG access and persistence curriculum in Senior English and continued their education at community college:

1. What do students perceive is needed for college success?

2. What course structures and practices used in the SSCG curriculum do current and former students report being supportive of college success?

3. What additional or different supports do students recommend adding to the SCCG curriculum to better support college success?

This chapter is organized by addressing the findings that correlate to each question. The qualitative and quantitative data addressed all three questions. The quantitative data is addressed first and subsequently elucidate the themes that arose from the qualitative data.

\section{Scope of the Data}




\section{Student Surveys}

Of the 56 high school students surveyed, 22 submitted consent forms ( $n_{h s}=22$ ).

All 14 college students surveyed submitted consent forms $\left(n_{c}=14\right)$. The total results for the survey data include 36 students. The data collected from the surveys were tabulated and organized in tables showing the Likert Scale response values, the proportion of students responding at each level and the number of students responding at each level. Included in each table is a 95\% Confidence Interval for the mean response level (constructed using t-procedures with 21 degrees of freedom for the high school data and 13 degrees of freedom for the college data). The confidence interval is used to estimate the average response score if the survey were to be conducted for a population of high school and/or college participants.

\section{Focus-group Interviews}

Of the 59 high school students enrolled in my Senior English classes 48 participated in the focus groups as part of my regular classroom practice. Of these 48 high school students, 22 submitted consent forms. High school students who submitted consent forms were directly quoted in the qualitative data, when applicable. Of the 15 college students who completed the survey, 8 were interviewed in focus groups through a recorded conference call. These 8 college students are also directly quoted in the qualitative data, when applicable. 
The participants varied somewhat in their demographic representation. The majority of the college participants were female (10 female to 3 male) but the high school participants were more balanced (12 female to 10 male). One college student self-identified as gender fluid. The majority of the college students identified as Latinx (8 of the 14) with some students identifying as Mixed, White or Filipino (3, 2 and 1 respectively). More high school students identified as Latinx than other ethnic backgrounds (9 of the 22) but also included White (6), Asian (3), Mixed (3), Indian (2) and Filipino (1). Student demographics are reviewed below in Table 4.1.

Table 4.1

Student Demographics

\section{Category: gender}

Male

Female

Fluid

\section{College students} 3

10

1

\section{High school students}

10

12

0

\section{Category: ethnicity}

Latinx

White

Indian

Asian

Filipino

Mixed

\section{College students}

8

2

0

0

1

3

\section{High school students}

9

6

2

3

1

3 


\section{Findings}

\section{Quantitative Findings}

The findings from the survey data are reviewed by question and subsequently compared to the qualitative findings when appropriate.

\section{Quantitative Data Analysis Survey Responses}

The quantitative survey data include 22 high school participants and 14 college participants. The degrees of freedom to construct a confidence interval using a $\mathrm{t}$-distribution is $\mathrm{n}-1$. The degrees of freedom for constructing the confidence interval for the true mean response of the high school participants is 21 . The degrees of freedom for constructing the confidence interval for the true mean response of college participants is 13. Note that Table 4.X.H denotes high school data while Table 4.X.C denotes college data.

Readings \& College Applications. For high school students, the data suggest a somewhat neutral opinion with regards to the effectiveness of readings on applying to colleges. The most common response was three and only nine students reporting a score of four or five. The $95 \%$ confidence interval includes values above and below three suggesting that the average response for the population of high school students may not be above three. This may mean that the high school students' attitudes toward the readings on college applications, on average, are neutral. In contrast, the majority of the 
college participants ( 8 of the 14) responded with a four or five indicating a positive attitude toward the readings and the college application process. Furthermore, the 95\% confidence interval strictly exceeds three suggesting that the average response for all college students is above three. This may mean that the college students' attitudes toward the readings on college applications are, generally, positive because they have a retrospective understanding of the readings needed to successfully apply for college. The data is summarized in Table 4.2.H and Table 4.3.C below.

Table 4.2.H

Class Readings For College Applications: High School Survey Response Scores

The class readings helped me successfully apply for college.

\begin{tabular}{|c|c|c|c|c|c|}
\hline Response & 1 & 2 & 3 & 4 & 5 \\
\hline Proportion & 0.045 & 0.227 & 0.318 & 0.273 & 0.136 \\
\hline Number & 1 & 5 & 7 & 6 & 3 \\
\hline
\end{tabular}


Table 4.3.C

Class Readings For College Applications: College Survey Response Scores

The class readings helped me successfully apply for college (if you have no opinion, please mark "3")

\begin{tabular}{|l|c|c|c|c|c|}
\hline Response & 1 & 2 & 3 & 4 & 5 \\
\hline Proportion & 0.00 & 0.071 & 0.357 & 0.289 & 0.289 \\
\hline Number & 0 & 1 & 5 & 4 & 4
\end{tabular}

$95 \%$ confidence interval for the mean response score: $(3.22,4.35)$

Significantly above 3 suggests sufficient evidence of positive response

Activities \& College Applications. For high school students, the data suggest that high school students, in general, had a positive opinion about the class activities associated with college applications. Twelve of the twenty-two high school students responded with four or five and only three students responded negatively (one or two). The $95 \%$ confidence interval includes values strictly above three suggesting that the average response for the population of high school students is above three. This may mean that the high school students' attitudes toward the activities for college applications, on average, are positive. Similarly, nearly all of the college participants (13 of the 14) responded with a four or five indicating a positive attitude toward the activities for the college application process. Furthermore, the $95 \%$ confidence interval strictly exceeds three suggesting that the average response for all college students is above three. 
This may mean that the college students' attitudes toward the activities for college applications are also, generally, positive. The students' overall positive responses toward class activities may suggest that students prefer learning through activities. The data is summarized in Table 4.4.H and Table 4.5.C below.

Table 4.4.H

Class Activities For College Applications: High School Survey Response Scores

The class activities helped me successfully apply for college.

\begin{tabular}{|l|c|c|c|c|c|}
\hline Response & 1 & 2 & 3 & 4 & 5 \\
\hline Proportion & 0.045 & 0.091 & 0.318 & 0.409 & 0.136 \\
\hline Number & 1 & 2 & 7 & 9 & 3 \\
\hline
\end{tabular}

95\% confidence interval for the mean response score: $(3.05,3.95)$

Significantly above 3 suggests sufficient evidence of positive response

Table 4.5.C

Class Activities For College Applications: College Survey Response Scores

The class activities helped me successfully apply for college (if you have no opinion, please mark "3")

\begin{tabular}{|c|c|c|c|c|c|}
\hline Response & 1 & 2 & 3 & 4 & 5 \\
\hline Proportion & 0.000 & 0.071 & 0.000 & 0.429 & 0.500 \\
\hline Number & 0 & 1 & 0 & 6 & 7 \\
\hline
\end{tabular}


Written Assignments \& College Applications. The results from high school students data suggest that high school students, in general, had a positive opinion about the written activities associated with college applications. Twelve of the twenty-two high school students responded with four or five and only three students responded negatively (one or two). The $95 \%$ confidence interval includes values strictly above three suggesting that the average response for the population of high school students is above three. This may mean that the high school students' attitudes toward the written assignments for college applications are, on average, positive. Similarly, most of the college participants (11 of the 14) responded with a four or five indicating a positive attitude toward the written assignments for the college application process. Furthermore, the $95 \%$ confidence interval strictly exceeds three suggesting that the average response for all college students is above three. This may mean that the college students' attitudes toward the activities for college applications are also, generally, positive. Both the high school and college students' attitudes toward the written assignments for college applications are, generally, positive because they have a lived experience understanding of the writing needed to successfully apply for college. The data are summarized in Table 4.6.H and Table 4.7.C below. 
Table 4.6.H

Written Assignments For College Applications: High School Survey Response Scores

The written assignments helped me successfully apply to college.

\begin{tabular}{|l|c|c|c|c|c|}
\hline Response & 1 & 2 & 3 & 4 & 5 \\
\hline Proportion & 0.045 & 0.091 & 0.318 & 0.318 & 0.227 \\
\hline Number & 1 & 2 & 7 & 7 & 5 \\
\hline
\end{tabular}

95\% confidence interval for the mean response score: $(3.10,4.08)$

Significantly above 3 suggests sufficient evidence of positive response

Table 4.7.C

Written Assignments For College Applications: College Survey Response Scores

The written assignments helped me successfully apply to college (if you have no opinion, please mark "3").

\begin{tabular}{|l|l|l|l|l|l|}
\hline Response & 1 & 2 & 3 & 4 & 5 \\
\hline Proportion & 0.000 & 0.071 & 0.142 & 0.500 & 0.289 \\
\hline Number & 0 & 1 & 2 & 7 & 4
\end{tabular}

95\% confidence interval for the mean response score: $(3.49,4.51)$

Significantly above 3 suggests sufficient evidence of positive response

Readings \& Financial Aid. The results from high school students data suggests that high school students, in general, had a neutral opinion about the readings associated with financial aid. Eleven of the twenty-two high school students responded with a three, 
three students responded negatively (one or two) and eight of the high school participants responded with four or five. The $95 \%$ confidence interval includes values above and below three suggesting that the average response for the population of high school students is not significantly different from three. This may mean that the high school students' attitudes toward the readings associated for financial aid, on average, are neither positive nor negative. Though eight of the college students responded with a four or five, six of the college participants responded with a one, two or three. The $95 \%$ confidence interval includes values above and below three suggesting that the average response for the population of college students is not significantly different from three. This may mean that the college students' attitudes toward the readings associated for financial aid are, on average, neutral. The overall neutral responses from the students also suggests that more information needs to be provided through readings on how to effectively navigate an understanding of financial aid opportunities. The data are summarized in Table 4.8.H and Table 4.9.C below. 
Table 4.8.H

Readings For Financial Aid: High School Survey Response Scores

The readings helped me successfully apply for financial aid.

\begin{tabular}{|c|c|c|c|c|c|}
\hline Response & 1 & 2 & 3 & 4 & 5 \\
\hline Proportion & 0.000 & 0.136 & 0.500 & 0.318 & 0.045 \\
\hline Number & 0 & 3 & 11 & 7 & 1 \\
\hline
\end{tabular}

Table 4.9.C

Readings For Financial Aid: College Survey Response Scores

The readings helped me successfully apply for financial aid (if you have no opinion, please mark "3").

\begin{tabular}{|l|c|c|c|c|c|}
\hline Response & 1 & 2 & 3 & 4 & 5 \\
\hline Proportion & 0.071 & 0.071 & 0.289 & 0.289 & 0.289 \\
\hline Number & 1 & 1 & 4 & 4 & 4 \\
\hline
\end{tabular}

95\% confidence interval for the mean response score: $(2.94,4.34)$

Not significantly above 3 suggests insufficient evidence of positive response

Activities \& Financial Aid. For high school students, the data suggests that high school students, in general, had a positive opinion about the class activities associated with college applications. Thirteen of the twenty-two high school students responded 
with four or five and only two students responded negatively (one or two). The $95 \%$ confidence interval includes values strictly above three suggesting that the average response for the population of high school students is above three. This may mean that the high school students' attitudes toward the activities for financial aid, on average, are positive. Similarly, most of the college participants (10 of the 14) responded with a four or five indicating a positive attitude toward the activities for the financial aid process. Furthermore, the $95 \%$ confidence interval strictly exceeds three suggesting that the average response for all college students is above three. This may mean that the college students' attitudes toward the activities for financial aid are, generally, positive. The positive response from all students suggests that the hands-on activities were helpful when applying for financial aid. The data are summarized in Table 4.10.H and Table 4.11.C.

Table 4.10.H

Class Activities For Financial Aid: High School Survey Response Scores

The class activities helped me successfully apply for financial aid.

\begin{tabular}{|c|c|c|c|c|c|}
\hline Response & 1 & 2 & 3 & 4 & 5 \\
\hline Proportion & 0.000 & 0.091 & 0.318 & 0.364 & 0.227 \\
\hline Number & 0 & 2 & 7 & 8 & 5 \\
\hline
\end{tabular}


Table 4.11.C

Class Activities For Financial Aid: College Survey Response Scores

The class activities helped me successfully apply for financial aid (if you have no opinion, please mark "3").

\begin{tabular}{|l|c|c|c|c|c|} 
Response & 1 & 2 & 3 & 4 & 5 \\
\hline Proportion & 0.000 & 0.214 & 0.143 & 0.143 & 0.500 \\
\hline Number & 0 & 3 & 3 & 3 & 7
\end{tabular}

95\% confidence interval for the mean response score: $(3.20,4.66)$

Significantly above 3 suggests sufficient evidence of positive response

Written Assignments \& Financial Aid. For high school students, the data suggests that high school students, in general, had a neutral opinion about the written assignments associated with financial aid. Only six of the twenty-two high school students responded with four or five whereas sixteen students responded with a three or lower. The $95 \%$ confidence interval includes values above and below three suggesting that the average response for the population of high school students is not above three. This may mean that the high school students' attitudes toward the written assignments for financial aid are neutral. However, nine of the fourteen college participants responded with a four or five indicating a positive attitude toward the written assignments for the financial aid process. Furthermore, the $95 \%$ confidence interval strictly exceeds three suggesting that the average response for all college students is above three. This may 
mean that the college students' attitudes toward the written assignments for financial aid are, generally, positive. This data also suggest that high school students need to be provided a more comprehensive understanding of how writing essays for a variety of scholarships can improve access to financial aid, an understanding that the college students may have already obtained through experience. The data are summarized in Table 4.12.H and Table 4.13.C.

Table 4.12.H

Written Assignments For Financial Aid: High School Survey Response Scores

The written assignments helped me successfully apply to financial aid.

\begin{tabular}{|l|c|c|c|c|c|}
\hline Response & 1 & 2 & 3 & 4 & 5 \\
\hline Proportion & 0.000 & 0.227 & 0.500 & 0.182 & 0.091 \\
\hline Number & 0 & 5 & 11 & 4 & 2 \\
\hline
\end{tabular}

$95 \%$ confidence interval for the mean response score: $(2.74,3.53)$

Not significantly above 3 suggests insufficient evidence of positive response 
Table 4.13.C

Written Assignments For Financial Aid: College Survey Response Scores

The written assignments helped me successfully apply to financial aid (if you have no opinion, please mark "3").

\begin{tabular}{|l|c|c|c|c|c|}
\hline Response & 1 & 2 & 3 & 4 & 5 \\
\hline Proportion & 0.071 & 0.000 & 0.286 & 0.286 & 0.357 \\
\hline Number & 1 & 0 & 4 & 4 & 5 \\
\hline
\end{tabular}

$95 \%$ confidence interval for the mean response score: $(3.18,4.53)$

Significantly above 3 suggests sufficient evidence of positive response

Readings \& Habits Of Mind. For high school students, the data suggests that they, in general, had a positive opinion about the readings associated with HOM. Thirteen of the twenty-two high school students responded with four or five and only two students responded negatively (one or two). The $95 \%$ confidence interval includes values strictly above three suggesting that the average response for the population of high school students is above three. This may mean that the high school students' attitudes toward the readings for HOM, on average, are positive. Similarly, most of the college participants (9 of the 14) responded with a four or five indicating a positive attitude toward the readings for the HOM. Furthermore, the 95\% confidence interval strictly exceeds three suggesting that the average response for all college students is above three. This may mean that the college students' attitudes toward the readings for HOM are, generally, positive. In 
general, the data suggest that understanding the HOM through readings was viewed as beneficial for all students. The data are summarized in Table 4.14.H and Table 4.15.C.

Table 4.14.H

Readings For The Habits Of Mind: High School Survey Response Scores

The readings helped expose me to the habits of mind needed to succeed as a college student.

\begin{tabular}{|l|c|c|c|c|c|}
\hline Response & 1 & 2 & 3 & 4 & 5 \\
\hline Proportion & 0.045 & 0.045 & 0.318 & 0.364 & 0.227 \\
\hline Number & 1 & 1 & 7 & 8 & 5 \\
\hline
\end{tabular}

95\% confidence interval for the mean response score: $(3.22,4.14)$

Significantly above 3 suggests sufficient evidence of positive response

Table 4.15.C

Readings For The Habits Of Mind: College Survey Response Scores

The readings helped expose me to the habits of mind needed to succeed as a college student (if you have no opinion, please mark "3").

\begin{tabular}{|l|c|c|c|c|c|}
\hline Response & 1 & 2 & 3 & 4 & 5 \\
\hline Proportion & 0.000 & 0.143 & 0.214 & 0.429 & 0.214 \\
\hline Number & 0 & 2 & 3 & 6 & 3 \\
\hline
\end{tabular}

95\% confidence interval for the mean response score: $(3.14,4.29)$

Significantly above 3 suggests sufficient evidence of positive response 
Activities \& Habits Of Mind. For high school students, the data suggest that high school students, in general, had a positive opinion about the class activities associated with HOM. Thirteen of the twenty-two high school students responded with four or five and only three students responded negatively (one or two). The $95 \%$ confidence interval includes values strictly above three suggesting that the average response for the population of high school students is above three. This may mean that the high school students' attitudes toward the activities for HOM, on average, are positive. All of the college participants (14 of the 14) responded with a four or five indicating a positive attitude toward the activities for the HOM. Furthermore, the $95 \%$ confidence interval strictly exceeds four suggesting that the average response for all college students is above four. This provides strong evidence that the mean that the college students' attitudes toward the activities for HOM are positive. The positive responses of both groups suggests that learning about the HOM through activities is an effective teaching method. The data are summarized in Table 4.16.H and Table 4.17.C 
Table 4.16.H

Class Activities For The Habits Of Mind: High School Survey Response Scores

The class activities helped expose me to the habits of mind needed to succeed as a college student.

\begin{tabular}{|l|c|c|c|c|c|}
\hline Response & 1 & 2 & 3 & 4 & 5 \\
\hline Proportion & 0.045 & 0.091 & 0.273 & 0.364 & 0.227 \\
\hline Number & 1 & 2 & 6 & 8 & 5 \\
\hline
\end{tabular}

$95 \%$ confidence interval for the mean response score: $(3.15,4.12)$

Significantly above 3 suggests sufficient evidence of positive response

Table 4.17.C

Class Activities For The Habits Of Mind: College Survey Response Scores

The class activities helped expose me to the habits of mind needed to succeed as a college student (if you have no opinion, please mark "3").

\begin{tabular}{|l|c|c|c|c|c|}
\hline Response & 1 & 2 & 3 & 4 & 5 \\
\hline Proportion & 0.000 & 0.000 & 0.000 & 0.714 & 0.286 \\
\hline Number & 0 & 0 & 0 & 11 & 3 \\
\hline
\end{tabular}

95\% confidence interval for the mean response score: $(4.02,4.56)$

Significantly above 4 suggests evidence of strong positive response

Written Assignments \& Habits of Mind. For high school students, the data suggests that they, in general, had a positive opinion about the written assignments associated with HOM. Twelve of the twenty-two high school students responded with 
four or five and only three students responded negatively (one or two). The $95 \%$ confidence interval includes values strictly above three suggesting that the average response for the population of high school students is above three. This may mean that the high school students' attitudes toward the written assignments on HOM, on average, are positive. Similarly, many of the college participants (11 of the 14) responded with a four or five indicating a positive attitude toward the written assignments associated with HOM. Furthermore, the $95 \%$ confidence interval strictly exceeds three suggesting that the average response for all college students is above three. This may mean that the college students' attitudes toward the written assignments for the HOM are, generally, positive. The overall positive response from both groups suggest that understanding the habits of mind through written assignments is viewed as beneficial. The data are summarized in Table 4.18.H and Table 4.19.C.

Table 4.18.H

Written Assignments For The Habits Of Mind: High School Survey Response Scores

The written assignments helped expose me to the habits of mind needed as a college student.

\begin{tabular}{|c|c|c|c|c|c|}
\hline Response & 1 & 2 & 3 & 4 & 5 \\
\hline Proportion & 0.045 & 0.091 & 0.318 & 0.455 & 0.091 \\
\hline Number & 1 & 2 & 7 & 10 & 2 \\
\hline
\end{tabular}


Table 4.19.C

Written Assignments For The Habits Of Mind: College Survey Response Scores

The written assignments helped expose me to the habits of mind needed as a college student (if you have no opinion, please mark "3").

\begin{tabular}{|l|c|c|c|c|c|}
\hline Response & 1 & 2 & 3 & 4 & 5 \\
\hline Proportion & 0.071 & 0.000 & 0.143 & 0.500 & 0.286 \\
\hline Number & 1 & 0 & 2 & 7 & 4
\end{tabular}

$95 \%$ confidence interval for the mean response score: $(3.30,4.55)$

Significantly above 3 suggests sufficient evidence of positive response

Financial Aid And College Persistence. The college participants survey data suggest a somewhat neutral attitude toward financial aid and college persistence. Of the college participants only six of the fourteen responded with a four or five whereas seven responded with a three and one responded with a two. However, the $95 \%$ confidence interval strictly exceeds three suggesting that the average response for all college students is above three. This may mean that the college students' attitudes toward financial aid and college persistence are, generally, positive. Since the SSCG curriculum went into more depth over time, the data suggest that the connection between financial aid and college persistence needs to be augmented. The data are summarized in Table 4.20.C. 
Table 4.20.C

Financial Aid And College Persistence: College Survey Response Scores

When I am worried about having enough money to continue college, I am successful in obtaining more financial aid (if you have no opinion, please mark "3").

\begin{tabular}{|l|c|c|c|c|c|}
\hline Response & 1 & 2 & 3 & 4 & 5 \\
\hline Proportion & 0.000 & 0.071 & 0.500 & 0.214 & 0.214 \\
\hline Number & 0 & 1 & 7 & 3 & 3 \\
\hline
\end{tabular}

95\% confidence interval for the mean response score: $(3.03,4.11)$

Significantly above 3 suggests sufficient evidence of positive response

Problem Solving And College Persistence. Many of the college participants (10

of the 14) responded with a four or five indicating a positive attitude toward the problem solving and college persistence. Furthermore, the $95 \%$ confidence interval strictly exceeds three suggesting that the average response for all college students is above three. This may mean that the college students' attitudes toward problem solving and college persistence, generally, are positive. The data suggest that the expectation for students to practice solving problems through the SCCG curriculum and environment was beneficial.

The data are summarized in Table 4.21.C. 
Table 4.21.C

Problem Solving And College Persistence: College Survey Response Scores

If a problem arises that I think might prevent me from continuing college, I am determined to find a way to solve the problem (if you have no opinion, please mark "3").

\begin{tabular}{|l|c|c|c|c|c|}
\hline Response & 1 & 2 & 3 & 4 & 5 \\
\hline Proportion & 0.000 & 0.071 & 0.214 & 0.286 & 0.429 \\
\hline Number & 0 & 1 & 3 & 4 & 6
\end{tabular}

$95 \%$ confidence interval for the mean response score: $(3.50,4.65)$

Significantly above 3 suggests sufficient evidence of positive response

\section{Qualitative \& Quantitative Findings}

More general qualitative themes emerged from coding feedback from both the high school and college students. The high school focus group discussions were divided into 215 idea segments and then matched to the themes determined in the process memos. The college focus group discussions were divided into 189 idea segments and then matched to themes determined in the process memos. Ideas that were repeated by multiple participants both within and across groups were chosen as the 12 themes reported in these findings.

Themes and/or quantitative data are labeled as "students" when they overlapped across the secondary and postsecondary levels and labeled as "high school" or "college" student(s) when themes and/or quantitative specifically apply to the comments solely for 
that particular group of participants. Students are labeled as "postsecondary" if they are visiting students who are speaking about their college experience and/or helping to facilitate activities. Students are also labeled as "secondary" or "postsecondary" when the group is discussed in general terms i.e., not in direct relationship to the participants in this study. In sum, students who are referred to as "students," "high school students" or "college students" are direct participants of this research study, whereas students who are labeled as "secondary" or "postsecondary" are not direct participants of this research study.

\section{RQ1: What Do Students Perceive Is Needed For College Success?}

Preparation For The College Environment. Half of the college students gave positive responses indicating that they felt prepared for the college environment. Two college students repeatedly described, while two others expressed agreement, that they were prepared for college through the SCCG curriculum because it was taught in a manner that replicated the college environment. They described their preparation as being readied for a more free, college-going environment through the student-focused, problem-solving curriculum. They felt that the environment was both caring and self-directed.

Denzell: 'Cause every time we would do something at the group.... you would give us freedom of choice. And you would tell us, "Oh yeah when you get to college it's a big thing. 'Cause you get to choose how you really want to do a lot 
of things. And who you want to do group things with...Because she would give me this perfect look like, "I'm gonna give you stuff to do. And if you feel like you've grown enough to do it. Do it. But if you need help, she's here to help you." Because she's not gonna like cookie-crumb you to the final paper. She wasn't gonna cookie-crumb you to like what your presentation should look like... If you need help, she was there to help you. Or she would give us stuff to help us with it...She would especially be doing what college professors do right now. Gabriel: I think for me it's like the experience of like how easy you are with us but you still care what we work on. And it's like having...[an] experience like real into college. Because in college, professors are just gonna give you...an essay and homework for English.

Denzell: You should let them know what they...should be expecting basically.... When I was listening to everybody else's English class, they thought like a four year university was going to be like, "Oh yeah." Like, it was going to be like a walk through of basically what they'd been going through since high school. And...when I was in your class I'm like, "I'm not, I'm learning how to like think differently. I'm learning how to present myself. I'm learning how to do careers."

High school students also expressed such an environment as being beneficial, but expressed this theme differently, as discussed in the next theme as "increased social 
support and collaboration." Unlike the college students, the high school students did not yet have a retrospective understanding of how the Senior English classroom environment compared to the college classroom environment.

This theme relates to the Habits of Mind (HOM) needed for college persistence because the Senior English class was run in such a way that these behavioral habits were necessary for success. The HOM are broken down into discrete components, as follows: Curiosity, Openness, Engagement, Creativity, Persistence, Responsibility, Flexibility \& Metacognition (Hazard, 2013; Karp, 2012; O’Neill et al., 2012; Sullivan, 2012). Tables $4.14-4.19$ show that the majority of all students had a positive experience when learning about the HOM through the reading materials, written assignments, and activities.

Furthermore, each of the $95 \%$ confidence intervals for the mean response scores exceeded three providing further evidence of students' strong positive responses to the HOM readings, written assignments, and activities.

However, four high school members of the at-capacity, 35-student high school class felt that their college-like run class was too much release of responsibility for some students who needed a more restrictive environment.

Shreya: The format of the class sometimes got a bit chaotic with people being loud and a lot of distraction going on when Ms. Malatesta...[is] giving instructions....it gets hard sometimes when you're trying to listen to...there's so much, such a loud background noise going on. 
There was also one particular group of students with whom I repeatedly reminded to work through the skills necessary to the HOM needed for college success rather than force them into silence through punitive methods. One student mentioned that these students needed more support in understanding the importance of the SCCG curriculum. Justin: Yeah, they didn't really understand how like, how beneficial it could be...they just like shooed it off as something that, oh another day in class. So before we start the presentations, we can preface it by...you actually like, literally...need like this information to better yourself off. And maybe some students could think..."oh maybe I actually have to listen”...You can't really control the students and how they do it. But you can try your best to attempt it I guess.

No students in the smaller Senior English class opposed the class being run with a more college-like atmosphere. The student survey did not address this concern so there is no quantitative data to support this statement.

Increased Social Support And Collaboration. Ten high school students described an increased sense of solidarity with classmates as a result of the common postsecondary preparatory experiences. Both first-generation and continuing-generation college students felt less alone and more unified in learning how to navigate their future lives.

Guadalupe: One major thing that really helped...it just really made things so 
much easier when we're able to work in groups to get ideas from one another, to bounce the ideas back and forth. So it clarifies every little thing that may have been confusing in the class. Or even helping one another in the financial aid or college application or the writing process. For writing comes the Common App, or whatever it may have been. We were always able to help one another...

Students felt that their increased access to college-going knowledge facilitated through a collaborative class environment helped to support them gain needed college-going navigational skills. For example, a first-generation high school student mentioned that her parents had high expectations but did not have access to the postsecondary navigational knowledge provided in class. Two first-generation college students, one from the high school level and another at the college level, also mentioned the need to better understand the financial aid process so that they could pass the information on to support their siblings.

Gabriel: Because I know like right now I have my younger...brother is now in like senior high school. And I've been asking him...to apply for [a] scholarship and...he do[es]n't know what scholarship and how to apply.

Overall, students indicated that the opportunity to collaborate and learn from one another throughout the process was helpful for their own college-going understanding and also to later guide their siblings. Tables 4.4, 4.5, 4.10, 4.11, 4.16, and 4.17 show that the majority of students had a positive experience when learning about college access and 
persistence through collaborative activities. Furthermore, each of the $95 \%$ confidence intervals for the mean response scores exceeded three providing further evidence of strong positive responses to the collaborative activities. In table $4.17100 \%$ of the college students responded with a 4 or a 5 on the HOM activities, thus providing strong evidence that the current college students value the hands-on activities that gave them the opportunity to teach one another.

Preparation For Self-Care Techniques. Five students also continued to utilize the self-care skills they learned in class. Four high school students continued to utilize the learning they obtained through the novel Siddhartha, by Herman Hesse (1982), and the accompanying activities emphasizing self-care and life balance. These two concepts were introduced and practiced during the last few weeks of high school for students in the Class of 2019. For example, some high school students began to utilize meditation in their everyday lives. The following quote concludes this discussion in which four participants are in agreement on the helpfulness of learning about wellness.

Victor: Good mental health [through mindfulness and meditation] could improve ...life, substantially.

Another example of this skill learned in class is applied to help with persistence is illustrated by how a college student purposefully enrolled in a yoga course and continues the meditation practice. She discussed the importance of maintaining a healthy life-work-school balance in order to succeed. 
Nicollete: I took a yoga class this semester, this past semester. And, you know how you helped us do the meditation....people are like, "Oh, it's college. It's so much harder. You're gonna, like, have so much pressure." Yeah,..but you have to...find a way around it..using what you have...knowing how to [say], like, "Okay, what can I do to, um, to give myself, like, a day off...each week? So, I have, like, a day to myself or a day with my family."

It is likely that only one college student mentioned self-care techniques because they were most fully taught through the last iteration of the SCCG curriculum, and the college student discussed above was exposed to the last iteration. There is no quantitative data correlated to self-care, beyond what can be observed in the HOM responses, to support or negate this qualitative theme.

\section{RQ2: What Course Structures And Practices Used In Senior English Do Current And}

\section{Former Students Report Being Supportive Of College Success?}

Understanding Differences Between Postsecondary Options. Six students felt

that learning about differences between postsecondary institutions was or would be helpful. Four high school students felt that assignments requiring them to work together to learn more about and present the difference between California's postsecondary options helped them determine which were a good fit. The high school students felt that the understanding of these differences allowed them to better determine where to apply. Justin: [The] college admission process, it actually really helped me because 
I was applying for three different colleges. And I didn't know which one I was gonna be able to go to because I'm moving.

Rihanna: I wanna talk about what we learned at the beginning of the year, when we learned about the differences between UC's and CSU's, private colleges....and what kind of where the plus is and minus is and differences between each one because that really taught me a lot about the differences, when I'd heard people say UCLA. I didn't know [the] difference between the UC and a CSU. And that was very helpful in making a decision on where to apply.

Mason: And I think having the people from...[the community college] come in, multiple times, to talk to us about the opportunities at the... [community college]...showed me, like, the other options that I had and, how to apply--how to like make use of all the different programs that I could find at like, not on a community college but at like any college.

The positive responses illustrated in the qualitative data are supported by the quantitative data. Table 4.4 shows that over $80 \%$ of high school students with a response score of three or better. A $95 \%$ confidence interval for the mean score for the question exceeds three providing further evidence that the high school students felt that class activities on how to apply to college were beneficial. Since the college students were already attending community college, two college students' focus tended toward the desire to learn more about how to transfer to four-year colleges rather than to differentiate 
between institutional types.

Laura: I think there should be tips and tricks about applying to college. And how college will be. Because I know there are courses in community college about how to apply to four year colleges.

Denzell: They should start bringing more than just... [the community college] to come...they should bring like a private college, a four year univer[sity]...to like explain differences or like explain how to apply to those schools. Because they all have different criteria. And you won't...know that unless you either were applying for it or like you have to ask or showed up by yourself.

College students also mentioned that they would have liked to have obtained more information via speakers from California's different postsecondary institutions (discussed below). Again, their focus was on the transfer process because they were already attending college and obtaining this knowledge was the next step in obtaining a college degree.

Assignment Accountability With Guided Learning. Thirteen high school students found that beginning their college-scholarship essays in class, having homework deadlines to allow for feedback to be given for college-scholarship essay revisions, having deadlines for scholarship and financial aid applications, and accessing designated in-class time to allow for guided learning helped support their college endeavors. 
Timothy: During the coming up and other application essays as sort of a homework assignment or essay assignment is good because it's something we...actually care about more than maybe other topics. So...we have to do it anyway...it's definitely a good, good thing, Olivia: [I] was really like, okay, I have to do it...cause how she pushed us to do stuff. It wasn't something like, oh, I just, I did... [when] I didn't know [its purpose]...because she was always pushing us.

Daniel: The college admittance process that way she helped us. She helped answer any questions that we had prior to applying and helped us throughout the process if needed.

Guided Learning. Four of the thirteen high school students specifically mentioned that they felt that the teacher and peer feedback on essays helped to improve their access to individually selected institutions. They had a better understanding of the reader's expectations because of deadlines combined with guided learning.

Maritza: Something else very helpful that she helped us do is she made us write our college application essays during class, so she gave us feedback and she allowed us to...make it better.

Jose: She made us like, do like, the common app essay and stuff so that we can be prepared. And she also gave us feedback with it which like, helped us set up, like, for the future. 
Madison: I think it also helped that she had us, like the beginning of the year like, write our essays...and then she graded them...gave us feedback. That was real helpful.

Andrea: I feel all this time in class in general I'm getting the free time to work on my essays...I'm getting the peer review and the peer editing from ...our classmates, and stuff really made my essays for college better.

Four of the thirteen high school students also felt they better understood scholarships and the financial aid application process because of guided learning. They were required to apply to at least one scholarship and could ask questions about the process during class.

Victor: The English class curriculum helped for applying to financial aid process...we had different lessons that you had on your [Senior English] live agenda, based on like, different things you could do, to further yourself financially. Like...even if like you...don't have enough money, you still always [had] a way to get enough. A little help, boost, to pay for your tuition.

Madison: And for financial aid, too. We had like a whole day where she was like, "You guys need to work on it."

Brooke: I think the financial aid process was helpful cause we had inside help...she walked us through the stuff. She told us what to do. And then if we didn't have something, like, "Oh," she'll be, like, "Oh, you need this and this and this." And then you go home and do it by yourself. 
Mason: She made us, in class...show her that we actually finished the [financial aid application].

Guided learning was also beneficial according to two high school students with unique circumstances. An international student and a Dreamer indicated that they lacked the navigational capital to access financial aid preceding the guided instruction.

Jana: International student and not knowing anything about um, American Universities and the whole process. I do have a lot of information coming from this class like um, how to write an essay, like some advices for writing an essay and also a lot of how, I got a lot of help for financial aid process and how to get that scholarships, outside scholarships, not only that I could use as an international student and not only...because I'm not eligible...for FAFSA. Another high school student indicated that guided learning was helpful because of being reminded to check email for financial aid offers.

The positive response in the qualitative data are supported by the quantitative data in Table 4.6 that indicates over $80 \%$ of the high school students felt positively toward the written assignments. The $95 \%$ confidence interval for the mean response score was more than three providing further evidence that the high school students had felt that they benefited from written assignments. Students were held accountable through writing deadlines and supported in successfully understanding and completing the assignments through in-class, guided learning. 
Interactive Postsecondary Adult And Student Speakers. Postsecondary adult and student speakers guided students through the technical components of applying for admissions, additional programs such as EOPS, and financial aid including the Promise Scholarship that pays for community college. Half of the high school students mentioned that they felt the hands-on support increased their understanding and completion of the admissions and financial aid processes. They also mentioned that listening to postsecondary student speakers helped them to prepare for the transition because they better understand what college life entailed.

Technical Guidance. Over a third of the high school students reiterated that they better understood admissions, programs, and financial aid application processes because they were able to directly ask postsecondary representatives questions.

Chloe: I also found it really helpful that we had people come in on multiple occasions to help us do the financial aid and answer our questions, like any kind of questions we had...it was also really helpful when we had like the EOPS people come from... [the community college] and...some students too, 'cause we were able to ask them questions that were directly related to us.

Mason: Miss Malatesta, she gave us a lot of thoughts from...[the community college] people...about financial aid and how to get it. And that really helped. Guadalupe: I agree...it was really helpful to have people come over and tell us about the different programs that they had and everything. 'Cause, you know, like, 
The Promise Program that they had, I had no idea what that was. And so they showed me how to apply for it and what it was about. And then I got it and so now my tuition's being paid in full and I get $\$ 300$ for books...that wouldn't have happened for me if I hadn't had people come in.

Justin: Yeah, yeah and for the financial..aid process, I feel like we had to get speakers talking about different scholarships and everything, I think it was good. And the thing I really learned was that you should go for any scholarship you can. Olivia: And then she brought in people to help us with the financial aid, so that was really helpful, too.

Andrea: I feel, like, for financial aid, like, the presentations are really helpful. We got presentations on FAFSA and Dream Act and stuff like that. Jose: She...was really helpful in bringing people in to speak to us about this process about this adding classes...how to apply for financial aid.

One of the high students mentioned that she was also able to access additional financial aid resources as the result of speaking with a postsecondary representative.

Shreya: The rep from...[the community college] also helped...us with financial aid, which is really helpful. The workshops that were at...[the community college] in different places that I need to know about that. That was also really, informational. I attended the one at...[the community college] which was helping with the financial aid. And that really helped me sort of answer all the questions 
that I had and also submit my application.

Transitioning To College Life. Six students also mentioned the positive effects of the postsecondary adult speakers. Of the six was a college student who felt that the presentations were helpful. The five high school students mentioned that the postsecondary student speakers were helpful because they guided the high school students through college life. High school students were able to ask questions, and the stories the postsecondary student speakers told enabled them to better visualize college life and actual college experiences. For example, the postsecondary student speakers discussed how to transfer and the coursework for their majors.

Emma: Yeah, I really like how she brought in some college students, just to share their stories on how college has been for them.

Jana: It was really helpful to have like other college students come in and talk about their experiences and in the transfer process and like what they are studying and the classes that they're taking.

Shreya: And then also there were students who came...and they were talking about their college lives. And that kind of helped us sort of visualize what college is like.

College students did not directly mention the helpfulness of the postsecondary student speakers, but one college student indirectly mentioned their impact through a request to hear from a larger variety of postsecondary students. The college student felt that hearing 
from student speakers from California's different systems would help to broaden high school students' understanding of the transition process.

Denzell: Maybe try to see if you can bring in students who would, who did different... like co- like who tried to go just straight to four year.

Both the qualitative and quantitative data support positive responses toward activities. In each of the tables $4.4,4.5,4.10$, and 4.18 more than $80 \%$ of the students responded positively to the survey questions focusing on the types of class activities. In table 4.11 , more than $75 \%$ of the college students responded positively. Also, each of the $95 \%$ confidence intervals was strictly greater than three suggesting that the mean response score for activities was more than three. The majority of participants felt class activities were helpful.

Importance Of Goal Setting. Ten students mentioned the role of setting both focused and broader college goals as important for access and persistence.

Focused College Access Goals. Three of the ten students were high school students who mentioned an appreciation the college checklist made available on the whiteboard. The checklist was updated and reviewed monthly, and the students indicated that it helped them to obtain a general overview of what goals they needed to set for the month.

Madison: Okay, I remember that she had the old board there with the whole schedule of everything to do. Do you guys remember that? She had like 
every little thing.

Olivia: Yeah, she would write on the board and list all the steps we had to take.

Julia: Kind of just compiling a really big list of things that...we needed to get into college was really, really helpful.

No quantitative data were collected on the effectiveness of the college checklist or other forms of goal-setting. However, the importance of goal-setting was also highlighted through three more high school students who requested an addition of more goal-setting guidance into the SCCG curriculum. They felt that goals tailored to students' individual goals would be more effective because it would focus the college-going process through individual differentiation.

Andrea: So, if you make the students make a calendar of "This is what I'm doing, and this all the dates I need to have it done by. And this is how I'm gonna get it done." And then you give them time to do it themselves. It's more self-directed and more useful.

Long-Term, Personal Goals. Of the ten students who highlighted the importance of goal-setting, four were high school students who felt that the final essay effectively incorporated this focus. They discussed how the essay helpfully required them to think and write about the purpose of college and set long-term, personal goals for college.

Timothy: Yeah, [it] really made me think about the real reason why I'm going to college and what I need to focus on during college. 
Mason: Yeah, I agree...I think it helps us, uh, serve to find some of the values in some of the things we should do when we go to college and come in with some knowledge is always a good way to navigate through the school.

Three college students, who had not been assigned this goal-setting essay during their iteration of the SCCG curriculum, also felt that students should be helped to set long-term personal goals for pursuing their postsecondary education. The college students emphasized that students who attend college for friends are less likely to persist. College students thereby suggested that students determine and discuss how to focus on their own college goals, their reasoning for attending.

Denzell: It's fine if you don't want to go to school....But it's like, there's no reason for you to go to school for somebody else...Because nine times out ten you're not gonna see your friends every day. You're not gonna hang out every week...that's not how it works no more. You know, we're not high schoolers. We don't have all this free time no more.

Laura: Also separate friends from school because I know a lot of people at... [the community college] who end up not going to their classes because they see their friends and they start talking to them. And they ditch.

Although I had not mentioned that a goal-setting essay had been assigned to the Class of 2019, two college students suggested students be required to write such an essay through the SCCG curriculum in order to increase college persistence. 
Gabriel: Maybe ask them, "Why are you going? What's your goal?"

Denzell: Yeah. You should...that could be one of their essays. Because I know you're required to make 'em write essays.....If you want to go to college, what's your reasoning? And if you don't want to go to college what's your reasoning? And what are you planning to do? 'Cause...that's like a lot of people don't even know why they're at college. And I feel like that's another reason why they drop out. 'Cause they don't even know why they're there. No. They just, they were at their high school and they're like, "Oh okay. This is what I was supposed to do." This qualitative data are supported in Table 4.18 through high school students' responses to the written assignments concerning HOM such as goal-setting. The quantitative data indicates that over $80 \%$ of the high school students had a favorable experience. The $95 \%$ confidence interval for the mean response for this survey question further supports the high school students' beliefs that HOM written assignments were helpful.

Habits Of Mind: Practical Goals And Behaviors. Additionally, sixteen students responded positively to the HOM portion of the SCCG curriculum. They indicated that the hands-on activity that required them to present and discuss specific examples to show specific HOM mindsets helped their metacognition of what was needed for college success. Twelve high school students felt that HOM activities helped them understand the differences in their approach to current high school behaviors versus 
long-term college success. The HOM activities helped them determine what they, personally, needed to work on to succeed in college. They better understood their strengths and where they needed to set goals for areas of improvement. High school students felt that this increased readiness through HOM knowledge helped them to feel more hopeful because they understood the specific college behavior they needed to be successful.

Brooke: I think the habits of mind will...help us. Because it shows that not everybody has...certain pathways. Like, learning or how they are prepared for college. Somebody might be really open or understanding, and then somebody may not be that responsible. So having these habits of mind...having a list of the habits of mind and seeing what things you need... what items you need to work on for college at this time is really hopeful. Cause you just try to hone the innermost skills and just try to perfect them.

The positive responses in the qualitative data are supported by the survey responses recorded in Table 4.18 because they provide evidence that the high school students had a positive experience with the class activities involving HOM. More than $85 \%$ of the respondents returned a score of three or more. Additionally, the $95 \%$ confidence interval for the mean response score for this question exceeded three providing additional evidence that high school students felt the HOM class activities were beneficial. 
Likewise, half of the college students gave positive responses towards the HOM readings and activities through the qualitative data. The college students indicated exposure to the HOM through their reading of articles and through the subsequent participation in expert group panels or poster presentations provided a better understanding of the HOM they needed to succeed in college.

Nicolette: I think the posters, the ones we did in class, yeah I think they helped because we got a better...definition of it....we all had to present...our example of what we thought of what it was and our drawing. And, I think it helped us keep it more in...our mind.

As aforementioned, the college students also emphasized the importance of the HOM they developed as a result of the class structure modeling a college environment. They felt the SCCG curriculum group work, discussion, and research activities were good practice for the release of responsibility, public speaking, and individual goal-setting needed for college. The college-like environment that included collaborative work requiring individuals to be responsible group members was an important HOM to learn to aid college success.

Denzell: 'Cause every time we would do something at the group... 'Cause you would give us freedom of choice. And you would tell us, "Oh yeah when you get to college it's a big thing. 'Cause like you get to choose how you really want to do a lot of things. "And who you want to do group things with."...And you would tell 
us all the time how when we get to college... "Yeah you'll be in school but you have more freedom in school too."

Two college students also reported that the overall class discussions and activities helped them learn how to be successful college students. Activities such as Socratic seminar discussions and presentations helped them improve their public speaking skills, a needed skill in the postsecondary environment.

Gabriel: For me I think the Socratic seminar really helped me. Because...I'm [an] introvert and during high school...I don't really talk too much. So...Socratic seminar[s]...helped me to participate. And not only like in my college English course, but all the class[es] that I take in college. Yeah. Getting used to talk[ing] and be[ing] open.

Laura: I think the Socratic seminars helped a lot, too, because we ended up doing some of those in college as well. So it helped me prepare for that too.

Three college students also felt that the individual research and accompanying presentation on earnings for a chosen career were also helpful in improving their individual long-term goals. They were able to imagine where they might enter the workforce after obtaining postsecondary schooling, and how this career would affect their lifelong earnings.

Laura: We did a poster one time in your class. And we wrote about like the career that we would want to do and then we shared it with the whole class. I think that 
one was very helpful as well.

Denzell: Yeah. Because she made us search up like the salary, you made us search up like how many years of school, you made us search up basically like literally everything you do to like research how to do something.

For four of the college students, the HOM skills also extended to more specific, practical skills such as seating choices and calendar usage. For example, two students mentioned learning about the importance of seating in the college classroom.

Laura: Oh yeah I remember the panels we all had to do a research on a topic and then present in class. And I think what stood out the most for me was the seating in college. I sat in the front. I think there was some specifics, but that you have a higher chance of passing your classes if you sit more in the front.

Denzell: But I think also what...with the seating...'cause you, you like let us sit wherever we want at first and then as the year went on you would explain to us the seating and how that would change how we are....And once you started explaining more about how seating helps you like mind wise, people started moving around. People started sitting like in the front. I remember...[another student,]...used to sit in the back. But then she started sitting in the front. And she said that helped her before. I remember I sat close to where you would be standing on purpose so I wouldn't be talking as much. Well 'cause like, I would think like I'm... I'm used to talking during class... So I figured out if I sit at least 
closer to the professor it stops me from talking in class.

Three college student also mentioned the importance of learning how to use a calendar for improved time management in college

Gabriel: You like, show us your calendar back then..that one is really helpful...you make sure...you put it on Google calendar. Like, everything ...personal, like life, and also work, and I think that one is really helpful.

The data presented in tables 4.15 and 4.17 support the qualitative finding that college students felt that the readings and activities associated with the HOM were helpful. For each survey question, the majority of students responded with responses of four or five. In table 4.17, all of the responses were four of five. The $95 \%$ confidence interval for the mean response scores for both survey questions exceeded three providing further evidence that the college students felt that the readings and activities for the HOM were helpful.

RQ3: What Additional Or Different Supports Do Students Recommend Adding To The Senior English Class Curriculum To Better Support College Success?

Removing Non-student-centered College-going Curriculum. Seven students indicated that, when observing their counterparts in other classes, the SCCG curriculum was more purposeful than other Senior English curriculum that did not center on postsecondary access and persistence. They noted that the students in the other classes were reading books and writing essays that were irrelevant for college readiness and 
therefore lacked meaning. One of the three high school student reframed this concern using a broader perspective of high school curriculum:

Victor: It helped a lot with preparing for college and stuff. It was more realistic than any other class I've ever had. All the other classes are just kind of like, you do this, you do that, you do this. This one was actually like actually helping...it wasn't just like doing straight schoolwork it was also helping like, real life situation.

Two college students also compared themselves to their classmates and noted that their stress was lower and their assignments were more engaging as they were more relevant and pressing for their future.

Denzell: I remember so much when we would come out or your class and...I wouldn't say we'd be doing like less than everybody else. But we would be doing stuff that had to do more with college...and everybody else would be like..."Oh I have an essay due." And I'm like, "Okay but what, why do y'all have [an] essay." It's like, "We don't know we're just reading a book." "Why are y'all reading a random ass book with no reason to read the book?"

Laura: The people in your class were less stressed like applying for college. Like those applied before you, because you gave us time. And the other people, who were in other classes, were more stressed, because they had to do it on their own time. Since they had a lot of stuff going on with their English classes as well. So 
they had a lot of due dates [and] they got more stressed than we were.

One college student particularly mentioned that teachers should focus on writing for scholarships instead of writing about novels.

Denzell: Everybody's doing an essay on a random book. When it should be essays about [applying for] scholarship.

Four high school students also found that the social-justice focused Expository Reading \& Writing (ERWC) based units, the non SCCG curriculum portion of our Senior English class, were also irrelevant and should be omitted.

Julia: A lot of stuff we read was sort of...it was, I guess it was interesting to read. But I don't really see how in the long run it pertained to learning.

Gabriel: Oh, I agree..feel in some part it did help me. But it didn't necessarily answer the questions I had for college...questions for financial aid...how do I apply...how do I answer these questions. There were some questions that I didn't understand.

The student survey did not address this concern so there is no quantitative data to support this statement.

Destigmatizing Community Colleges By Focusing On Its Benefits. Students felt that the benefits of attending community college were numerous and thus are institutions that need to be destigmatized through knowledge-providing class activities.

Stigmatization Of Community Colleges. Four students discussed the importance 
of fully understanding college choices regardless of prestige. One high school student who planned to attend community college and one community college student felt stigmatized in the high school environment for choosing to attend a community college.

Denzell: 'Cause I feel like you...and like two other teachers were the only ones who pushed community college. Like there were so many other teachers that I told them I'm going to community and they gave me this, this weird like, "Oh." "Well whatever works." Like they gave me this just weird...like, "I feel bad for you, but okay."

Two college students felt that high students needed to better understand that they should not attend a particular college based on its prestige.

Denzell: Yeah that's literally it. That it's just a name. Yeah. It's like clothing but it's basically like... Or 'cause you can... 'cause I'm gonna be real, I be eating them off-brand cereals. And they be tasting better sometimes than the on-brand. Gabriel: I think what makes the student go to like university is like the name of it. Like, and now, like, right now, people...in corporate...they are more on like experience....Like the learning that university is just like a name.

Informing All Students About The Benefits Of Attending Community College.

Five students felt that an active effort to reduce community college stigma should be incorporated in the SCCG curriculum. One high school student suggested including more in-class assignments to show the benefits of attending community college as a way 
to diminish the stigma. College students also made specific suggestions for reducing the stigma. Three college students emphasized how the cost-savings of attending community college gave them more freedom.

Nicollete: The advice that I would give is one, to continue the education...I'm going to...[the community college] for free, basically, since I got the grant and..the Promise Scholarship.

Gabriel: Because I know like a lot of people dropping college because either their parents or other people expect them to finish college...four years...[or] in [a] small amount of time. I feel like giving them a choice....I don't want to force myself to finish college in just four years...[but] after..two years, three years, students kind of feel, "Oh...I really need to finish college really soon." Because...[they] already have a lot of...student loans. [They think,] "I need to get a job."

Denzell: That's why I went to community first. And I'm so happy I went to community first...You don't have to just go full on into debt first....You could push it off for a bit.

Laura: There are also a lot of people who go to a four year and then regret it and end up going back to the community college... Or something happens and they end up going to a community college...I know a lot of people who hated...going straight off from high school to a four year, because they felt like they weren't 
ready. And then [they] ended up spending a lot [of] money and then having to go back to community college.

Two college students also mentioned emphasizing that the quality of education at community colleges is the same as at four-year universities.

Laura: Let them know that most of the classes that you're taking at community college would be also the classes that you would take at a four-year for a much cheaper price. And that's what my professors would tell me my first semester of college. They would introduce the course name and say, "Remember this is the same course you could take at a four year college."

Denzell: I slowly asked my professors, like, "Oh do you...did you teach anywhere else?" Like, "Oh have you, have like ever taught anywhere else?" And they'll tell me, "Oh yeah, I've taught at a UC before." Or "I've taught at somewhere in Southern California." And they'll be like, "And literally, it's nothing different from community college."

Three college students also mentioned that high school students should learn about the resources that are readily available to them at community colleges. They felt that high school students should know that community colleges are welcoming, supportive environments in which students are easily able to obtain academic help.

Laura: And they actually give you much more help [at community college]. Because there's... most of the time there are less students.....I think there's more 
resources at community college....these resource centers to help you with your work and help you succeed in your classes.

Gabriel: Giving the seniors student [the understanding] that there...[are] a lot [of] resources in community college. That, and don't be shy and like asking for assistance and like resources. There's a lot. And...make sure [to] use all their resources as [much as] possible.

Nicollete: I went...to tutoring sessions. I would go to the Math Center and...ask for help and then I would try to do it myself and, with the knowledge I got....I would email her [the tutor] days before a test and be like, "Hey, I'm studying this but I don't understand it. Can you help me out?" Because, every Maths class has a tutor or two. And tutors helped me so much in class.

The student survey did not address this concern so there is no quantitative data to support this statement.

Skill-based Learning And College Navigation. High school and college students recommended the following additions to the SCCG curriculum: high school students should learn more about financial aid and the HOM. College students also recommended the following additions be made to the SCCG curriculum: high school students should learn more about how to enroll their first semester, to use college resources, to manage their time, and to understand college majors.

Access Skill: Learning More About Financial Aid. Seven students felt that it 
would have helped to have more detailed financial aid guidance through a discussion of scholarships, the length of federal aid availability, additional scholarship assignments, and individual conferencing. Two college students from the classes of 2017 and 2018 suggested adding more details about how to access financial aid into the SCCG curriculum. They discussed this need for guidance more generally, likely because the 2019 graduates received more direct instruction during the last iteration of the SCCG curriculum.

Kelsey: Maybe go over, like, the process... Of how to get financial aid and stuff. Like just more in detail or something. Denzell: I feel like we should have talked more about scholarships. Just a little bit more.

Gabriel: I think more in scholarships...more on how to apply in this scholarship. And the criteria of applying to the scholarship. Another college student mentioned that it is important for students to understand that financial aid is available for postsecondary students. This knowledge would help them feel more supported financially if they need to attend for longer than four years.

Nicolette: I found out that [the] FAFSA helps you up to six years. I did not know that. I thought it was just you had to finish school in those four years. [Students should learn that they] don't have to finish in four years. You're not racing someone. 
Two high school students mentioned that they would have liked to increase the number of required scholarship application assignments since only one had been assigned. Students felt this would remind them how important and how available financial aid can be.

Timothy: And for financial aid, to improve the curriculum, I think that you could make more scholarship essays due, 'cause we only have like one that we, we're required to do and, if we had more, then we probably could've got a lot more financial aid.

High school students additionally suggested that they should have individual conferences with the teacher in order to more individually tailor the information for students' needs. For example, one high school international student and one college Dreamer discussed their need for more support with the application process and to determine the scholarships that are available for them.

Maria: Okay. Oh, sorry, um, I was going to say personally, I would like, it's just that you did cover it, but not really about the Dream App[lication for financial aid] and undocumented financial help, I guess. I would just say, like, for me, it was harder to, like...find scholarships. So I guess, like, scholarships could be a thing.

Jana: Ms. Malatesta also told me about [an] outside scholarship that I...can apply for...that was a huge help for me. 
Another high school student suggested individual conferencing to discuss financial aid opportunities targeted for each student.

Justin: The only thing that I think you could change, possibly to improve the lesson is, maybe, just have a day where students can come up and ask individual questions that they have. So clarify the process with you.

The student survey did not address this concern directly. However, Table 4.12 provides some support for the high school students' perspective of wanting more support when it comes to financial aid because only $70 \%$ of the high school students responded with a survey score of three or more (discussed below). The $95 \%$ confidence interval contains values both above and below three suggesting that there is not sufficient evidence to state the students' mean response for financial aid written assignments was mostly positive.

Access Skill: Learning More About How To Enroll In Classes. Almost half of the college students felt that high school students should use class time to practice or actually enroll in their first semester of college. Students felt high school students need more guidance in selecting classes for their first semester.

Olivia: [At community college] we just haven't really gotten to...what we should be taking. We're doing that more this semester, but I feel like it would have been more helpful knowing that first semester, knowing what we should take.

Gabriel: Yeah for me it's [the first semester of college was] stressful. (laughs)....I 
think there will be at least [something] like orientation...for each class. And what to expect. And for me, I thought college, it's easy [since]...it's only half-day. And they already have like 15 units...during my first semester of college I was doing [a] full time job, full time student, and still having a training every Wednesday in [the] Marines...it burned me out...I dropped some [classes].

One suggestion for remediating this problem was to practice enrolling via course catalog practice.

Nicolette: It's still stressful. When every month we have to choose, we have to sign up for classes...we have to base our classes on a career class or...a major class.... [Is it] possible, like, to have them, like, look for classes, like, using a catalog or something? [Where] they have to find classes using, like, a campus they want to go to or something...? [To] look for classes as if we were pretending to sign up...like we know what we're going to expect, or somewhat expect, from when we do start signing up for classes.

In addition to practicing enrolling in classes, one student suggested that students need to learn about dropping, particularly when it is still possible to obtain a refund.

Denzell: Like some people will have a F from like the first day until like that middle point and I'm like, "So you had a F this whole time. And you want to drop it the day after you can't get a refund?" Yeah. 'Cause I work with students and they get mad 'cause they're like, "I can't get a refund." And I'm like, "Why didn't 
you talk to us before?"

The student survey did not address this concern so there is no quantitative data to support this statement.

Affective Skills: Learning More About The Habits Of Mind. Six students suggested improving the SCCG curriculum through a deepening of the HOM activities. Four high school students suggested that they learn more about the skills earlier in the year, use them throughout senior year, be held accountable to practice each habit with a specific homework assignment, and review at the conclusion of the class on how they will help them be a better student both in terms of work ethic and as a person.

Brooke: And then for understanding habits of mind we could maybe do a bigger project on that and have more time to focus on it...one week could be we're gonna practice engagement this week, everyone's gonna be really engaged. That way we're really practicing those habits, not just reading them....And then we could have a creativity week or something like that. I mean, it doesn't have to be a big deal. But just mini little things each day to remind us this is how to be a good student in college.

It is likely that college students from the Class of 2017 did not suggest deepening the HOM activities because they had more extensive panel discussions on the HOM. However, two college students recommended incorporating additional FGCS support through the SCCG curriculum. They felt that providing guidance through an awareness 
of imposter syndrome overview would benefit these students.

Gabriel: I think learning like real life uh learning like imposter syndrome....

Because I know back in high school as I remember I have a problem applying [to] college and university because I don't know if I'm worth it enough to be in this college or university. Or...So, I think that will be a really good to put in [a] curriculum...building up confidence and.... It'd be nice if they put stuff like that in the curriculum because a lot of students, they literally will get to college and ...they don't understand how they're supposed to be thinking. They don't understand why they feel certain ways they feel. And...I know it's supposed to be like a English course, but...why can't people write down paragraphs about what it's like, probably [to] feel like that.

This college student also suggested that high school students prepare and improve their HOM through exposure.

Gabriel: Why can't we watch...documentaries, so we need to watch like more videos on how it felt like to be in college.

Another college student also recommended students improve their HOM skills through practice. She felt problem solving practice would help them successfully navigate particular situations to increase self-advocacy practice for improved persistence.

Nicollete: Give them a situation with a professor and say, "Okay, what would you do?"...have them be in groups...have four ideas of what they think they could 
do...[using] the resources they have with the school on campus or the resources they have online, too...asking them what they could do in a way so when they...go into college...they already kind of know what they should do.

The student survey did not address this concern so there is no quantitative data to support this statement.

Practical Skill: Learning How To Use College Resources. Almost half of the college students emphasized the importance of using available resources such as attending Office Hours, obtaining help at the writing/math tutoring centers, and forming relationships with the adult contacts in the resource offices.

Nicollete: They taught, they showed us the resources we could use [in the community college transition program]...every school has their own resources...to help the students...that's what I learned and that's what I, like, put it to use. Gabriel: Like homework where like they ask teacher or like counselor for like essays...have them maybe like call like one the resource centers and like make them, I guess like, like for homework like, make them write down like maybe a paragraph or two of like what did they ask, and what did they say... also asking them for like the professor. For like um... Like class hours. Yeah. Office Hours....During my first semester that's like the hardest thing for me. Like asking my professor for...help.

Two college students also felt high school students needed to understand the 
importance of accessing academic counseling. They felt that exposure to this resource, including how to select an effective academic college counselor and how to frequently check in with college counselors, were key to college success.

Laura: I just like go to my counselor at least like once every two weeks to talk to her. And like that really helps. Oh that's another thing. Always tell the students no matter where they go they can choose a different counselor. Like you're not linked to one...counselor.

Gabriel: And tell your counselor like every decision you want to make. Like if you want to drop your class, tell your counselor first.

One of the college students also suggested bringing in a college counselor to explain how to select and enroll in classes.

The student survey did not address this concern so there is no quantitative data to support this statement.

Organizational Skill: Learning About Time-management. Half of the college students felt that high school students need a better understanding of the workload difference between the secondary and postsecondary levels in order to maintain a balance and avoid dropping classes. They felt that there was a significant difference between the workload of college credits and high school units. As discussed above, college students feel that secondary students need to understand that less time in class does not mean more free time, so college students thought high school students needed to fully understand that 
they need to learn how to navigate having less time. They felt that pacing oneself is critical for college success, and emphasized that high school students should understand that they do not need to complete their degrees in four years. Half of the college students indicated they struggled with completing classes because they enrolled in too many units because the amount of time they needed to dedicate to each course was not understood.

Nicollete: Because, I- I had to drop a class at the beginning of the semester...it wit would [have] be[en] too much for me.

Denzell: I wish I was dropped [by the college professor]. But I was, I was part time working...I think the hardest part was just doing all the work on time. Because you feel like...you have so much time. And then like, it's finally the day that it's due. And it's like, "Oh."

Kelsey: Yeah, I had, like, a bunch of anxiety my first semester there, 'cause I had to withdraw from one class, and then I ended up failing another...

In order to prevent setting oneself up to be overwhelmed, over half of the college students suggested that secondary students be better guided through practicing time management skills.

Nicollete: How to prepare m- ourselves mentally, how to push ourselves and having more...time management...give them...[a schedule where] they have classes these days at these times... [and] find a way... where you can do your homework...either go home or...to your dorm. Do some chores you have to do and 
have it all done by that day or at the end of the day. Like, finding a way around, like, the classes you have....doing your homework in between classes and not, like, going out and...partying so much. Have some time for yourself and have some time for school.

Denzell: Yeah maybe give everybody...like a similar schedule...[a] random print out schedule. And then be like, "Okay, I want y'all to put down what time you'll be... you'll do homework. What time you'll hang out with friends." "When you'll go to work."

Gabriel: And also like the commute time....like in my program right now, where we need to put even our commute [time in our schedule], and the time we sleep. Two college students suggested that high school students also learn how to prioritize classes as part of time management.

Kelsey: Uh, maybe try to take your major stuff a little bit earlier. I had to cram a bunch of history in at the same time, and that wasn't, like, that fun doing a bunch at once...

Three college students suggested using technology for effectively managing postsecondary students' time.

Denzell: A lot of us have phones now... y'all should setting yourself reminders to do your stuff...there's also some professors that...let you take pictures of stuff. Or...they'll have like the homework on the board or something like that be in the 
class...It's not difficult to just take a picture of what you have to do. And then like on your way to the next class put it in your calendar. Or alarm that... just tell them I'm gonna do this assignment or whatever.

Another college student suggested repeatedly referring to their syllabus in order to schedule due dates using a calendar.

Laura: They would tell you one time [about due dates] and never tell you again. So what I realized was that you need to keep your syllabus with you at all times. And keep reviewing it and checking it because most of the time the professors don't tell you. And they don't want to answer your questions because you have to read through the syllabus and all the answers would be there. But Office Hours and all the times that you can reach them would be there. So, I feel like I would tell seniors to keep their syllabus with them and review it and look at the due dates that are on the syllabus for help...every day to see if I have any homework due for most of my classes. Because there are some classes that tell you stuff and put it on...[the learning management system]. But there are some that don't and they tell you how they grade, and when everything is due, and when the final and the midterms are. So you just have to know what classes have stuff...[posted digitally] and which ones don't, to know if you have to look at the syllabus or not. The student survey did not address this concern so there is no quantitative data to support this statement. 
Aspirational Skill: Learning About The College Major. Six college students suggested incorporating research of a major into the SCCG curriculum. They suggested using surveys, hobbies, and course catalog descriptions to help secondary students think about a potential college major. College students suggested that secondary students subsequently present on their college major individually, as groups, and via class discussion.

Nicolette: There's online quizzes that say, like, supposedly what they know your major is depending on...the online quizzes and...giving them a list...when they ask you what your major is gonna be and they give you...asking them what they're interested in. Like, some people want to be engineers, other people want to be architects. Like, asking them, like, what their hobbies is and...looking for background things that could lead up to a possible major they want. Kelsey: Maybe help people figure out what their major possibly could be or narrow it down a little.

Mariah: Just going through detail about the majors that people seem interested in and talk about them maybe and give them background...of the majors... what they're about...and more information before they sign up for it.

Olivia: Doing a presentation of a major we're interested in. And then we can explore and research what we want to...all of the majors that we'd like to do. That'd be kind of cool. 'Cause then we'd...get to explore and...research. 
Denzell: You should have the seniors, if they have [a] major already in mind, search up the job offers for that major. And the years of school you need...and they should all present that. But if they are undeclared...have them search a career, that they think they would want to do. And make them search like the process you need to do that career... or if you, if you just know the major and you don't know the career, search up the major and search up the careers [that] can come out of it. The student survey did not address this concern so there is no quantitative data to support this statement.

\section{Supporting A Wider Variety Of Postsecondary Institutional Goals. Eight}

students felt that the curriculum should increase access for all students by including adult and student speakers from every type of postsecondary institution.

Learning More About Four-year Postsecondary Institutions. One college student spoke generally about her interest in hearing more information about the college experience and how to transfer to different institutions.

Laura: I think there should be tips and tricks about applying to college. And how college will be. Because I know there's, there are courses in community college about how to apply to four year colleges.

As discussed above under the theme of goal-setting, two high school students also felt that the teacher should thereby provide more guidance through an overview calendar and require that students add on to the calendar--as needed--with a more individualized 
calendar of college deadlines. Five high school students also suggested that more information on all postsecondary options be included in the SCCG curriculum. One of these students framed this request in terms of what she believed about students in the tracked classes.

Rihanna: I think that it depends on the student because some people are very clear about what they wanna do and some people don't know and they're just trying to figure out that next step, and I feel like this class is catered to the latter type of people. Because generally AP [honors] classes tend to be the students that are you know very focused on something and know exactly...and CP [lower-track] classes are people who are kind of still figuring it out. But I think when it comes to senior year, AP lit is such an intense class, you get a really even mix of students who are normally AP or CP, so I feel like it should make sure next year it would be great if the curriculum can focus on both of those groups.

Two of these five students also suggested that alternative assignments be provided for students such as themselves who have already determined their major and selected their postsecondary institution.

The student survey did not address this concern so there is no quantitative data to support this statement.

Increased Essay Instruction. Four high school students also suggested that more time be dedicated to college essay instruction. Two of these students advocated for more 
time spent on the different postsecondary application essays as well as multiple revisions.

Timothy: And maybe, instead of just like, one revision, maybe have multiple revisions on each essay.

One high student also suggested that the teacher require earlier essay deadlines to allow more time for teachers to comment on multiple drafts and for students to thereby have the opportunity to revise more extensively.

Mason: I think like making more essays due. Write the college essays would help a lot. Because I felt like I was rushing a little towards the end, like as my deadlines were approaching.

He also suggested that the importance of the writing component for college admission should be emphasized so that students have a better understanding of their role in the application process.

Mason: And when I think, like, stressing how important the actual essays are [for] the admissions process would help, because I didn't really realize how important they were. 'Cause I thought it was just like a bunch of numbers that they look at and I was wrong.

The majority of the qualitative data suggest that particulars of the writing assignments were helpful, as does the quantitative data. Table 4.6 shows that more than $80 \%$ of the high school students had a positive response to the written assignments for college applications. The $95 \%$ confidence for the mean response score was strictly 
greater than three further supporting the high school students' perception of the effectiveness of the written assignments. Although much of the data support positive responses, the qualitative data reviewed in this section also highlight that high school students believe there are multiple ways in which the writing assignments can be improved. Community college students did not include this topic as part of the discussion, likely because some had just begun community college and others had just begun to think about the transfer process.

Learning More From Different Postsecondary Students. Almost half the college students were also interested in learning more about different postsecondary institutions from students who are/have attended a variety of four-years.

Denzell: Because I know a lot of people they like, they don't even know... what, what classifies as a four-year [institution]. They don't even know which one's CSU [California State University] with the UC [University of California]. One college student thought that it would be helpful for postsecondary students who had begun at four-year institutions, but then left and attended community college also to be included as speakers.

Laura: You should basically tell them, tell them your experience...try to see if you can like bring in students who...tried to go just straight to four-year....And then maybe bring... Like talk about other students' experiences. Because, you know...everybody has their own way of doing it. But just like you should just give 
'em the knowledge at least. To be like you have options.

The student survey did not address this concern so there is no quantitative data to support this statement.

Increasing Interactive Assignments. Students felt that their learning and retention of concepts would increase through additional hands-on, interactive activities. Throughout the chapter it can be perceived that all of the additional materials suggested by students required teamwork.

Jose: Understanding the habits of mind, she did it pretty well because we did multiple posters which I did very well on. That was fun and an insightful way to learn.

Andrea: And I also feel, like, writing...handwriting our own posters was really helpful because you remember it better when you make it yourself. And the pictures are really good for your memory...And then for understanding the habits of mind. I feel those, little articles, kind of like little short, like, summaries of what we read, which was very helpful...it was good, we got to each focus on one, but at the same time, like, other presentations...helped us, like, understand all of them. And we got to take notes on it. So it was a lot of review of that. Which is really good.

Shreya: Uh, of habits of mind, I think we really liked the class because it was so open and engaging....and discussions...different topics so we got to talk about. 
These positive responses towards hands-on learning are supported by both the qualitative and the quantitative data. Table 4.4.H shows that over $50 \%$ of high school students had a positive response to the activities associated with applying to colleges. The $95 \%$ confidence interval for the mean response score was strictly greater than three further supporting the high school students' perception of the activities for college applications. Table 4.5.C shows that nearly all of the surveyed college students had a positive response to the activities associated with the application process. The $95 \%$ confidence interval for the mean response score was strictly greater than three further supporting the college students' perception of the activities for college applications. Table 4.10.H shows that over $50 \%$ of high school students had a positive response to the activities associated with applying for financial aid. The $95 \%$ confidence interval for the mean response score was strictly greater than three further supporting the high school students' perception of the activities for applying for financial aid Table 4.11.C shows that over $70 \%$ college students had a positive response to the activities associated with applying for financial aid. The $95 \%$ confidence interval for the mean response score was strictly greater than three further supporting the college students' perception of the activities for applying for financial aid. Table 4.16 .H shows that over $50 \%$ of high school students had a positive response to the activities associated with the HOM. The $95 \%$ confidence interval for the mean response score was strictly greater than three further supporting the high school students' perception of the HOM activities. Table 4.17.C 
shows that $100 \%$ of the college students had a positive response to the activities associated with the HOM. The $95 \%$ confidence interval for the mean response score was strictly greater than four further supporting the college students' perception of the HOM activities.

\section{Conclusion}

The findings in this chapter suggest that the SCCG curriculum can assist the students in better navigating the postsecondary system. The quantitative findings revealed that students learned beneficial information about how to apply for colleges, apply for financial aid, and obtain the habits of mind needed for access and persistence. The qualitative findings elucidated the particulars about how the delivery and content of the current iteration of the SCCG curriculum is effective and what might be improved. The students suggested additional content that could be integrated in order to improve postsecondary access and persistence. The suggestions of the participants in the focus groups provide a more thorough understanding of how the SCCG curriculum could support all students in their diverse array of postsecondary endeavors.

In the next chapter, an analysis of the findings is reviewed, as well as the implications for the significance of the findings as they relate to college access and persistence followed by recommendations for action and further study. 


\section{Chapter Five: Discussion \& Recommendations}

\section{Overview}

This study was executed to develop an understanding of how we might better support students' postsecondary access and success through a transition curriculum embedded in a Senior English class, a class that is required of every twelfth grade student nationwide. This study serves as a starting point for the research needed to better understand how its curriculum can provide equitable postsecondary access and persistence for all students.

In this study, the students' feedback uncovered in the qualitative results illuminated what worked and what could be improved in the Student-Centered College-Going (SCCG) curriculum embedded in Senior English. The findings show what supports students in accessing and persisting in their postsecondary aspirations. The students in this study reported that learning to self-direct, learning about postsecondary education collaboratively, learning about self-care, learning the difference between postsecondary institution types, and learning to set goals were helpful components of the SCCG curriculum. They felt that guided learning through assignment deadlines and in-class presentations and facilitations were also beneficial for college access and persistence.

One major finding from the qualitative data suggests that a broader array of postsecondary institution representatives need to become involved in presenting and 
facilitating information to students enrolled in Senior English. Correspondingly, another major finding from the qualitative data suggests that curriculum supporting a larger variety of goals for students attending different postsecondary institutions needs to be added to the SCCG modules. The qualitative data also suggest that students learned best from interactive assignments and recommended that even more information be learned in this manner. This information includes learning more about obtaining financial aid, enrolling in classes, practicing the habits of mind (HOM), using on-campus postsecondary resources, applying time-management techniques, and exploring college majors. Three major themes from the qualitative findings illustrated a need to actively change any Senior English course's non-SCCG curriculum to make time for a SCCG curriculum and also augment the existing SCCG curricula. The first theme arose recommending that teachers shift away from what students perceive as arbitrary texts and towards the SCCG curriculum. The second theme arose recommending that the SCCG curriculum actively destigmatize negative attitudes toward community colleges by adding in activities that emphasize the benefits of attending community colleges. The third theme arose recommending that students be supported in gaining a full-spectrum understanding of the different types of postsecondary institutions.

The quantitative results included the degree of correlation with the qualitative data determining which course structures and practices used in Senior English current and former students reported being supportive of college success. The results suggested that 
most structures and practices that focused on SCCG curriculum were supportive: the content results showed statistical significance on twenty items. Although the quantitative data did not specifically address areas of improvement, neutral responses in the quantitative data and recommendations made in the qualitative data indicated where the SCCG curriculum might be improved.

\section{Interpretation of Findings}

This section describes the interpretation of the findings that address each of the research questions.

\section{Question 1: What Do Students Perceive Is Needed For College Success?}

The qualitative findings illustrated that the thirty-six participants were able to recount how the SCCG curriculum helped them understand what was needed for college success. The participants described how the SCCG curriculum helped them understand what they needed to do to access and persist in postsecondary institutions. They described how their understanding of college access was augmented when learning about college applications, financial aid, and the HOM. For example, when the Class of 2017 students participated in the expert-group panels for the HOM, they better understood the importance of collaborative work and strategic seating to improve college success. When students were exposed and supported during the application process, financial aid process, and the HOM awareness, the qualitative data suggest that they were able to work collaboratively and support one another in learning how to access and persist in 
postsecondary institutions. The mixed-methods data suggest that the activities and readings gave students a better understanding of what they did and did not know about college access and persistence, and to receive preparatory instruction during the learning process. It also suggests that providing students the curriculum to partake in an understanding of the postsecondary access and persistence process strengthened their abilities to become group members of college-going aspirants.

The students' opinions on the HOM activities, from the survey, support the qualitative findings. The mean response from college and high school students were 4.29 and 3.76 respectively; both above a neutral response of three. Furthermore, both 95\% confidence intervals based on the survey data are strictly above three suggesting that the mean response for all college and high school students will exceed three. The quantitative results suggested that students from both groups of participants believed that exposure to persistence skills were helpful. The results are summarized in Table 5.1.

Table 5.1

Habits Of Mind Activities: Survey Response Scores

\begin{tabular}{|l|c|c|c|}
\hline & Mean & Sd & $95 \%$ CI \\
\hline College & 4.29 & 0.47 & $(3.49,4.02)$ \\
\hline High School & 3.76 & 0.97 & $(3.15,4.12)$ \\
\hline
\end{tabular}


The focus group interviews enabled students to convey their experiences more informally. The quantitative data seem to agree with qualitative data: students found the HOM activities to be helpful. The focus group findings in comparison to the quantitative surveys gave a more nuanced understanding of these positive results.

One key theme is that the students appreciated learning in a self-directed college-like environment. Many students appreciated the combination of reviewing a monthly list of college deadlines as well as being required to adhere to deadlines to begin the application process earlier and thus make them accountable. They also felt that they were provided an effective, collaborative method of exploring postsecondary possibilities by working with their classmates. Yet while all college-students felt that being exposed to a more college-like environment helped to prepare them to be successful postsecondary students, some high school students indicated they would have preferred for the environment to have been more authoritarian. They felt that some of their peers did not grasp the value of the SCCG curriculum for their imminent future lives and therefore needed more direct management.

\section{Question 2: What Course Structures And Practices Used In The SCCG Curriculum Do Current And Former Students Report Being Supportive Of College Success?}

The qualitative and quantitative data suggest that students felt that the readings, class activities, and written assignments helped students understand the college application process, the financial aid process, and the HOM needed for college 
persistence. The implications of these findings is that students learn and retain college-going information through guided, hands-on activities. A stronger preference for hands-on activities is reiterated in student focus groups. For example, high school students felt that their increased understanding of the difference between California's postsecondary institutions improved their ability to understand college fit and thereby apply accordingly. Students repeatedly mention peer interactions, group presentations and speaker facilitations as helpful.

The mean response for the HOM Activities from college students was 4.29, well above a neutral response of three and the mean response for HOM Readings from college students was 3.71, again higher than a neutral response of three. Comparing the means of the two categories from the survey using a $95 \%$ confidence interval on the difference of the means yields an interval that contains zero. This would be interpreted as insufficient evidence of a difference in strength of opinions between the HOM activities and HOM readings for college students. The quantitative data, from the survey responses for Activities and Readings for the HOM aspects of the curriculum showed no significant difference countering the qualitative data.

Similarly, the mean response for the HOM activities and readings for the high school students were 3.76 and 3.67, respectively. Comparing the difference in mean scores using a 95\% confidence interval again yielded an interval that contained zero 
suggesting that the two categories could possibly have an equal mean response in a large population of students.

The quantitative data do not give evidence that activities are favored over readings as the qualitative data suggest. The results are summarized in the table below.

Table 5.2

Student Responses: Means, Standard Deviation And Confidence Intervals

\begin{tabular}{|l|l|l|l|}
\hline Mean responses & Sd responses & $\begin{array}{l}95 \% \text { CI for the } \\
\text { difference in means }\end{array}$ \\
\hline College & $\begin{array}{l}\text { mean(activities })=4.29 \\
\text { mean(readings })=3.71\end{array}$ & $\begin{array}{l}\text { sd(activities })=0.47 \\
\text { sd(readings })=0.99\end{array}$ & $\begin{array}{l}(-0.04,1.19) \\
* \text { contains zero }\end{array}$ \\
\hline High school & $\begin{array}{l}\text { mean(activities })=3.76 \\
\text { mean(readings })=3.67\end{array}$ & $\begin{array}{l}\text { sd(activities })=0.97 \\
\text { sd(readings })=0.93\end{array}$ & $\begin{array}{l}(-.27,4.56) \\
* \text { contains zero }\end{array}$
\end{tabular}

Students completed readings in order to participate in the activities. The responses from the survey are consistent with an understanding of the connection between the readings and activities.

A key theme specifies the SCCG curriculum focused class readings and fiction texts as preparation for wellness. They were seen as helpful for learning more about self-care and the life-study-work balance. However, high school students also mention that the class readings developed through the Expository Reading \& Writing Course (ERWC) framework were mind-broadening but irrelevant in comparison to the SCCG curriculum. High school students felt that their time would be better spent on the latter. 
Students also compared themselves to their peers and mentioned that the class readings in other Senior English classes were unrelated to the SCCG curriculum, not supportive of college success, and thereby not worth learning in Senior English classes. Students felt they were more prepared and less stressed than their counterparts: for the majority of the course students were able to focus on relevant SCCG curriculum, students were able to access guidance in class, and students had designated class-time time carved out for them. Thus, increased peer social support and collaboration as well as interactive help from adults and postsecondary students were also key qualitative themes.

The qualitative data also reveals that students felt setting a purpose and goal for furthering their formal education was helpful. High school students set this goal by researching a self-chosen career and the pathway to obtain it, and presented this information to their classmates. Students in the 2019 cohort were also asked to write a final essay to determine the goal of their postsecondary education and to subsequently make an argument for this objective. Although high school students did not directly mention the helpfulness of these just-completed goal-setting activities, college students did retrospectively. The 2017-2018 college students recommended that future students write an essay determining their goal for postsecondary attendance before being apprised that this writing assignment had already been incorporated into the curriculum for the 2019 cohort. Students in all focus groups reiterated the helpfulness of the HOM activities 
to raise their awareness of how to work on their own skills to improve their college persistence.

\section{Question 3: What Additional Or Different Supports Do Students Recommend Adding To The SCCG Curriculum To Better Support College Success?}

The survey did not address additional or different curricular supports recommended by the students, so there is very little or no quantitative data to support the following student recommendations. Nonetheless, the qualitative data served to provide an opportunity for students to specify suggestions that would further support student success. These suggestions frequently focused on the "key learning skills and techniques" that are central to college and career readiness (Conley \& French, 2014, p. 1020). These learning skills and techniques included helping students understand their motivation for attending postsecondary institutions of learning, helping students learn how to seek help and exhibit self-efficacy at postsecondary institutions, and learning time management skills to promote success in postsecondary classes. They were reiterated as important, necessary skills to learn and are thereby key findings.

The qualitative findings also provide evidence that students would like for high school teachers and students to change their negative attitudes toward attending community college. Students felt that most high school teachers and non community college-going peers contributed to the perpetuation of a negative postsecondary myth by stigmatizing the abilities of students who attend community colleges and implying 
community colleges provided comparatively poor education opportunities as opposed to four-year universities. Students suggested that awareness activities such as illustrating the high return on investment (ROI) through comparative data, listening to the reasoning of student speakers who left four-years to attend community colleges, and reviewing the high credentials of community college professors would decrease this stigma. Although indirectly connected as a remedy to dispelling this myth, the qualitative data suggest that students felt that the SCCG should include activities to teach secondary students about self-advocacy techniques as well as college resources and how to use them. The recent shift toward setting up postsecondary institutions with supportive resource systems rather than gatekeeping methods is consistent with the current research as illustrated throughout the literature review.

The qualitative findings also reveal that students felt that high school teachers who did not include the SCCG were spending time on curriculum that lacked personal meaning. Students thereby suggested that high school teachers focus solely on the SCCG curriculum in Senior English. High school students suggested that the non-SCCG curriculum I had included be removed in order to make room for the SCCG that would make a difference for their immediate future. Students also made this suggestion for the teachers of all Senior English classes. Students discussed how busy they were during their final year of high school, and how their stress level decreased in comparison to their peers who were not exposed to the SCCG curriculum. Students also recounted that they 
were more easily able to meet application and financial aid deadlines because of the allocated class time and the ability to have their questions answered during class. The importance of relevant curriculum to improve student college outcomes is consistent with the research (Conley \& French, 2014).

The qualitative data also suggests that students would like to learn more about the four-year needed HOM and college admission process because the SCCG curriculum mainly used the community college liaisons as resources. Only one CSU student spoke to the seniors as compared to the inclusion of only community college college adult facilitator-speakers and majority community college student facilitator-speakers. College students mentioned their interest in learning more from students who had transferred to and also directly attended four-year colleges. High school students also indicated that they would also like to hear from and ask questions to four-year attending college students. Four-year college-bound high school students wanted the SCCG curriculum to emphasize the importance of writing and admission, and to be provided more big-picture, individualized deadlines for four-year universities. They also mentioned that they would have liked to have had the SCCG curriculum include activities for students such as themselves who had already chosen a specific goal for pursuing a postsecondary education at a four-year institution. This lack of collaboration between secondary and postsecondary institutions, collaboration being requested by college-bound students, is consistent with the research as illustrated throughout the literature review. 
Students also suggested a deepened understanding for the established SCCG curriculum. High school students would have liked to have spent more time on the HOM, students would have liked more time spent deepening their understanding of financial aid, and students would like to spend more time on activities. College students had received more lengthy instruction on the HOM through collaborative expert-group panels and indicated this information was very helpful. Their absence of a request to spend more time on the HOM suggests that they were provided sufficient information on the HOM in comparison to their high school counterparts. Students also frequently asked for more information on financial aid such as individual conferences, targeted scholarships for specific groups, and individual conferences for a more tailored understanding of financial aid opportunities. More generally, students felt they would learn even more from one another through adding in more group discussions and additional collaborative, interactive presentations to the SCCG curriculum.

Last, the quantitative data illustrate a difference between high school and college students' perceptions on three different counts: two through quantitative responses and one through qualitative responses. High school students felt neutral toward readings and college applications as well as written assignment and financial aid. Contrastingly, college students' responses were positive. High school students felt that the ERWC readings were unnecessary whereas college students felt that ERWC readings helped them to succeed in the college environment. This may mean that the college students' 
attitudes toward the readings on college applications, written assignments and financial aid, and the ERWC readings are positive because they have a retrospective understanding of the knowledge needed to successfully apply for college, successfully apply for financial aid, and successfully navigate the college environment. The data illustrating some effectiveness of the ERWC curriculum supporting students' college success (Hafner, Joseph \& McCormick, 2010) highlights the differences in retrospective understanding between the student groups' responses.

\section{Limitations of the Study}

This study was limited in three aspects: (a) the participant selection process, (b) the length of the study, and (c) the depth and breadth of questions. The absence of a small non-random sample size leads to an inability to reliably disaggregate the quantitative data by demographics or graduating class. In order for the results to be generalizable, further studies would need to be conducted with a larger number of participants. An additional limitation to the participation selection process is the lack of a controlled comparison group. In this study, there is insufficient quantitative supporting evidence to claim that the SCCG curriculum is "better" than the Eurocentric literaturebased curriculum more frequently taught in Senior English classes.

The second limitation, the length of study, did not afford the students in the 2019 cohort to spend longer than one semester in community college. The short length of the study did not allow for a deepened understanding of what students felt their counterparts 
needed to persist beyond the first year of college. The short length also did not allow for the saturation of repeated focus group themes.

The last limitation was that the survey questions lacked depth and breadth. In the future, the questions would need to be more specific with additional questions focusing on subthemes. This would allow for a more detailed analysis of the students' perspectives.

\section{Implications \& Recommendations for Action}

Based on the findings in this study and correspondent literature review, implications and recommendations for action will be articulated in terms of the teacher's role in creating a supportive environment for learning about college access \& persistence, understanding institutional differences \& resources, learning college-going knowledge, and collaboration between secondary \& postsecondary institutions.

\section{Teacher's Role}

\section{Creating A Supportive Environment For Learning About Access \& Persistence}

According to the qualitative data in this study, Senior English content should focus on SCCG curriculum instead of the typical Eurocentric, fiction-heavy curriculum based on the colonized mindset. Students felt that the SCCG curriculum was more meaningful, and this is consistent with recent research correlating relevant curriculum with improved student outcomes, particularly in light of our increasingly diverse student populations (Conley \& French, 2014). Public K-12 schools have shifted their focus to 
meeting the Common Core Grades 11-12 Reading, Writing, Speaking \& Listening, and Language standards, delineated in the Common Core Standards Initiative (2019), and these easily align with the components included in the SSCG curriculum.

Students should also be introduced to a college-going Senior English environment in which postsecondary attainment is the common goal. The qualitative data suggested an improved college-readiness with exposure to a more college-like environment that was self-directed, hands-on, interactive, collaborative and had a problem-solving focus. This data also revealed that the successful completion of college and financial aid applications could be attributed to the accountability required through students meeting short-term goals via class assignment deadlines. The opportunity to work on applications during designated class time in which students were able to ask questions that guided their learning also correlated to an increased completion of postsecondary and financial aid applications. Working together also created a supportive social environment, in which students felt an increasing amount of solidarity as the result of the experience of working towards a common goal that was more challenging to navigate individually.

\section{Teaching About Institutional Differences \& Resources}

Students should spend more time understanding the differences between California's different postsecondary opportunities. The data suggest that some students felt learning the different purposes for each institutional type was helpful when deciding where to apply. In this manner students could make more long-term goals and determine 
their purpose for attending (Scott-Clayton, 2011).

The data also provide evidence that secondary teachers should help their secondary students obtain an awareness of the college help available at their postsecondary destinations through class activities. They should also maintain a positive attitude toward community colleges and support an awareness of its benefits by reviewing the college dropout rate and the high ROI of community colleges when comparing costs between postsecondary institutions.

\section{Teaching College-going Knowledge}

Students should also learn more practical knowledge during Senior English class to improve college access and persistence. The neutral responses elicited from both groups of students in the quantitative data, and the suggestions made by both groups of students in the qualitative data provide evidence that students would like to be given more personal guidance about financial aid in addition to applying for state and/or federal aid. The scholarship writing assignment should be tailored for students' individual situations including but not limited to international students and Dreamers.

The data suggest that students felt that they should learn more time-management and self-efficacy skills in Senior English in order to promote postsecondary success. Students had difficulty understanding the time-commitment difference between high school credits and college units. This resulted in postsecondary students having difficulty learning how to balance school, work, and self-care. Students felt that the wellness 
techniques studied in class enabled them to create a healthier balance. They also felt that they needed more practice with affective behaviors related to the HOM. These included learning how to ask for help, learning to use on-campus academic resources, and learning how to self-advocate during discussions with professors.

\section{Collaboration Between Secondary \& Postsecondary Institutions}

At least one group of representatives from each of California's postsecondary institutions--from the private university system, from the UC system, from the CSU system, and from the community college system--need to visit every Senior English class in their local high school in order to review the application and the financial aid opportunities. The data indicate that students wanted more speaker-facilitators from every institution to improve their understanding of the application and financial aid process as well as to obtain a better understanding of the student experience. Although I was able form collaborative connections with college-going facilitators at the community college-level and have recently begun to make connections with college-going facilitators at the CSU level, this is not the norm. Instead of waiting for a non-systemic program to outreach to students, secondary school administrators, secondary-level English Curriculum Council leads, and representatives from each type of institution need to work together to provide the navigational capital requested by the students as illustrated in the qualitative data (Perna \& Armijo, 2014).

\section{Dissemination of Results}


The results from this study will be disseminated in a multitude of ways. A non-profit organization that supports FGCS is currently using a portion of the curriculum I provided to meet their students' needs. I also plan to submit this study to the American Educational Research Association (AERA) for publication in order to disseminate the findings and collaborate with other interested researchers. The results will also be shared with the head of Bay Area Union High School District's (BAUHSD) English Council, International Baccalaureate (IB) Coordinator, and ERWC trainer. We will then discuss how to best disseminate this information to district administrators, the Board, and English Department Chairs. The ERWC trainer is also a facilitator of the curriculum at the county level, and we will discuss how to best develop this curriculum to meet the needs of twelfth-grade students. The units could be developed in such a way that ERWC teachers throughout California can teach them individually or collectively, i.e. based upon the needs of their students.

\section{Recommendations for Further Study}

A quantitative finding in this study suggested that college students with low GPAs also had a poor understanding of how to acquire financial aid. Although this study is too small to correlate these variables, further studies could be designed to determine if there is a relationship between the SCCG curriculum's financial aid knowledge and college persistence. Additional studies could be conducted to include the feedback of the students who accessed the SCCG curriculum and attended UCs, CSUs and California's 
private postsecondary institutions. These studies could be disaggregated collectively and by institution to better understand how/if students attending four-year schools make different recommendations for improving the SCCG curriculum in order to increase college success.

Based on this study, other additional questions could be developed and subsequently added to the surveys to deepen our understanding through more nuanced feedback. For example, questions could be utilized to help to determine if students felt the interweaving of the SCCG and ERWC framework prepared them to both persist in college and succeed in their first-year postsecondary English course. In this manner the curriculum could be reviewed and revised as needed, again based on students' input, for its ability to provide college-going and postsecondary English skills in a manner in which they are not mutually exclusive. More studies could be conducted by following up with secondary students in the postsecondary realm to determine if the SCCG curriculum has had any longitudinal effects in both first-year English and more generally through college persistence and completion.

If the SCCG curriculum is thus further researched and refined, the curriculum might be developed into a larger publication. If the SCCG curriculum is disseminated more widely and suggests a correlation to supporting students' college completion rates in multiple schools, my goal is also to approach a lawmaker to consider putting forth a bill that will require that SCCG curriculum be a required component of Senior English 
classes.

\section{Conclusion}

The lack of collaboration between secondary and postsecondary institutions has resulted in a disconnected transition. The consequences of this disconnect affects our most vulnerable student populations because they can neither afford to pay for the needed resources to make the transition nor do they systemically access outside support systems. This study revealed a way in which to provide a cost-effective transition curriculum to each and every one of California's students: through the SCCG embedded in Senior English classes. The results garnered in this study will further an understanding of the information students need to make a successful transition and persist in postsecondary institutions. Thinking about how to reach every student in an already-established, compulsory course can help improve students' college completion rate and thereby improve the futures for every Californian both individually and collectively. 


\section{References}

Almeida, D. J. (2016). Low-income Latino students and California's early assessment program: The role of sensemaking in the use of college readiness information. Journal of Hispanic Higher Education, 15(4), 310-339.

Arana, R., Castañeda-Sound, C., Blanchard, S., \& Aguilar, T. E. (2011). Indicators of Persistence for Hispanic Undergraduate Achievement: Toward an Ecological Model. Journal of Hispanic Higher Education, 10(3), 237-251. https://doi.org/10.1177/1538192711405058

Assem. Bill 2015, 2017-2018 Reg. Sess, 2018 Cal. Stat.

Astin, A. (2016). Are you smart enough?: How colleges' obsession with smartness shortchanges students (First ed.). Sterling, Virginia: Stylus Publishing.

Atherton, M. C. (2014). Academic preparedness of first-generation college students: Different perspectives. Journal of College Student Development, 55(8), 824-829.

Auguste, B., Hancock, B., \& Laboissiere, M. (2009). The economic impact of the achievement gap in America's schools. New York, NY: McKinsey \& Company.

AVID. (n.d.). AVID national snapshot [Data file].

https://www.avid.org/cms/lib/CA02000374/Centricity/Domain/8/AVID\%20Natio nal\%20Snapshot.pdf

AVID. (2019). Research confirming AVID's success. Retrieved December 14, 2019, from https://www.avid.org/research 
Bailey, M. J., \& Dynarski, S. M. (2011). Gains and gaps: Changing inequality in US college entry and completion (No. w17633). National Bureau of Economic Research.

Bailey, T., \& Karp, M. M. (2003). Promoting college access and success: A review of dual credit and other high school/college transition programs. U.S. Department of Education

Bailey, T. R., Jaggars, S. S., \& Jenkins, D. (2015). Redesigning America's community colleges. Harvard University Press.

Barnett, E. A., Bucceri, K., Hindo, C., \& Kim, J. (2013). Ten key decisions in creating early colleges: Design options based on research. Columbia University, Teachers College, National Center for Restructuring Education, Schools, and Teaching.

Barnett, E., Fay, M., Bork, R., and Weiss, M. (2013). Reshaping the college transition: States that offer early college readiness assessments and transition curricula. Community College Research Center: Teachers College, Columbia University. Bay area high school school (pseudonym) profile 2017-2018 [pdf file]. http://bayarea(pseudonym).org/sites/default/files/pdfs/2017-2018\%20EHS\%20Sc hool\%20Profile.pdf

Bell, A. D., Rowan-Kenyon, H. T., \& Perna, L. W. (2009). College knowledge of 9th and 11th grade students: Variation by school and state context. The Journal of Higher Education, 80(6), 663-685. 
Bers, T., \& Younger, D. (2014). The first-year experience in community colleges. New directions for institutional research, 2013(160), 77-93.

Bird, G. (2018). The impact of parents' education levels. Inside Higher Ed. https://www.insidehighered.com/news/2018/02/08/students-postsecondary-educati on-arcs-affected-parents-college-backgrounds-study

Blumenstyk, G. (2014). American Higher Education in Crisis?: What Everyone Needs to Know. Oxford University Press.

Bonilla-Silva, E. (2015). The structure of racism in color-blind, "post-racial” America. American Behavioral Scientist, 59(11), 1358-1376.

Bonilla-Silva, E. (2006). The central frames of color-blind racism. In Racism without racists: Color-blind racism and the persistence of racial inequality in the United States (pp. 25-52). Rowman \& Littlefield Publishers.

Bowles, S., \& Gintis, H. (2011). Broken promises: school reform in retrospect. In Schooling in capitalist America: Educational reform and the contradictions of economic life. Haymarket Books.

Brooks, S. D. (2018). Cultural competence, race, and gender: Portraits of teaching in high school college access programs. The High School Journal, 101(3), 177-198.

byrd, d. (2019). Uncovering hegemony in higher education: A critical appraisal of the use of "institutional habitus" in empirical scholarship. Review of Educational Research, 89(2), 171-210. 
California Community Colleges (CCC). (2018). 2018 Student success scorecard [Data file]. https://scorecard.cccco.edu/scorecardrates.aspx?CollegeID=000\#home California Community Colleges (CCC). (2016). Welcome to the california community colleges chancellor's office. http://www.cccco.edu/

California Department of Education. (2018a). 2017-2018 College-going rate for high-school students by postsecondary institution type [Data file]. https://dq.cde.ca.gov/DataQuest/DQCensus/CGR.aspx?agglevel $=$ state $\& c d s=00 \&$ year $=2017-18$

California Department of Education. (2018b, November 19). State superintendent Torlakson announces 2018 rates for high school graduation, suspension and chronic absenteeism [Press release]. https://www.cde.ca.gov/nr/ne/yr18/yr18rel76.asp

The California State University. (2014, July 2). Summer bridges barriers for first-generation students.

https://www2.calstate.edu/csu-system/news/Pages/summer-bridges-barriers-for-fir $\underline{\text { st-generation-students.aspx }}$

Cammarota, J., \& Romero, A. (2011). Participatory action research for high school students: Transforming policy, practice, and the personal with social justice education. Educational Policy, 25(3), 488-506.

Carman, C. (2011). Stereotypes of giftedness in current and future educators. Journal for 
the Education of the Gifted, 34(5), 790-812.

Carnevale, A. P., Smith, N., \& Strohl, J. (2013). Recovery: Job growth and education requirements through 2020. Georgetown University Center on Education and the Workforce.

https://cew.georgetown.edu/cew-reports/recovery-job-growth-and-education-requi rements-through-2020/\#full-report

Carolan-Silva, A., \& Reyes, J. R. (2013). Navigating the path to college: Latino students' social networks and access to college. Educational Studies, 49(4), 334-359.

Cataldi, E. F., Bennett, C. T., Chen, X., and Simone, S. A. (2018). First-generation students: College access, persistence, and postbachelor's outcomes. National Center for Education Statistics. https://files.eric.ed.gov/fulltext/ED580935.pdf

Chambers, T. T. V., \& Huggins, K. S. (2014). The influence of school factors on racial opportunity cost for high-achieving students of color. Journal of School Leadership, 24(1), 189-225.

Chambers, T. V., Huggins, K. S., Locke, L. A., \& Fowler, R. M. (2014). Between a "ROC" and a school place: The role of racial opportunity cost in the educational experiences of academically successful students of color. Educational Studies, 50(5), 464-497.

Chambers, T. V., \& Tabron, L. A. (2013). Academic success for students of color...at 
what cost? The importance of school context at birch high school. Journal of Cases in Educational Leadership, 16(4), 31-44.

Chan, D., \& Cochrane, D. F. (2008). Paving the way: How financial aid awareness affects college access and success. The Institute for College Access and Success. https://ticas.org/wp-content/uploads/legacy-files/pub files/Paving the Way.pdf

Charmaz, K. (2014). Constructing grounded theory (2nd ed.). Sage.

Cochran-Smith, M., \& Lytle, S. L. (Eds.). (1993). Inside/outside: Teacher research and knowledge. Teachers College Press.

Columbia University. (2019). Community college FAQs. Teachers College Community College Research Center. $\underline{\text { https://ccrc.tc.columbia.edu/Community-College-FAQs.html }}$

Conley, D. (2014). Getting ready for college, careers, and the common core: What every educator needs to know (First ed.). Jossey-Bass.

Conley, D. T., \& French, E. M. (2014). Student ownership of learning as a key component of college readiness. American Behavioral Scientist, 58(8), 1018-1034.

Contreras, F. (2011). Strengthening the bridge to higher education for academically promising underrepresented students. Journal of Advanced Academics, 22(3), $500-526$.

Cowan, J., \& Goldhaber, D. (2015). How much of a" running start" do dual 
enrollment programs provide students?. The Review of Higher Education, 38(3), 425-460.

Crosnoe, R., and C. Muller. (2014). Family socioeconomic status, peers, and adolescents' path to college. Social Problems 61:1-23.

Darling-Hammond, L. (2015). The flat world and education: How America's commitment to equity will determine our future. Teachers College Press.

Dawson, P., van der Meer, J., Skalicky, J., \& Cowley, K. (2014). On the effectiveness of supplemental instruction: A systematic review of supplemental instruction and peer-assisted study sessions literature between 2001 and 2010. Review of Educational Research, 84(4), 609-639.

DeAngelo, L., Franke, R., Hurtado, S., Pryor, J. H., \& Tran, S. (2011). Completing college: Assessing graduation rates at four-year institutions. Higher Education Research Institute, UCLA. https://heri.ucla.edu/DARCU/CompletingCollege2011.pdf

Del Valle, G. (2019). The outrageously expensive world of college counseling services, explained. Vox. https://www.vox.com/the-goods/2019/3/14/18265847/college-counseling-coachin g-services-ivy-league

Duncheon, J. C., \& Relles, S. R. (2019). Brokering College Opportunity for First-Generation Youth: The Role of the Urban High School. American 
Educational Research Journal, 56(1), 146-177.

Edmunds, J. A., Arshavsky, N., Lewis, K., Thrift, B., Unlu, F., \& Furey, J. (2017).

Preparing students for college: Lessons learned from the early college. NASSP Bulletin, 101(2), 117-141.

Education Trust. (2019). California: State Equity Report Card. http://stateequity.org/state/california

Education Trust--West. (2017). The majority report: Supporting the success of Latino students in California. https://west.edtrust.org/resource/the-majority-report/

Engberg, M. E., \& Allen, D. J. (2011). Uncontrolled destinies: Improving opportunity for low-income students in American higher education. Research in Higher Education, 52(8), 786-807.

Common Core State Standards Initiative. (2019). English language arts standards » reading: Literature " grade $11-12$. http://www.corestandards.org/ELA-Literacy/RL/11-12/

Esteban-Guitart, M., \& Moll, L. C. (2014). Lived experience, funds of identity and education. Culture \& Psychology, 20(1), 70-81.

Flores, S., \& Gomez, M. (2011). Strategies for increasing Advanced Placement participation for underrepresented students: Barriers, practices, and positive outcomes. NASSP Bulletin, 95(1), 65-79.

Freire, P., Ramos, M., \& Macedo, D. (2000). Pedagogy of the oppressed (30th 
anniversary ed.). New York: Continuum.

Garriott, P. O., Flores, L. Y., \& Martens, M. P. (2013). Predicting the math/science career goals of low-income prospective first-generation college students. Journal of Counseling Psychology, 60(2), 200.

Geiser, S., \& Atkinson, R. C. (2013). Beyond the master plan: The case for restructuring baccalaureate education in California. California Journal of Politics and Policy, $4(1), 67-123$.

Gershenfeld, S. (2014). A review of undergraduate mentoring programs. Review of Educational Research, 84(3), 365-391.

Goldberg, Harmony. (2016). Antonio Gramsci a brief introduction to his concepts of hegemony, war of position \& the historic bloc [PDF file]. https://mplsstudygroup.files.wordpress.com/2016/05/gramsci-introduction-by-har mony-goldberg.pdf

Gopalan, M., \& Brady, S. T. (2020). College Students' Sense of Belonging: A National Perspective. Educational Researcher, 49(2), 134-137. https://doi.org/10.3102/0013189X19897622

Groundwater-Smith, S., \& Mockler, N. (2011). Speaking of quality and research that counts: Making an impact on practice. Action Researcher in Education, 11, 10-18.

Hafner, A., Joseph, R., \& McCormick, J. (2010). College readiness for all: Assessing 
the impact of English professional development on teaching practice and student learning. Journal of Urban Learning, Teaching, and Research, 6, 15-30.

Hamilton, L. T. (2016). Parenting to a degree: How family matters for college women's success. University of Chicago Press.

Hammond, Z. (2014). Culturally responsive teaching and the brain: Promoting authentic engagement and rigor among culturally and linguistically diverse students. Corwin Press.

Hancock, M. E., Amankwaa, L., Revell, M. A., \& Mueller, D. (2016). Focus group data saturation: A new approach to data analysis. The Qualitative Report, 21(11), 2124.

Harper, S. R. (2012). Race without racism: How higher education researchers minimize racist institutional norms. The Review of Higher Education, 36(1), 9-29.

Haxton, C., Song, M., Zeiser, K., Berger, A., Turk-Bicakci, L., Garet, M. S. \& Hoshen, G. (2016). Longitudinal findings from the early college high school initiative impact study. Educational evaluation and policy analysis, 38(2), 410-430.

Hazard, L. (2013). Cultivating the habits of mind for student success and achievement. Research and Teaching in Developmental Education, 29(2), 45-48.

Hehir, T., Grindal, T., Freeman, B., Lamoreau, R., Borquaye, Y., \& Burke, S. (2016). A summary of the evidence on inclusive education. Alana Institute.

Holme, J. J., Diem, S., \& Welton, A. (2014). Suburban school districts and demographic 
change the technical, normative, and political dimensions of response.

Educational Administration Quarterly, 50(1), 34-66.

Howell, J. S., Kurlaender, M., \& Grodsky, E. (2010). Postsecondary preparation and remediation: Examining the effect of the Early Assessment Program at California State University. Journal of Policy Analysis and Management, 29(4), 726-748.

Huerta, J., \& Watt, K. M. (2015). Examining the college preparation and intermediate outcomes of college success of AVID graduates enrolled in universities and community colleges. American Secondary Education, 43(3), 20.

The Institute for College Access \& Success. (2017). College costs in context: a state-by-state look at college (un)affordability. https://ticas.org/wp-content/uploads/legacy-files/pub_files/college_costs_in_conte xt.pdf

Kallick, B., \& Zmuda, A. (2017). Students at the center: Personalized learning with habits of mind. Association for Supervision and Curriculum Development.

Kanno, Y., \& Kangas, S. E. (2014). “I'm not going to be, like, for the AP” English language learners' limited access to advanced college-preparatory courses in high school. American Educational Research Journal, 51(5), 848-878.

Karp, M. M., \& Bork, R. H. (2012). “They never told me what to expect, so I didn't 
know what to do": Defining and clarifying the role of the community college student (CCRC Working Paper No. 47). Columbia University, Teachers College, Community College Research Center.

Kelly, S., \& Price, H. (2011). The correlates of tracking policy opportunity hoarding, status competition, or a technical-functional explanation?. American Educational Research Journal, 48(3), 560-585.

Kirsch, I., Braun, H., Yamamoto, K., \& Sum, A. (2007). America's perfect storm: three forces changing our nation's future. The Catalyst, 36(1), 3-5.

Kirst, M., \& Venezia, A. (2004). From high school to college: Improving opportunities for success. San Francisco: Jossey-Bass.

Kitchen, J. (2020). Supporting first-generation, low-income, and underrepresented students' transitions to college through comprehensive and integrated programs. The American Behavioral Scientist, 64(3), 223-229.

Klugman, J. (2013). The Advanced Placement arms race and the reproduction of educational inequality. Teachers College Record, 115(5), 1-34.

Klugman, J. (2012). How resource inequalities among high schools reproduce class advantages in college destinations. Research in Higher Education, 53(8), 803-830.

Kolluri, S. (2018). Advanced Placement: The dual challenge of equal access and effectiveness. Review of Educational Research, 88(5), 671-711. 
Litow, Stanley (2019). The bigger college scandal isn't about admission bribes, but graduation rates. Barron's. https://www.barrons.com/articles/the-bigger-college-scandal-isnt-about-admission -bribes-but-graduation-rates-51552996831

Llamas, J. D., López, S. A., \& Quirk, M. (2014). Listening to students: Examining underlying mechanisms that contribute to the AVID program's effectiveness. Journal of Education for Students Placed at Risk (JESPAR), 19(3-4), 196-214.

Lucas, S. R. (2017). An Archaeology of Effectively Maintained Inequality Theory. American Behavioral Scientist, 61(1), 8-29.

Lynch, M., Engle, J., \& Cruz, J. L. (2010). Subprime Opportunity: The Unfulfilled Promise of For-Profit Colleges and Universities. Education Trust. https://edtrust.org/resource/subprime-opportunity-the-unfulfilled-promise-of-for-p $\underline{\text { rofit-colleges-and-universities/ }}$

Marx, D., Ko, S., \& Croizet, J. (2019). Introduction to the special issue on group-based inequalities in educational outcomes. Group Processes \& Intergroup Relations, $22(3), 323-329$.

McCabe, J. M. (2016). Connecting in college: How friendship networks matter for academic and social success. University of Chicago Press.

McCabe, J., \& Jackson, B. A. (2016). Pathways to financing college: Race and class in students' narratives of paying for school. Social Currents, 3(4), 367-385. 
Mehta, S. S., Newbold, J. J., \& O'Rourke, M. A. (2011). Why do first-generation students fail?. College Student Journal, 45(1), 20-36.

Mitchell, D. E., Shipps, D., \& Crowson, R. L. (Eds.). (2017). Shaping education policy: Power and process. Routledge.

Moran, C., Cooper, C. R., López, A., \& Goza, B. (2009). Developing effective P-20 partnerships to benefit Chicano/Latino students and families. Journal of Hispanic higher education, 8(4), 340-356.

National Association for College Admission Counseling. (2014). State-by-state student-to-counselor ratio report. https://www.schoolcounselor.org/asca/media/asca/Publications/ratioreport.pdf

National Student Clearinghouse Research Center (NSC Research Center). (2017). Completing college national by race and ethnicity--2017. https://nscresearchcenter.org/signaturereport14/

National Student Clearinghouse Research Center (NCS Research Center). (2018). Persistence \& retention--2018. https://nscresearchcenter.org/snapshotreport33-first-year-persistence-and-retention/ Oakes, J. (2008). Keeping track: Structuring equality and inequality in an era of accountability. Teachers College Record, 110(3), 700-712.

Omi, M., \& Winant, H. (2015). Racial formation in the United States (Third ed.). Routledge/Taylor \& Francis Group. 
O'Neill, P., Adler-Kassner, L., Fleischer, C., \& Hall, A. (2012). Creating the "Framework for Success in Postsecondary Writing". College English, 74(6), 520-524.

Orfield, G., Marin, P., \& Horn, C. L. (2005). Higher education and the color line: College access, racial equity, and social change. Harvard Education Press.

Patton, L. D. (2016). Disrupting postsecondary prose: Toward a critical race theory of higher education. Urban Education, 51(3), 315-342.

Permzadian, V., \& Credé, M. (2016). Do first-year seminars improve college grades and retention? A quantitative review of their overall effectiveness and an examination of moderators of effectiveness. Review of Educational Research, 86(1), 277-316.

Perna, L. W., \& Armijo, M. (2014). The persistence of unaligned K-12 and higher education systems: Why have statewide alignment efforts been ineffective?. The Annals of the American Academy of Political and Social Science, 655(1), 16-35.

Perna, L. W., Klein, M. W., \& McLendon, M. K. (2014). Insights and implications for state policy-makers. The Annals of the American Academy of Political and Social Science, 655(1), 209-230.

Perna, L. W., May, H., Yee, A., Ransom, T., Rodriguez, A., \& Fester, R. (2015). Unequal access to rigorous high school curricula: An exploration of the opportunity to benefit from the International Baccalaureate Diploma Programme (IBDP). Educational Policy, 29(2), 402-425.

Peters, S. , \& Gentry, M. (2010). Multigroup construct validity evidence of the "hope 
scale": Instrumentation to identify low-income elementary students for gifted programs. Gifted Child Quarterly, 54(4), 298-313.

Pew Research Center. (2012, Feb 27). Most parents expect their children to attend college [Data file]. https://www.pewresearch.org/fact-tank/2012/02/27/most-parents-expect-their-chil dren-to-attend-college/

Pew Research Center. (2016, February 24). Hispanic, black parents see college degree as key for children's success [Data file]. https://www.pewresearch.org/fact-tank/2016/02/24/hispanic-black-parents-see-col $\underline{\text { lege-degree-as-key-for-childrens-success/ }}$

Phelps, L. A., \& Chan, H. Y. (2016). Optimizing technical education pathways: Does dual credit course completion predict students' college and labor market success?. Journal of Career and Technical Education, 31(1), 61-84.

Philip, T. M., Bang, M. \& Jackson, K. (2018) Articulating the 'how', the 'for what', the 'for whom', and the 'with whom' in concert: A call to broaden the benchmarks of our scholarship, Cognition \& Instruction, 36(2), 1-6. https://doi.org/10.1080/07370008.2018.1413530

Pinchak, N. P. (2018). The relationship between teacher regard and college attendance expectations: socioeconomic and racial-ethnic disparities. Social Psychology of Education, 21(1), 209-221. 
The Postsecondary National Policy Institute (PNPI). (2018, September 26).

First-generation students in higher education.

https://pnpi.org/first-generation-students/

Poynton, T. A., \& Lapan, R. T. (2017). Aspirations, achievement, and school counselors' impact on the college transition. Journal of Counseling \& Development, 95(4), 369-377.

Pugh Jr, P. M., \& Tschannen-Moran, M. (2016). Influence of a school district's advancement via individual determination (AVID) program on self-efficacy and other indicators of student achievement. NASSP Bulletin, 100(3), 141-158.

Ramsey, E., \& Brown, D. (2018). Feeling like a fraud: Helping students renegotiate their academic identities. College \& Undergraduate Libraries, 25(1), 86-90.

Richardson, L. (2000). Evaluating Ethnography. Qualitative Inquiry, 6(2), 253-255. https://doi.org/10.1177/107780040000600207

Rios-Aguilar, C., Kiyama, J. M., Gravitt, M., \& Moll, L. C. (2011). Funds of knowledge for the poor and forms of capital for the rich? A capital approach to examining funds of knowledge. Theory and Research in Education, 9(2), 163-184.

Roderick, M., Coca, V., \& Nagaoka, J. (2011). Potholes on the road to college: High school effects in shaping urban students' participation in college application, four-year college enrollment, and college match. Sociology of Education, 84(3), 178-211. 
Sablan, J. R. (2014). The challenge of summer bridge programs. American Behavioral Scientist, 58(8), 1035-1050.

Schneider, D., Hastings, O. P., \& LaBriola, J. (2018). Income inequality and class divides in parental investments. American Sociological Review, 83(3), 475-507.

Scott-Clayton, J. (2011). The Shapeless River: Does a lack of structure inhibit students' progress at community colleges? CCRC Working Paper No. 25. Assessment of Evidence Series. Community College Research Center, Columbia University.

Seidman, I. (1998). Interviewing as qualitative research: A guide for researchers in education and the social sciences. New York, NY: Teachers College Press.

Silver, B. R., \& Roksa, J. (2017). Navigating uncertainty and responsibility: Understanding inequality in the senior-year transition. Journal of Student Affairs Research and Practice, 54(3), 248-260.

Staats, C. (2016). Understanding Implicit Bias: What Educators Should Know. American Educator, 39(4), 29.

Starr, C. R. (2018). “I’m not a science nerd!” STEM stereotypes, identity, and motivation among undergraduate women. Psychology of Women Quarterly, 42(4), 489-503.

Steele, C. M. (2011). Whistling Vivaldi: How stereotypes affect us and what we can do. WW Norton \& Company.

Sullivan, P. (2012). Essential Habits of Mind for College Readiness. College English, 
74(6), 547-553.

Theokas, C., \& Saaris, R. (2013). Finding America's missing AP and IB students. Ed Trust.

Turner, E. O. (2015). Districts' responses to demographic change: Making sense of race, class, and immigration in political and organizational context. American Educational Research Journal, 52(1), 4-39.

Tyler, A. C. (2016). "Really just lip service": Talking about diversity in suburban schools. Peabody Journal of Education, 91(3), 289-308.

University of California. (2019). Student opportunity: resources.

https://www.universityofcalifornia.edu/initiative/student-opportunity/first-generati on-students/resources

U.S. Department of Education. (2018). Stats in brief first-generation students: College access, persistence, and postbachelor's outcomes. https://nces.ed.gov/pubs2018/2018421.pdf

U.S. Department of Housing and Urban Development. (2018). Displacement of lower-income families in urban areas report. https://www.huduser.gov/portal/sites/default/files/pdf/DisplacementReport.pdf

Valenzuela, A. (2010). Subtractive schooling: US-Mexican youth and the politics of caring. Suny Press.

Vela, J. C., Zamarripa, M., Balkin, R., Johnson, M., \& Smith, R. (2013). Understanding 
Latina/o students' perceptions of high school counselors and acculturation as predictors of enrollment in AP courses. Professional School Counseling, 17(1), 142-152.

Venezia, A., \& Jaeger, L. (2013). Transitions from high school to college. The future of children, 117-136.

Venezia, A., Kirst, M., \& Antonio, A. (2003). Betraying the college dream. The Bridge Project Stanford Institute for Higher Education, 2-12.

Venzant Chambers, T. T., Locke, L. A., \& Tagarao, A. M. (2015). "That fuego, that fire in their stomach”: academically successful Latinas/os and racial opportunity cost. International Journal of Qualitative Studies in Education, 28(7), 800-818.

Walker, S. A., \& Pearsall, L. D. (2012). Barriers to advanced placement for Latino students at the high-school level. Roeper Review, 34(1), 12-25.

Watanabe, M. (Ed.). (2012). Heterogenius Classrooms: Detracking Math and Science, a Look at Groupwork in Action. Teachers College Press.

Watt, K. M., Butcher, J., \& Ramirez, E. F. (2013). Advancement Via Individual Determination (AVID) at a postsecondary institution: Support for first-generation college-goers. Journal of Latinos and education, 12(3), 202-214.

Watt, K. M., Huerta, J., \& Martinez, J. (2017). A mixed methods examination of gender disparity in high schools implementing advancement via individual determination (AVID). Educational Studies, 53(4), 377-389. 
Welton, A. D., Diem, S., \& Holme, J. J. (2015). Color conscious, cultural blindness: Suburban school districts and demographic change. Education and Urban Society, 47(6), 695-722.

Welton, A. D., \& Martinez, M. A. (2014). Coloring the college pathway: A more culturally responsive approach to college readiness and access for students of color in secondary schools. The Urban Review, 46(2), 197-223.

Werblow, J., Urick, A., \& Duesbery, L. (2013). On the wrong track: How tracking is associated with dropping out of high school. Equity \& Excellence in Education, 46(2), 270-284.

Wilbur, T. G., \& Roscigno, V. J. (2016). First-generation disadvantage and college enrollment/completion. Scopius, 2, 1-11.

Wilkins, A. C. (2014). Race, age, and identity transformations in the transition from high school to college for Black and first-generation White men. Sociology of Education, 87(3), 171-187.

Wilson, M. A. F., \& Yull, D. G. (2016). A critical ethnographic approach to transforming norms of whiteness in marginalized parents' engagement and activism in schools. In New Directions in Educational Ethnography: Shifts, Problems, and Reconstruction (pp. 165-192). Emerald Group Publishing Limited.

Wolniak, G. C., Wells, R. S., Engberg, M. E., \& Manly, C. A. (2016). College enhancement strategies and socioeconomic inequality. Research in Higher 
Education, 57(3), 310-334.

Yosso, T. J. (2005). Whose culture has capital? A critical race theory discussion of community cultural wealth. Race ethnicity and education, 8(1), 69-91.

Yull, D., Wilson, M., Murray, C., \& Parham, L. (2018). Reversing the dehumanization of families of color in schools: community-based research in a race-conscious parent engagement program. School Community Journal, 28(1), 319-347. 
Table 6

\section{High School Survey \& Demographic Profile Questionnaire}

\section{College Access \& Persistence Survey}

Purpose: Ms. Malatesta would like to improve the College Access \& Persistence Units. Your feedback is very important for this process. Your responses are confidential and will not be identified by the individual.

\section{Demographic Profile Questionnaire Part I}

What is your last name?

(Short answer)

What is your first name?

(Short answer)

Period 4 or Period 6

Personal (non-school) email address (optional)

(Short answer)

\section{Google Doc Directions:}

Please select one number per line

\begin{tabular}{|l|l|l|l|l|}
$\begin{array}{l}\text { Strongly } \\
\text { Disagree }\end{array}$ & Disagree & $\begin{array}{c}\text { No } \\
\text { Opinion }\end{array}$ & Agree & $\begin{array}{c}\text { Strongly } \\
\text { Agree }\end{array}$ \\
\hline
\end{tabular}

College Applications Feedback

1. The readings helped me successfully apply to college.

\section{1}

2. The class activities helped me successfully apply to college.

3. The written assignments helped me successfully apply to college.

\section{Financial Aid Feedback}

4. The readings helped me successfully apply for financial aid.

5. The class activities helped me successfully apply for financial aid.

6. The written assignments helped me successfully apply to financial aid.

\section{Habits of Mind Feedback}

Habits of Mind are defined as follows: Curiosity, Openness, Engagement, Creativity, Persistence, Responsibility, Flexibility \& Metacognition.

7. The readings helped expose me to the habits of mind

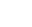


Table 6

\section{High School Survey \& Demographic Profile Questionnaire}

\section{Demographic Profile Questionnaire Part II}

How old are you?

What college/university will you be attending next year? Or will you be working, taking a gap year, etc.?

How many semesters have you been enrolled in at least one community college course through concurrent enrollment?

What is your overall high school GPA?

What is your ethnic identity (e.g. African-American/Black, Asian, European-American, Filipino, Hispanic/Latino, Native American, Pacific Islander, Mixed, Decline to State, etc.)

What is your gender identity (e.g. Male, Female, Fluid,

Trans, Decline to State, etc.)
16

17

(Short answer)

0

$<1.0$

$2.5-3.3$

(Short answer)

(Short answer) 
Table 7

\section{College Survey \& Demographic Profile Questionnaire}

Purpose: Ms. Malatesta would like to improve her transition to college Senior English curriculum. Your feedback is very important for this process. Your responses are confidential and will not be identified by individual. Thank you in advance for your time!

Google Doc Directions:
Please select one number per line

College Applications Feedback

1. The readings helped me successfully apply to college.

2. The class activities helped me successfully apply to college.

3. The written assignments helped me successfully apply to college.

\section{Strongly Disagree}

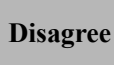

\begin{tabular}{c|c} 
No & Agree \\
Opinion
\end{tabular}

Strongly Agree

\section{Financial Aid Feedback}

4. The readings helped me successfully apply for financial aid.

5. The class activities helped me successfully apply for financial aid.

6. The written assignments helped me successfully apply to financial aid.

$\begin{array}{lllll}1 & 2 & 3 & 4 & 5 \\ 1 & 2 & 3 & 4 & 5 \\ 1 & 2 & 3 & 4 & 5\end{array}$

When I am worried about having enough money to continue college, I am successful in obtaining more financial aid.
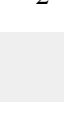

$\begin{array}{lllll}1 & 2 & 3 & 4 & 5 \\ 1 & 2 & 3 & 4 & 5 \\ 1 & 2 & 3 & 4 & 5 \\ 1 & 2 & 3 & 4 & 5\end{array}$

\section{Habits of Mind Feedback}

Habits of Mind are defined as follows: Curiosity, Openness, Engagement, Creativity, Persistence, Responsibility, Flexibility \& Metacognition.

7. The readings helped expose me to the habits of mind needed to

9. The written assignments helped expose me to the habits of mind I needed to solve problems in order to succeed as a college student.

If a problem arises that I think might prevent me from continuing college, I am determined to find a way to solve the problem. 
Table 7

\section{College Survey \& Demographic Profile Questionnaire}

Demographic Profile Questionnaire

What is your last name?

What is your first name?

How old are you?

How many semesters have you been enrolled in at least one community college course?

What is your overall GPA?

Your racial identity

Your gender identity
(Short answer)

(Short answer)

$\begin{array}{ccccc}17 & 18 & 19 & 20 & 21 \\ 1 & 2 & 3 & 4 & 5 \\ <1.0 & 1.0-1.5 & 1.5-2.3 & 2.5-3.3 & 3.3-4.0\end{array}$

African-American/Black, Asian, European-American, Filipino, Hispanic/Latino, Native American, Pacific Islander, Mixed, Decline to Answer, Other: (Short answer)

Male, Female, Fluid, Trans, Decline to Answer, Other: (Short answer) 
Table 8

Focus Group Variables

\begin{tabular}{l|l|l} 
Variable name & Description & Coding \\
\hline Role & $\begin{array}{l}\text { High school or community } \\
\text { college student }\end{array}$ & $\begin{array}{l}\text { High school or community } \\
\text { college }\end{array}$ \\
\hline
\end{tabular}

Level of experience

Number of semesters in

Number

attendance at community

college

Age

Age

Number

GPA

GPA

Number

Race

Race, to evaluate alignment

As defined for student with postsecondary outcomes

of student population 


\title{
Appendix A \\ SCCG Curriculum CP English Syllabus
}

\author{
CP Senior English 2018-2019 \\ Ms. Malatesta (she/her/hers) \\ Office Hours* \\ B-days after school in X, Thursdays Period 7 in X, and by arrangement \\ *Check Google calendar/withe me before meeting to verify both time and \\ location
}

\section{Course Description}

The goals of Senior English are to build on the foundations of previous English classes and help prepare each student to begin their post-high school plans. The course is based on the English Language Arts Common Core State Standards (ELA CCSS $)$, as well as the Expository Reading and Writing Course (ERWC) developed collaboratively by high school teachers and professors from the California State University. It is designed to help students obtain the reading and writing skills necessary to help students succeed in college and/or their chosen career after high school; units integrate strategies and activities in order to continue to develop academic skills for the following: college-level reading \& vocabulary, writing \& grammar, speaking \& listening, synthesizing sources, and rhetoric/persuasion.

My pedagogical approach grounded in constructivist principles. This means that I believe that knowledge is created collaboratively and that learning happens when individuals work together to create and construct new ideas. Consequently, the course is designed to discuss present-day issues and solicit the students' proposed solutions to these problems via the lens of social justice \& equity. The course will thereby focus on topics decided upon by both teacher and students, particularly during the spring semester.

\section{Fall 2018}

- ERWC unit (adapted): "Rhetoric of the Op-Ed Page: Ethos, Pathos \& Logos"

- ERWC unit (adapted): "What's Next? Thinking about Life after High School" with the college application process and financial aid navigation + College/Scholarship Essay

- ERWC Unit (adapted): "Language, Gender \& Culture"

- Documentary The Mask You Live In (culture of masculinity), dress codes (the female body \& culture of control), documentary Gender Revolution (non-binary gender)

- Visual Analysis with The Handmaid's Tale by Margaret Atwood + multimodal final

Spring 2019

- Evaluating \& Integrating Evidence: Technology

- ERWC Unit (adapted): "Racial Profiling" \& "The Value of Life" + The New Jim Crow by Michelle Alexander + Social Justice Synthesis Essay focusing on a topic chosen by each student

- College and Career Preparedness with Siddhartha by Herman Hesse (going away)

- Final: Postsecondary Goal-setting Essay, Career Presentation \& Group HOM presentation 


\section{Appendix B \\ Guide for Choosing CP or AS English in BAUHSD}

Students and parents are encouraged to use this guide when choosing between CP (College Preparatory) and AS (Advanced Standing) English in grade 9 and/or 10. Please note that some school sites in BAUHSD offer heterogeneous English 1 and/or 2 in place of leveled English courses in grade 9 and/or 10.

Among other activities, students in English class will:

- Read core fiction texts representing a range of time periods and culturally responsive perspectives

- Read shorter, rigorous nonfiction and fiction texts that complement core texts

- Write literary analysis, narrative, argumentative, informative, and synthesis paragraphs and essays

- Participate in small and large group discussions

- Conduct short-term and long-term research projects

- Use technology to gather, process, and present information

- Complete regular homework

\begin{tabular}{|c|c|}
\hline College Preparatory (CP) & Advanced Standing (AS) \\
\hline $\begin{array}{l}\text { Best for students who read at or approaching } \\
\text { grade level, at a moderate or slower pace } \\
\text { Best for students who benefit from direction and } \\
\text { support when analyzing text for style and craft } \\
\text { Best for students who write at or approaching } \\
\text { grade level } \\
\text { Best for students who write more confidently } \\
\text { with additional structure and support } \\
\text { Best for students who want to focus on essential } \\
\text { writing skills } \\
\text { Best for students who want help learning to } \\
\text { self-advocate } \\
\text { Best for students who want support and structure } \\
\text { with meeting deadlines, note taking, class } \\
\text { discussion, and completion of larger } \\
\text { assignments } \\
\text { Best for students who want time to commit to } \\
\text { studies in other subject areas and after school } \\
\text { activities }\end{array}$ & $\begin{array}{l}\text { Best for students who read above grade level, } \\
\text { at an accelerated pace, with persistence } \\
\text { Best for students who read often and beyond } \\
\text { what is assigned in class } \\
\text { Best for students who read with an analytical } \\
\text { approach and an appreciation of style and craft } \\
\text { Best for students who write above grade level } \\
\text { in a variety of contexts } \\
\text { Best for students who write with sentence } \\
\text { variety, advanced vocabulary, excellent control } \\
\text { of grammar and usage, and attention to } \\
\text { audience and purpose } \\
\text { Best for students who are planning to take } \\
\text { AP/IB English courses in grade } 11 \text { and/or } 12 \\
\text { Best for students who are organized and } \\
\text { skilled at time management } \\
\text { Best for students who are able to self-advocate } \\
\text { and seek help as needed } \\
\text { Best for students who naturally take initiative } \\
\text { and show interest in extended discussion } \\
\text { Best for students who are particularly } \\
\text { committed to studies in English } \\
\text { Best for students who desire a faster and more } \\
\text { intellectually demanding workload }\end{array}$ \\
\hline
\end{tabular}

Movement between CP and AS classes is allowed at designated times. Also, a student may still opt to take AP or IB courses after taking CP classes. Students, teachers, parents, and counselors should be consulted to determine appropriate course selection.

Updated 3.20.20 


\section{Appendix C \\ Recruitment Flyer for College Students}

Attention BACC Students

You are invited to participate in a San Francisco State University Research Study

Who? We are looking for students who

- Graduated from Bay Area High School in 2017 or 2018 and now attend BACC and are 18 years or older

- Completed a full year of Senior English with Ms. Janeen Malatesta

What? A researcher from San Francisco State University is conducting a study on the topic of how the curriculum included in 12th grade English classes has affected your transition to college. If selected to participate, you will participate in a 5-10 minute survey following a 60-70 minute focus group discussion with up to 3 other students. With your community college peers who also graduated from Bay Area High School, you will discuss your experience transitioning from the Bay Area Union High School District to Bay Area Community College. For participating in the focus group, you will receive a $\$ 25$ gift card at the end of the survey and at the end of the focus group discussion.

When? Tentative dates for the focus group is the beginning of January at a time agreed upon by participants. If you are interested but cannot make these dates, please contact the number or the email below for a possible alternative date.

Where? Focus groups will take place through a recorded conference call.

If interested in participating, please contact the researcher, Janeen Malatesta@(650)303-7524 (mobile) or at jemalatesta@gmail.com 


\section{Appendix D}

Introductory Letter to Participants

May X/December X, 2019

Dear Participant,

I am currently enrolled in San Francisco State's Doctoral of Education Program in Social Justice \& Equity Leadership. As a part of my degree requirements, I am conducting a study to better understand the navigational tools needed by current or former Bay Area High School students to enroll and succeed in postsecondary institutions. The Human Subjects Review Committee at San Francisco State University approved this study.

Participation in this study will involve an individual survey as well as a focus group discussion based on the same questions as those in the survey. The data collected will be kept confidential. There will be no risk or discomfort as a result of your participation. Your participation will be strictly voluntary and you may discontinue your involvement at any time.

If you consent to participate in this study, please indicate your approval on the attached consent form with the enclosed self-addressed envelope. If you need clarification or have any concerns I may be contacted at the following contact information on the consent form at any time.

I thank you in advance for an opportunity to work with you while conducting my research. I look forward to receiving your consent form.

Sincerely,

Ms. Janeen Malatesta 


\author{
Appendix E \\ Informed Consent for College Students \\ San Francisco State University \\ Informed Consent to Participate in Research \\ Cultivating Postsecondary Access \& Persistence in Senior English
}

\title{
A. PURPOSE AND BACKGROUND
}

The purpose of this research is to learn how to improve my Senior English class curriculum in order to help students succeed in college. The researcher, Janeen Malatesta, is a graduate student at San Francisco State University (conducting research for a

doctorate in Education. You are being asked to participate in this study because you were once a student in my Senior English class.

B. PROCEDURES

If you agree to participate in this research, the following will occur:

- You will turn in your consent form.

- You will take a survey, for approximately 5-10 minutes, about how your experiences in Senior English affected your transition to college.

- You will meet with the researcher in focus groups of 2-4 participants to discuss how your experiences in Senior English affected your transition to college.

- You will discuss the focus group questions for approximately 60-70 min.

- The focus group discussion will be audio recorded to ensure accuracy in reporting your statements.

- The focus group will take place at the college during a time most convenient for you.

- The total time commitment will be approximately 80 minutes.

\section{RISKS}

There is a risk of loss of privacy. However, no names or identities will be used in any published reports of the research. Only the researcher will have access to the research data. Also, because the focus groups include discussion of personal opinions, extra measures will be taken to protect each participant's privacy. The researcher will begin the focus group by asking the participants to agree to the importance of keeping information discussed in the focus group confidential. He/She will then ask each participant to verbally agree to keep everything discussed in the room confidential and will remind them at the end of the research period not to discuss the material outside. Only the researcher will have access to the data collected. Audio recordings and transcripts of the focus group will be destroyed five years after the conclusion of the study.

\section{CONFIDENTIALITY}

The research data will be kept in a secure location and only the researcher will have access to the data. All research data will be stored in an encrypted document on a password protected computer.

\section{E. DIRECT BENEFITS}

There will be no direct benefits to the participant.

\section{F. COSTS}

There will be no cost to you for participating in this research.

\section{G. COMPENSATION}

(Or) Compensation for participating in this research will be a $\$ 25$ gift card sent after the survey completion and focus group discussion.

\section{H. ALTERNATIVES}

The alternative is not to participate in the research.

I. QUESTIONS

You have spoken with Janeen Malatesta about this study and have had your questions answered. If you have any further questions about the study, you may contact the researcher by email at jemalatesta@gmail.com or you may contact the researcher's advisor, Professor Stephanie Sisk-Hilton at stephsh@sfsu.edu. Questions about your rights as a study participant, or comments or complaints about the study, may also be addressed to the Human and Animal Protections at 415: 338-1093 or protocol@sfsu.edu.

\section{J. CONSENT}

You have been given a copy of this consent form to keep.

PARTICIPATION IN THIS RESEARCH IS VOLUNTARY. You are free to decline to participate in this research or to withdraw your participation at any point, without penalty. Your decision whether or not to participate in this research will have no influence on your present or future status at San Francisco State University.

Participant's Name

Participant's Signature

Researcher's Signature

Date

Date 


\title{
Appendix F \\ Parental Permission Form for High School Students
}

\author{
San Francisco State University \\ Informed Consent to Participate in Research \\ Cultivating Postsecondary Access \& Persistence in Senior English
}

By my signature on this form I acknowledge the following:

1. My child's participation in this study is an invitation and therefore strictly voluntary.

2. I have been assured that my child's responses will remain strictly confidential with regard to my child's identity.

3. I understand the research requirement is that the focus group discussion be audio recorded and that no identifying information will be associated with any individuals in the study.

4. I understand that if my child chooses to participate in the focus group follow-up discussion the only risk is a possible loss of privacy because the focus groups include discussion of personal opinions. Extra measures will, therefore, be taken to protect each participant's privacy. The researcher will begin the focus group by asking the participants to agree to the importance of keeping information discussed in the focus group confidential. She will then ask each participant to verbally agree to keep everything discussed in the room confidential and will remind them at the end of the research period not to discuss the material outside.

5. I understand that to protect all students' privacy, all research data will be stored on a password-protected encrypted box server. Only the researcher and her faculty advisor will have access to the data.

6. I understand that all identifying information will be removed and pseudonyms for participants and their schools will be provided.

7. I understand that five years after the conclusion of the study, data, audio recordings and notes will be destroyed.

8. I understand that I may choose not to have any of my child's responses included in the research and that my child may stop participating at any time without penalty.

9. I understand that my child and I will receive no direct benefits from participating; however, the researcher hopes to utilize the information to help inform other educators, administrators, and the school board of the students' recommendations with regard to helping students access and persist in postsecondary institutions.

10. I understand that there will be neither costs nor payments made to myself or my child.

11. I understand that I have the opportunity of seeing the results of this study if I so request.*

*I request a copy of the research results be sent to me at the following address:

You have been given a copy of this consent to keep. If you have any questions about the research you may contact the researcher at missmala@sfsu.edu, or you may contact my advisor, Professor Stephanie Sisk-Hilton, at stephsh@sfsu.edu., or Human and Animal Protections at protocol@sfsu.edu or 415-338-1093.

Participant's Name

Participant's Signature

Date

Parent/Guardian's Signature

Date

Researcher's Signature

Date 


\author{
Appendix G \\ San Francisco State University \\ Assent Form for Minors: Ages 18 and Below
}

\title{
Purpose of Research
}

My name is Janeen Malatesta. I am a graduate student at San Francisco State University and I am conducting a research study about twelfth-grade students' perceptions of my Senior English class curriculum and how it can be improved in order to help students succeed in college. I am inviting you to participate in the research because you are enrolled in my Senior English class.

\section{Research Procedures}

If you agree to participate, The total time commitment will be 80 minutes: 5-10 minutes for the survey, and 60-70 minutes for the focus group discussion. You will take the survey as part of your regular coursework during class time. The focus group will take place in the regular classroom, and I will audiotape the discussion to make sure I understand what you have said. If I need to clarify your statements, I will contact you after the focus group in person.

\section{Risks}

The only risk to you is a possible loss of privacy. To protect your privacy, I will keep the audiotapes and transcripts of the interviews in a locked cabinet in a secure location to ensure the confidentiality of the data. I will not use your name or any other identifying information in the research reports. At the end of the study, I will destroy the audiotapes, and will remove all identifying information from transcripts of the tapes.

\section{Benefits}

There is no direct benefit to you for taking part in the research. However, I hope that your input will help me inform educators and administrators about how to improve college access and persistence.

\section{Costs and Compensation}

There will be no costs to you other than your time. You will not be paid for participation.

You have been given a copy of this consent to keep. If you have any questions about the research you may contact the researcher at missmala@sfsu.edu, or you may contact my advisor, Professor Stephanie Sisk-Hilton, at stephsh@sfsu.edu., or Human and Animal Protections at protocol@sfsu.edu or 415-338-1093.

Please note that participation in research is voluntary. You may answer only those questions you want to answer, and you may stop participating at any point in the process with no penalty.

Participant's Name

Participant's Signature Date Date 


\section{Appendix $\mathbf{H}$ \\ College Focus Group Script}

Investigator will collect consent forms.

"Welcome and thank you for participating in this focus group.

The purpose of this focus group discussion is to get your feedback about how high school seniors English teachers can better serve students, such as yourselves. Specifically, I want to understand what part of the curriculum helped you complete your college application, apply for financial aid, and successfully persist (and make progress) at this institution. I also want to understand what I can do to improve the curriculum.

The underlying assumption that I am working with is that all students experience barriers as they make their way toward graduation. I believe that students who are making progress toward graduation have specific knowledge and take specific actions to overcome these barriers. I want to hear from you what you believe was helpful during our senior English class, and what I should do to improve the curriculum.

I would like to remind you that to protect the privacy of focus group members, all transcripts will be coded with pseudonyms and we ask that you not discuss what is discussed in the focus group with anyone else.

The focus group discussion will last about an hour and we will audiotape the discussion to make sure that it is recorded accurately.

Do you have any questions for me before we begin?" 


\section{Appendix I}

\section{High School Focus Group Script}

Investigator will collect consent forms.

"I would like to improve the College Application \& Financial Aid Unit included in the Fall 2018 semester, and the College Success Unit included in the Spring 2019 semester. Your feedback is very important for this process. However, please remember that you are being invited to participate in the study and you can opt out of having your information included: please do what is best for you.

The focus group will last about an hour and we will audiotape the discussion to make sure that it is recorded accurately. Although everyone's responses are being recorded, they are confidential and will not be identified by other individuals.

Do you have any questions for me before we begin?" 


\section{Appendix $\mathbf{J}$ \\ Focus Group Questions}

\section{Purpose}

The purpose of this discussion is for you to think about your own learning in order to retain and apply it as needed in the future, as well as to help me improve this curriculum for future seniors. (Thanks!)

\section{High School Directions}

1. Please read through the questions silently and, if so desired, jot down brief notes to help you answer verbally.

2. Create discussion groups. Each discussion group should have no more than 4 participants in order to share the speaking space.

3. Discuss your answers \& record it using Vocaroo or your phone. Remember to introduce all discussion members at the beginning of the recording. Submit your discussion to jmalatesta@smuhsd.org or my cell phone@650-303-7524.

\section{Discussion Questions}

1. What do you remember about what we read, wrote, and did to help to (better) understand:

a. the college admissions process?

b. the financial aid process?

c. the habits of mind* needed for college persistence?

2. What in the English class curriculum helped you with:

a. applying to college admissions?

b. applying for financial aid/the financial aid process?

c. understanding the habits of mind* needed for college persistence? (*The "Habits of Mind" are defined as...Curiosity, Openness, Engagement, Creativity, Persistence, Responsibility, Flexibility \& Metacognition.)

3. What suggestions do you have to improve the curriculum to help with

a. applying for college admissions?

b. applying for financial aid?

c. understanding the habits of mind* needed for college persistence? (*The "Habits of Mind" are defined as...Curiosity, Openness, Engagement, Creativity, Persistence, Responsibility, Flexibility \& Metacognition.) 


\section{Appendix K}

\section{Timeline}

1) January-April 2019 - Continued reading and development of procedures and development of focus group/survey questions

2) April-May 2019 - IRB submission \& approval, high school survey, high school focus groups: BAHS graduating Class of 2019

3) June-September 2019 - Completed dissertation proposal, scheduled proposal defense, began qualitative analysis

4) September-December 2019 - Proposal defense, continued qualitative analysis

5) December - Scheduled dissertation defense, continued qualitative analysis, began quantitative analysis, community college survey

6) January 2020 - Community college focus groups: graduating classes of 2017, 2018 \& 2019 , completed first round of qualitative and quantitative analysis

7) February - Second round of analysis, development of findings, thesis writing

8) March 2020 - Third round of analysis, development of findings, thesis writing, dissertation defense 